\title{
EFFECTS OF SEX, SEXUAL ORIENTATION, INFIDELITY EXPECTATIONS, AND LOVE ON \\ DISTRESS RELATED TO EMOTIONAL AND \\ SEXUAL INFIDELITY
}

\author{
By \\ OLIVIA ANN LEEKER \\ Bachelor of Arts in Psychology \\ University of Missouri - St. Louis \\ St. Louis, Missouri \\ 2004
Master of Science in Educational Psychology
Oklahoma State University
Stillwater, Oklahoma
2007
Submitted to the Faculty of the
Graduate College of the
Oklahoma State University
in partial fulfillment of
the requirements for
the Degree of
DOCTOR OF PHILOSOPHY

July 2011 


\section{EFFECTS OF SEX, SEXUAL ORIENTATION, INFIDELITY EXPECTATIONS, AND LOVE ON DISTRESS RELATED TO EMOTIONAL AND SEXUAL INFIDELITY}

Dissertation Approved:

\begin{tabular}{c} 
Dr. Al Carlozzi \\
\hline Dissertation Advisor \\
Dr. John Romans \\
\hline Dr. Steve Harrist \\
\hline Dr. Julie Dorton Clark \\
Dr. Janice Miller \\
\hline Outside Committee Member \\
Dr. Mark E. Payton \\
\hline Dean of the Graduate College
\end{tabular}




\section{ACKNOWLEDGMENTS}

This dissertation would not be possible without the support and guidance from my dissertation committee, especially from my advisor Dr. Al Carlozzi. Thank you, Al, for your wisdom, patience, and ability to calm my anxieties throughout this process with humor and reassurance. I would also like to thank Mr. Aarond Graham, who patiently and unselfishly spent countless hours helping me to format this survey online.

I am eternally grateful to my parents, Martha and Lewis, who perfectly demonstrate unconditional positive regard and live unselfishly for their children. Thank you for always telling me how proud you are of me. Your never-ending support constantly makes me feel special, worthwhile, and truly loved. I only hope I will be able to do the same for my children.

To my brother Phillip, thank you for showing me the healing power of laughter and the importance of not taking life too seriously. I am moved by your fearlessness in serving our nation and following your educational aspirations. And to Becky, my sister in heaven and my guardian angel - thank you for helping me appreciate life and helping our family find strength in pain. You are deeply missed. And to my uncles, Gabe and Gary, thank you for always showing interest in my life and brightening my days with your laughter, support, and love.

And to my life-long friends, whether from St. Louis or graduate school - you are my second family. Thank you for keeping me grounded, reminding me to laugh, and just being there whenever I needed you. Lastly, to Beth and Jenny, my two best friends of over ten years, I admire your wisdom, creativity, ambition, and compassion. You are shining examples of the woman I strive to be. I am blessed to have you in my life. 


\section{TABLE OF CONTENTS}

$\begin{array}{lll}\text { Chapter } & \text { Page }\end{array}$

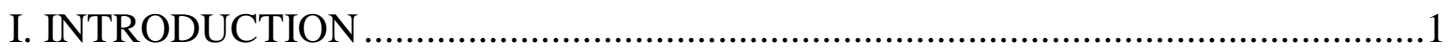

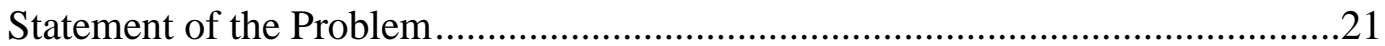

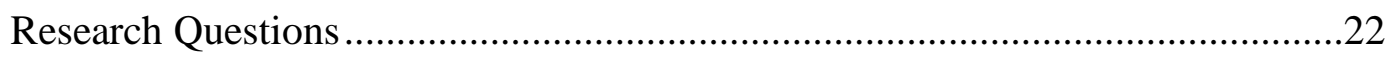

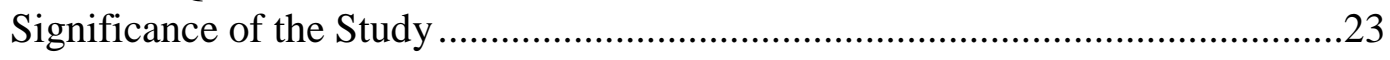

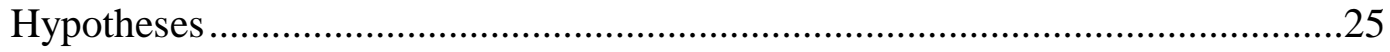

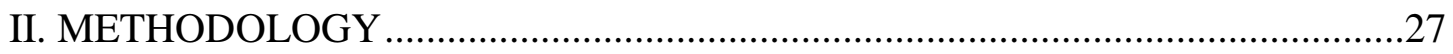

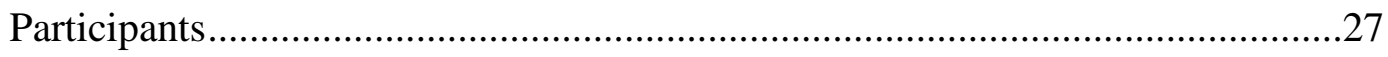

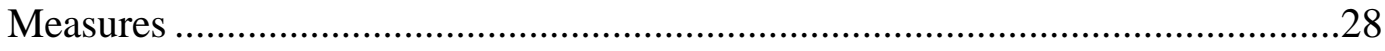

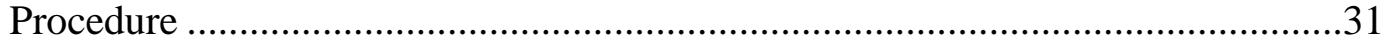

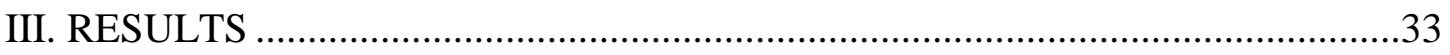

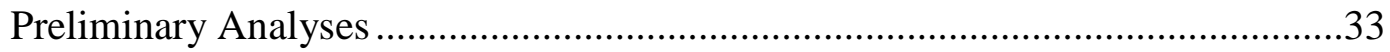

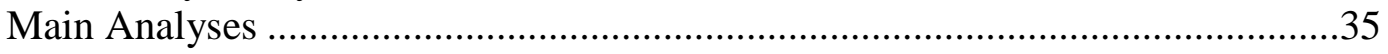

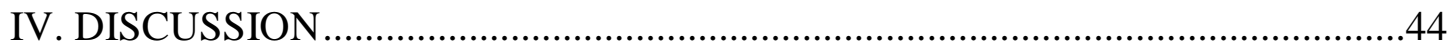

Implications for Practice ………………........................................................51

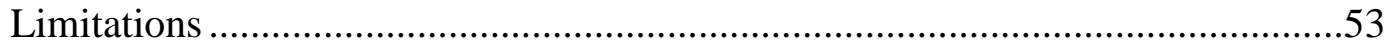

Recommendations for Future Research ...........................................................55

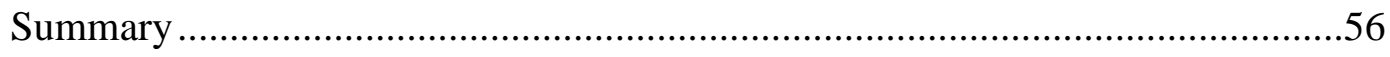

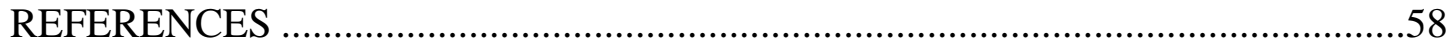

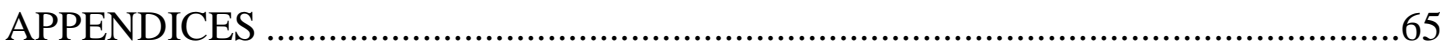

Appendix A: Review of the Literature................................................................65

Appendix B: Tables ...................................................................................103

Appendix C: Figures ..................................................................................113

Appendix D: Research Study Materials.........................................................116

Appendix E: Institutional Review Board Approval................................................133 


\section{LIST OF TABLES}

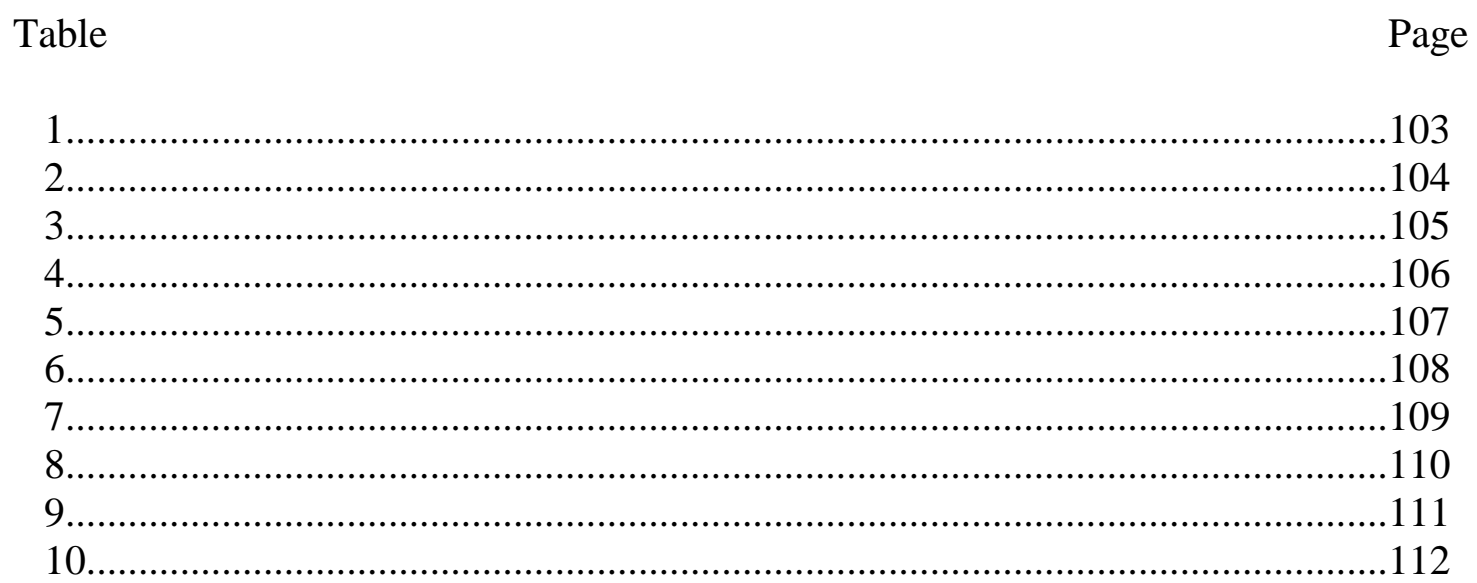




\section{LIST OF FIGURES}

Figure $\quad$ Page

1 .

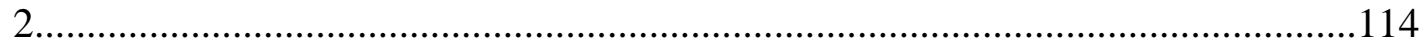

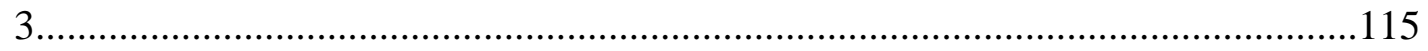




\section{CHAPTER I}

\section{INTRODUCTION}

It is safe to say that many people think about meeting that "special someone", falling in love, and spending the rest of their lives in a loving relationship. At the core of these fantasies lies the ideal "other" whom we have created in our minds, based on early childhood relationships with our parents, friends, and other important persons (Pines, 1998). This image of our ideal romantic partner embodies what we search for when meeting potential mates.

In finding someone who closely matches our ideal lover, the possibility of forming a romantic relationship with this person comes alive. As romance unfolds, new lovers experience intense feelings of excitement, hope, and sheer joy. These positive feelings are just one benefit of being romantically involved. Based on an extensive literature review, lower levels of physical and emotional stress have consistently been found for married couples in comparison to unmarried persons (Coombs, 1991). Married individuals also report the highest levels of wellbeing and happiness, followed by cohabitating couples, dating couples, and last of all, single persons (Kamp, Dash \& Amato, 2005). Supporting the results of Kamp et al. (2005), Soons \& Liefbroer (2008) found that married persons reported the highest levels of well-being in a Dutch sample of young adults, followed by cohabiting individuals, dating adults, and then singles. These researchers suggest that increases in physical and psychological well-being are the result of greater access to material, social, and personal resources that are associated with involvement in a romantic relationship. 
Romantic partnerships can be associated with negative emotions as well, particularly once the beginning stage of passion inevitably ends and disillusionment with one's new partner surfaces (Person, 2007). As time goes by, we no longer idealize our once "perfect" partner to such a significant degree. Situations change and new roles and responsibilities emerge, which can lead to a falling out of love (Person, 2007). For individuals with existing mental health issues, negative feelings within one's relationship (e. g. fear, dependency, resentment, anger, jealousy) are more likely to lead to acting-out in unhealthy ways. For example, in the face of conflict, young adults who engaged in more attacking behaviors with romantic partners reported more symptoms of depression (Marchand-Reilly, 2009). More specifically, depressive symptoms in men and increased levels of attachment anxiety (e. g. fear of abandonment, feelings of rejection) in women were strong predictors of utilization of negative behaviors during conflict (ReeseWeber \& Marchand, 2002).

One of the most distressing events that can occur in romantic partnerships is the suspicion of or actual bouts of infidelity. Not only has it been reported as the leading reason for divorce around the world (Buss, 2000), but it is immensely hurtful and can completely breach the trust between partners. Moreover, acts of infidelity leave people feeling heartbroken, regardless of cultural group or ethnicity (Druckerman, 2007). When asked to share a hurtful event they had experienced, college students within romantic dyads were most likely to talk about a partner's sexual infidelity. Sexual infidelity was not only associated with the greatest amounts of hurt, rejection, and negative self-perception (Feeney, 2004), but it had the greatest negative long-term effects on the victims and the romantic relationships.

The assortment of painful feelings that are evoked upon discovering a partner's unfaithfulness fit neatly under the umbrella of emotional distress. Common emotional reactions include feelings of anger, hurt, humiliation, self-blame, and insecurity, along with fears of rejection, abandonment, and lifelong loneliness. But possibly the most frequently experienced emotion when faced with a partner's infidelity is the universal feeling of jealousy, or "a state that 
is aroused by a perceived threat to a valued relationship or position and motivates behavior aimed at countering the threat" (Daly, Wilson, \& Weghorst, 1982, p. 12). From an evolutionary perspective, jealousy is an innate, protective mechanism that we have acquired over thousands of years to identify and eliminate reproductive threats. According to Buss (2000), "the vast majority of jealous episodes are useful expressions of effective coping strategies that are designed to deal with real threats to relationships" (pp. 35-36). Jealousy can be a sign of commitment to one's partner, can intensify sexual passion, and is often associated with love (Buss, 2000; Pines, 1998). Moreover, it can compel lovers to take a closer look at their relationship (Pines, 1998). On the other hand, jealousy is often accompanied by a multitude of negative emotions such as anger, insecurity, rejection, fear, betrayal, paranoia, depression, loneliness, confusion, envy, and resentment (Buss, 2000), not to mention symptoms of PTSD such as intrusive memories, avoidance behaviors, and hypervigilance (Pines, 1998). Although neither sex is more jealous than the other, women and men express jealousy in very different ways (Buss, 2000; Fisher, 1992). Women, for example, are more likely to express their hurt feelings by crying, self-blaming, making themselves more physically attractive, inducing jealousy in their partners (Pines, 1998), or avoiding their jealous feelings in order to salvage the relationship (Fisher, 1992; Pines, 1998). Men, on the other hand, are more likely to become angry (Pines, 1998) and abandon the relationship in order to maintain self-esteem and pride (Fisher, 1992). Interestingly enough, level of perceived power within one's relationship has been shown to influence the expression of jealousy. Namely, women who feel powerful and are less dependent on their partners tend to react similarly to men by acting on their anger and ending the relationship (Pines, 1998). Exploring sexual orientation differences in jealousy, lesbian, gay, and bisexual (LGB) individuals have been posited to be more susceptible to jealous feelings than heterosexuals, particularly when one or both partners keep the same-sex relationship hidden out of fear of discrimination. This can cause insecure feelings, which often increases one's risk of jealousy (Pines, 1998). 
These findings create a perplexing question: If infidelity is so hurtful that it leaves people broken-hearted, evokes powerful feelings of jealousy, stimulates feelings of depression and anger, and quite often leads to the termination of romantic partnerships, then why do people cheat? When asked this question, almost 70 percent of adults agreed that the top reason for cheating was finding the extra-pair partner attractive (Brand, Markey, Mills, \& Hodges, 2007). Other reasons stated by women were unhappiness in the current relationship (54.6\%) and feeling that the extrapair partner made them feel attractive (42.3\%), with both of these reasons endorsed significantly more by women than men. Men seemed to engage in unfaithful acts more than women as a result of boredom in the current relationship (42.9\%) and simply because the opportunity presented itself (32.1\%). Looking at what is evolutionarily advantageous for both sexes, men are more likely cheat in order to increase sexual variety and consequently increase the chances of spreading their genes (Buss, 2000), whereas women are more likely to engage in outside sexual relations in order to acquire additional or better resources (Fisher, 1992). Women also have to be more careful about whom they choose to mate with, since getting pregnant by a man who does not or cannot provide adequate resources has severe consequences for the woman and her offspring (Barash \& Lipton, 2001). It has also been suggested that women have the luxury of choice because their eggs are often considered invaluable to men (Barash \& Lipton, 2001). Personality traits have also been identified that predict one's vulnerability to being either a perpetrator or victim of infidelity (Buss, 2000). For example, individuals with high levels of narcissism, low levels of conscientiousness (e. g. unreliable, careless, lazy, impulsive), and high levels of psychoticism (e. g. poor self-control, sociopathic traits, lack of empathy) are more likely to cheat. On the other hand, individuals are more likely to be cheated on if they are emotionally unstable and frequently initiate arguments with their partners.

When prevalence rates of sexual infidelity across the lifetime are gathered from nonrandom samples, the numbers are astonishing yet incredibly deceiving, with estimates ranging from 25 to almost 75 percent (Fisher, 1992). But when nationally representative samples of the 
United States population are investigated, a remarkably different picture unfolds, with average rates of sexual infidelity while married falling between 11 and 23 percent (Smith, 2006;

Wiederman, 1997). Moreover, men report engaging in sexual infidelity significantly more than women. For example, among individuals who had ever been married, 11.6\% of women and $22.7 \%$ of men reported engaging in extramarital sex at least once in their lifetime (Wiederman, 1997). Similarly, in a study comprised of more than 2,000 participants (Smith, 2006), men reported higher frequencies of sexual infidelity during the course of marriage than women (approximately $21 \%$ and $12 \%$, respectfully).

In recent years, this apparent sex difference has seemed to disappear or even reverse for Americans, with women reporting higher rates of infidelity than men. One explanation for this is related to how cheating is being defined. For example, when infidelity is defined as "any form of romantic and/or sexual involvement, short or long-term, including kissing, while the individual is in a relationship with another person" (Brand et al., 2007, p. 104), 31.4\% of female university students reported having been unfaithful at some point as compared to $24.0 \%$ of males. In a follow-up study, more women $(50.6 \%)$ reported a history of cheating than men (39.3\%). This sex difference disappeared when cheating was limited to acts of sexual intercourse, with $19 \%$ of women and $21 \%$ of men endorsing engagement in this behavior. Note, however, that these samples were not randomly selected, and the majority of participants reported episodes of cheating that occurred in dating relationships. Therefore, these findings cannot be directly compared with results from Smith (2006) and Wiederman (1997) in which randomly-sampled individuals were queried about infidelity committed during one's marriage. In another nonrandom sample of university students, more college-aged women reported extradyadic dating (44.7\%) than men (39.5\%; Wiederman \& Hurd, 1999). Although women and men reported similar levels of romantic kissing (61.0\% and 68.2\%, respectfully), men reported statistically significantly higher rates of kissing with fondling, performing and receiving oral sex, and having sexual intercourse. 
Another reason for this new trend is that younger generations are responding to these surveys much differently than older cohorts. At present in the United States, sexuality saturates the media and is regularly discussed and displayed in public domains, making it less taboo and more socially acceptable. Additionally, women's sexual freedoms have increased dramatically over the past several decades, and women are independently engaging in dual roles as both caretaker and career professionals in remarkable numbers. With these changes, it seems plausible that women are less dependent on men for needed resources and less fearful of being publically ostracized if deciding to commit infidelity. Therefore, it makes intuitive sense that women in today's Westernized societies are much more willing and able to stray from their partners if they are inclined to do so. Support for these generational differences was found by Wiederman (1997), who observed the disappearance of the sex difference when looking at lifetime rates of extramarital sex for individuals under 40 years of age. A similar trend was found by Smith (2006), with a greater frequency of extramarital relations being reported among younger generations.

Cross-cultural explorations of infidelity reveal that individuals from the United States report similar or lower rates of infidelity than those in most other countries (Druckerman, 2007). Moreover, women and men in the United States report similar rates of infidelity in a 12-month period, $3.1 \%$ and $3.9 \%$ respectively, whereas men from most other countries cheat at drastically higher rates than women. Americans also tend to believe that perpetrators of infidelity should feel tremendously guilty about their affairs and punish themselves relentlessly. Once affairs are discovered, it is not uncommon for American couples to ruminate constantly over the infidelity for months or even years, disclose all the fine details of the unfaithful acts, and attend couples counseling. This sharply contrasts how infidelity is perceived and reacted to in other countries including France, Russia, Japan , and South America, where infidelity is often less devastating, more prevalent, more tolerated, and less devastating. After exploring infidelity cross-culturally, a 
general conclusion can be made that "adultery brings heartache everywhere, but context and expectations determine the strength of the heartache" (Druckerman, 2007, p. 276).

Thus far, infidelity has been presented as a negative behavior that leads to varying degrees of emotional distress, shatters trust among partners, and destroys relationships. In the United States, in particular, infidelity is commonly viewed with disgust and declared as unacceptable and intolerable. But why is this, exactly? How did engaging in romantic or sexual relations with two or more people during the same time frame become viewed as negative? How did monogamy become the ideal, standard practice for people in so many cultures? Theoretical explanations for the development of monogamy and a historical exploration of the condemnation of adultery provide us with answers to these perplexing questions.

Although American society demands that couples practice monogamy, this is unnatural and difficult to maintain (Barash \& Lipton, 2001; Reichard \& Boesch, 2003). Out of some 4,000 mammal species, only three to five percent practice social monogamy (Brotherton \& Komers, 2003; Buss, 2000; Sun, 2003). Around the world, only 200 out of 563 human societies (approximately 35\%) practice some form of monogamy, with the other 65 percent engaging in other practices such as polygamy (Low, 2003). Despite the evidence that monogamy is unnatural, it is unquestionably the most widely-accepted form of romantic pairing in the United States and other modern societies. This can be explained in two general ways: first, social monogamy is favored when its benefits outweigh its costs (Brotherton \& Komers, 2003; Kanazawa \& Still, 2001; Low, 2003), and second, "no other marital pattern - polygyny, polyandry, group marriage, 'open' marriage - has been shown to work better” (Barash \& Lipton, 2001, p. 190).

Various theories on the development of monogamy have been posited. Evolutionarily speaking, the development of monogamy can be traced back as far as our humanoid ancestors, who found mate pairing to be most advantageous as this allowed females and males to provide the best care for their offspring (Fisher, 1992). Others have proposed that women hold more power than men regarding mate choice and choose monogamy when pairing with one man will 
provide them with more resources than sharing another man's abundance of resources with multiple women (Kanazawa \& Still, 2001). It has also been theorized that monogamy became the social norm in Westernized societies with the growth of agriculture, which rendered women less powerful and forced them to live monogamously as they needed the strength of a reliable mate partner to operate heavy farming equipment. Monogamy is reinforced with fidelity when people fear ostracism from their community or church, a partner's rage and potentially violent behavior, or the possibility of abandonment and poverty (Barash \& Lipton, 2001).

Adultery, when committed by women, was legally punished with execution as early as 1800 B. C. in ancient Mesopotamia and was later identified as a sin with the creation of the Ten Commandments (Fisher, 1992). The belief that adultery was sinful and morally wrong was brought to America by the Puritans following independence from British rule (Druckerman, 2007), and violators were often punished with public beatings and sometimes death. This Christian model of faithful and everlasting monogamy has prevailed throughout the history of the United States (Cott, 2000). By the mid $19^{\text {th }}$ century, adultery was viewed in most states as a legitimate reason for divorce. In time, infidelity became a private, family matter as opposed to a legal issue, and by the mid to late $20^{\text {th }}$ century, most adultery laws were revoked (Druckerman, 2007).

As presented above in detail, Westernized societies have ruled that monogamy is the acceptable standard to be practiced among opposite-sex relationships. In same-sex relationships, however, social norms do not exist regarding whether or not extradyadic involvement should be accepted or tolerated and to what degree (Heaphy, Donovan, \& Weeks, 2004). This is due largely to the fact that lesbian, gay, and bisexual (LGB) individuals have had to struggle, and still do, to keep their sexual identities a secret in fear of being rejected, disowned by family, exiled from their communities, or even murdered for preferring to have romantic relationships with members of the same sex. Discrimination against LGB individuals has been evident throughout the history of the United States government. Even today, civil unions or domestic partnerships are only legal 
in a few states (e.g. i.e. New Jersey, Oregon, Washington, Nevada, California), and same-sex marriages are only permissible in Massachusetts, Connecticut, Vermont, Iowa, and New Hampshire (Godoy, 2009).

By keeping their sexual preferences hidden, LGB individuals have thwarted modern societies from making rules about how to behave in romantic partnerships. As a result, LGB individuals have the freedom and creativity to derive their own rules as relationships develop. These rules vary greatly from one same-sex relationship to another. For example, whereas some same-sex couples may verbally agree upon having a mutually exclusive or monogamous relationship, others do so indirectly without ever having a dialogue about this subject. On the other hand, some same-sex couples decide to have non-exclusive relationships, setting limits on how often and with whom outside sexual encounters can occur (Martell \& Prince, 2005). They might also decide that outside sexual relations are only acceptable if protection is used. This may be especially true for gay male couples, who have been documented to be seven times more likely to engage in casual sexual encounters than others (Buss, 2000). Other couples may prefer to allow one-time sexual relations with outside individuals yet declare it unacceptable to become emotionally involved with extradyadic partners. The opposite may also be the case, where compromises are made in which emotional attachments but not sexual involvements are appropriate. With a lack of clear rules or guidelines to follow, same-sex individuals build their relationships from scratch. Therefore, when discussing infidelity in same-sex relationships, monogamy cannot be assumed as the standard practice.

When rules are left unspoken, infidelity becomes more difficult to define. Hypothetically, this poses less risk for heterosexual couples since they can, in a way, assume that monogamy is the rule since this is imposed on them by society. For same-sex couples, however, not having a dialogue about expectations for the relationship can cause unnecessary hurt if one partner becomes involved with a third party and unknowingly violates the other partner's implicitly derived rules for the relationship. Regardless of sexual orientation, it seems probable that an 
individual would be more distressed by emotional infidelity then sexual infidelity if he or she assumed that emotional infidelity was not allowed within the relationship. On the other hand, one would likely be more upset by sexual infidelity than emotional infidelity when there is an implicit rules that sexual relations with third parties are prohibited while emotional relationships are acceptable. The third possibility, and probably the most common, would be an unspoken rule that forbids both emotional and sexual infidelities. In this scenario, similarly high levels of distress might be experienced in response to emotional and sexual infidelity.

According to Lusterman (2005, p. 337), infidelity has occurred "when one member of the couple continues to believe that the commitment to monogamy obtains, while the other secretly violates it". Although this definition of infidelity is acceptable for the majority of couples, it is problematic for those who have agreed to practice non-monogamy or partial non-monogamy in their relationships. This applies not only to some same-sex couples but heterosexual couples who have "open" relationships or are swingers. Therefore, in the present study, infidelity will be defined as a violation of the ground rules established by the couple regarding emotional and sexual involvement with third parties.

As mentioned earlier, how infidelity is defined is critical when investigating such topics as prevalence rates, views about cheating, and emotional and behavioral responses to bouts of infidelity. Whereas some people believe that infidelity should only be defined as secret acts of sexual intercourse with another person, others say the definition should incorporate any form of sexual relations, including kissing. Many individuals feel that secretly becoming emotionally involved with an outside party is enough to constitute infidelity. Demonstrating these beliefs in a sample of Turkish university students, Yeniçeri \& Kökdemir (2006) found that more than 70 percent of participants thought that either sexual or emotional infidelity could be regarded as an act of betrayal. Because "research that limits the definition of infidelity to sexual intercourse minimizes the devastating effects that other types of sexual involvement and emotional connections can have on relationships" (Blow \& Hartnett, 2005, p. 220), it seems pertinent to 
include both sexual and emotional types of infidelity when conducting research on this topic. For this study, sexual infidelity will be defined as the occurrence of sexual involvement with a third party that violates the ground rules established by the couple (e.g. kissing, fondling, oral sex, vaginal sex, anal sex). Similarly, emotional infidelity will be defined as the occurrence of emotional involvement with a third party that violates the ground rules established by the couple (e.g. trusting another, sharing your deepest thoughts with another, falling in love in another, being vulnerable with another, being more committed to another, spending more money on another).

A plethora of researchers agree that both infidelity types must be explored in order to gain a more comprehensive understanding of this phenomenon, and many have done so in relation to which infidelity type is more distressing or upsetting: emotional infidelity or sexual infidelity. Across a multitude of studies, a reported sex difference has emerged regarding which infidelity type is viewed as more upsetting, with men seemingly more distressed by sexual infidelity as compared to women, and women experiencing more distress towards emotional infidelity than men (Buss, Larsen, Westen, \& Semmelroth, 1992; Buss et al., 1999; Buunk, Angleitner, Oubaid, \& Buss, 1996; Cramer, Abraham, Johnson, \& Manning-Ryan, 2001; Cramer, Lipinski, Meteer, \& Houska, 2008; DeSteno \& Salovey, 1996; DeSteno, Bartlett, Braverman, \& Salovey, 2002; Edlund, Heider, Scherer, Farc, \& Sagarin, 2006; Fernandez, Vera-Villarroel, Sierra, \& Zubeidat, 2007; Green \& Sabini, 2004; Harris, 2003; Harris \& Christenfeld, 1996; Penke \& Asendorpf, 2008; Sabini \& Green, 2004; Sagarin, Becker, Guadagno, Nicastle, \& Millevoi, 2003; Schützwohl, 2008; Ward \& Voracek, 2004).

The exploration of this sex difference in which infidelity type is viewed as more distressing began with Buss et al. in 1992. Using forced-choice questions with an undergraduate sample, they found that males were significantly more distressed by sexual infidelity than females, even though approximately $53 \%$ of males were more distressed by emotional infidelity than sexual infidelity on one of the two questions. This suggests it was women's significant distress to emotional infidelity that created the sex difference. For men, history of being in a 
sexually committed relationship was associated with increased distress in response to sexual infidelity. According to Buss and his colleagues, this sex difference supports an evolutionary hypothesis that men are more likely to be upset by sexual infidelity than women because this raises uncertainty about paternity and increases the threat of providing for children that are not their own. Women, on the other hand, should be more upset by emotional infidelity than men because a man who becomes emotionally attached to another woman is more likely to give his resources to this other woman instead of to the betrayed woman.

Potential sex differences were then examined cross-culturally among adults from the United States, Holland, and Germany (Buunk et al., 1996) using Buss et al.'s (1992) forcedchoice questions. Men in all three countries were found to be significantly more upset by sexual infidelity when compared to the women in their respective countries. However, only on the first forced-choice question did men from the U.S. and Holland rate sexual infidelity as more upsetting than emotional infidelity. On all other questions, men from all three countries found emotional infidelity to be more upsetting than sexual infidelity. Moreover, the sex difference between American men and women yielded large effect sizes, whereas the sex differences between Dutch and German participants yielded small to medium effect sizes.

Critics of Buss et al.’s (1992) evolutionary hypothesis proposed a “double-shot hypothesis" (DeSteno \& Salovey, 1996) to explain this sex difference. They speculated that women are more upset by emotional infidelity because women believe that when a man is emotionally unfaithful, he must also be sexually unfaithful. Similarly, they proposed that men are more upset than women by sexual infidelity because a woman's sexual infidelity implies that she has also been emotionally unfaithful. Testing this hypothesis, they found females were more upset by emotional infidelity than men. Moreover, participants' beliefs about the co-occurrence of emotional and sexual infidelity was shown to be a reliable predictor of which type of infidelity was chosen as more distressing, whereas sex was not a reliable predictor once beliefs were entered into the analysis. Additional support for the "double-shot hypothesis" was provided by 
Harris \& Christenfeld (1996), who found that males were once again more upset by sexual infidelity than women, even though the majority of men were more distressed by emotional (53\%) than sexual infidelity (47\%). This suggests that the sex difference was significant given the substantial percentage of women who reported being more distressed by emotional infidelity (88\%). In another study (DeSteno et al., 2002), the sex difference only appeared when the forcedchoice questions were asked or when participants were allowed to think for awhile about their responses. But when responding to continuous questions or when forced to make spontaneous decisions without deliberation, both women and men reported more distress towards sexual infidelity than emotional infidelity.

In 1999, Buss et al. responded to critics by creating four infidelity scenarios that rendered the items either mutually exclusive (only one of the infidelity types occurred) or combined (both infidelity types occurred). These four scenarios were merged with the two previous forced-choice scenarios for a total of six scenarios that comprised the Relationship Dilemmas Questionnaire (RDQ). Across all six infidelity dilemmas, when it was clearly stated that either one or both types of infidelity had occurred, undergraduate males from the United States, Korea, and Japan reported more distress by sexual infidelity in comparison to females in response to almost all of the dilemmas. However, on several of these questions, the majority of men found emotional infidelity to be more upsetting than sexual infidelity when looking at within sex differences.

Further support for the evolutionary hypothesis was lent by Cramer et al. (2001), who reported that undergraduate males in the United States were more upset by sexual infidelity, whereas females were more upset by emotional infidelity. Years later, these results were replicated among another U. S. undergraduate sample (Cramer et al., 2008). Similar results were found among an Australian sample of undergraduate students, with men typically reporting more distress in response to sexual infidelity than women (Ward \& Voracek, 2004). In a correlational study, undergraduate males' desire for having genetically-related children was positively related to distress attributed to thoughts of sexual infidelity, thereby lending support to the evolutionary 
perspective that males are more upset by sexual infidelity due to fear of raising children that are not genetically theirs (Mathes, 2005). Additional cross-cultural support for the evolutionary hypothesis was established in a sample of university students in Spain (Fernandez et al., 2007). Once again, men were more upset by sexual infidelity than women. However, within-sex analyses revealed that the majority of men found emotional infidelity to be more distressing than sexual infidelity.

Results from a meta-analysis of 32 samples reveal a moderate effect size for this sex difference when forced-choice questions are used (Harris, 2003), with men reporting significantly more distress to sexual infidelity than women. Of interest, this effect size increased when samples of lesbian/gay individuals and adults with a mean age of 26 years or more were excluded from the analyses. Interestingly, the sex difference often did not emerge when continuous measures were used, among culturally-diverse groups, and when participants are asked to reflect on actual experiences with emotional and sexual infidelity instead of hypothetical infidelity scenarios.

Harris’ findings (2003) were supported by Sabini \& Green (2004), who examined specific emotions elicited by infidelity. They found that anger and blaming the unfaithful partner were more consistently provoked by sexual infidelity than emotional infidelity, whereas hurt feelings were more often attributed to emotional infidelity than sexual infidelity. Generally speaking, the well-documented sex difference in response to emotional and sexual infidelity was reproduced more easily among undergraduate students but failed to emerge among nonstudent samples. The authors concluded that the sex difference is more likely to emerge when broader terms of distress and upset are used, whereas findings are less predictable when specific emotions are queried.

Believing that the samples gathered in their previous studies were not large enough to capture variances due to age, Green \& Sabini (2006) conducted a follow-up study with a U.S. representative sample. Looking at specific emotions, both women and men experienced more hurt in regard to emotional infidelity and were more likely to become angry and blame their partners 
over sexual infidelity. Moreover, women were statistically significantly more likely to experience anger over sexual infidelity than men. Whereas women were significantly more upset by emotional infidelity than men when forced-choice questions were used, no sex difference was found using continuous questions.

Another group of researchers attempted to test whether the sex difference would appear using both forced-choice and continuous measures and how this might be influenced by prior experiences with infidelity (Sagarin et al., 2003). Among U. S. undergraduate students, statistically significant sex differences were found using both forced-choice and continuous measures, with men reporting significantly more distress to sexual infidelity when compared to women. Regarding past histories with infidelity, men who had previously been victims of infidelity were found to be significantly more upset by sexuality infidelity than men who had not been cheated on in the past. Additionally, women who had cheated in the past were significantly more distressed by sexual infidelity than women who did not have a history of cheating on a partner.

Sex differences related to which infidelity type evokes more jealousy were examined by another group of authors using both forced-choice and continuous measures (Edlund et al., 2006). In addition, they inquired about participants' levels of jealousy in response to both hypothetical scenarios and actual experiences with infidelity. The authors stated that the predicted sex differences, with men being significantly more jealous than women in response to sexual infidelity and women being significantly more jealous than men in response to emotional infidelity, were found with undergraduate students and working adults, using both forced-choice and continuous measures, and across hypothetical and actual infidelity scenarios. Effect sizes were greater for those who had experienced infidelity in the past, ranging from moderate to large. For those who had not been cheated on in the past, effect sizes were moderate or close to moderate. A significant difference was found among undergraduates regarding overall feelings of 
jealousy, with undergraduate women reporting greater overall levels of jealousy to both emotional and sexual infidelity than undergraduate men.

Participant relief when imagined scenarios of emotional and sexual infidelity were said not to have occurred has also been examined (Schützwohl, 2008). On the forced-choice question, significantly more women (82\%) than men $(53 \%)$ were relieved to know that emotional infidelity had not occurred, even in the face of sexual infidelity. When examining emotion ratings from the continuous questions, men were significantly more relieved than women to find out that sexual infidelity had not occurred. Within sex, women were significantly more relieved to learn that emotional infidelity had not taken place.

The proposed evolutionary basis to the sex difference in distress related to emotional and sexual infidelity was recently explored by Penke \& Asendorpf (2008). They argued that support must be found for two evolutionary hypotheses, with a total of four sub-hypotheses, in order to say that there is an evolutionary basis to this sex difference. The first hypothesis and its two associated sub-hypotheses focus on between-sex differences, stating that "men react more jealous to sexual infidelity than women" and that "women react more jealous to emotional infidelity than men" (p. 5). The other two hypotheses and accompanying sub-hypotheses, which relate to withinsex differences, state that "men react more jealous to sexual infidelity than emotional infidelity" and that "women react more jealous to emotional jealousy than to sexual infidelity" (p.5). They explained that in order for the evolutionary theory to be confirmed, an interaction effect would have to be found with both hypotheses and all four sub-hypotheses supported. In other words, ordinal effects alone would provide insufficient support for the evolutionary theory. Testing these hypotheses, they found only ordinal effects across the forced-choice questions: women were significantly more likely to choose emotional infidelity as more upsetting than men, but withinsex analyses revealed the majority of men rated emotional infidelity as more upsetting than sexual infidelity. Participants were also instructed to rate the degree to which emotional and sexual infidelity caused them to feel angry, anxious, jealous, and humiliated. In regard to sexual 
infidelity, women and men reported similar levels of anger, anxiety, jealousy, and humiliation. Across emotional infidelity scenarios, however, women responded with significantly greater levels of anxiety, jealousy, and humiliation than men. This sex difference was not found for anger. Looking at degree of distress across all four emotions, women were significantly more distressed by both emotional and sexual infidelity in comparison with men. Because only ordinal effects were found, Penke \& Asendorpf (2008) said the evolutionary theory could be supported but not confirmed.

Summarizing the results of the aforementioned studies, a sex difference does seem to exist in relation to which type of infidelity is viewed as more distressing, with women feeling significantly more distressed by emotional infidelity than men. However, the other ordinal effect, with men reporting significantly more distress to sexual infidelity than women, is typically not found, which leads to the absence of an interaction effect. Moreover, multiple within-sex analyses reveal that men are either equally or more distressed by emotional infidelity than sexual infidelity (Buss et al., 1992; Buss et al., 1999; Buunk et al., 1996; Edlund et al., 2006; Fernandez et al., 2007; Green \& Sabini, 2006; Harris, 2002; Harris \& Christenfeld, 1996; Penke \& Asendorpf, 2008; Sabini \& Green, 2004; Schützwohl, 2008; Ward \& Voracek, 2004). Therefore, women seem to be responsible for the presence of this sex difference by responding with incredibly high levels of distress to emotional infidelity and less distress to sexual infidelity as compared to their male counterparts. Moreover, the sex difference in distress related to emotional and sexual infidelity has failed to emerge or has lessened in significance in some studies due to several influential factors: cultural background (Buss et al., 1999; Buunk et al., 1996; Harris, 2003), sexual orientation (Harris, 2003), age (Harris, 2003; Sabini \& Green, 2004), history of past infidelity experiences (Harris, 2002; Harris, 2003), and use of continuous measures (DeSteno et al., 2002; Green \& Sabini, 2006; Harris, 2003).

Whereas this sex difference has been studied numerous times, only a few researchers have explored the influence of sexual orientation on which type of infidelity is viewed as more 
distressing (Bailey, Gaulin, Agyei, \& Gladue, 1994; deSouza, Verderane, Taira, \& Otta, 2006; Dijkstra, Groothof, Poel, Laverman, Schrier, \& Buunk, 2001; Harris, 2002; Sheets \& Wolfe, 2001). Because same-sex couples often create their own guidelines for how to behave within their relationships, definitions of infidelity vary greatly among these dyads. Given this, it is possible that lesbian and gay individuals will also differ in their beliefs about which type of infidelity is more distressing.

The earliest study that explored the influence of sexual orientation on infidelity views was published by Bailey et al. (1994). Using Buss et al.'s (1992) forced-choice methodology with a community sample of heterosexual, lesbian, and gay adults, heterosexual men were statistically significantly more distressed by sexual infidelity than emotional infidelity when compared with heterosexual women, lesbian women, and gay men. In addition, these latter three groups experienced similar levels of distress to emotional infidelity over sexual infidelity.

In an attempt to model this study, Dijkstra et al. (2001) had a community sample of Dutch lesbian and gay participants respond to Buss et al.'s (1999) infidelity dilemmas. Results indicate that lesbians were significantly more distressed by sexual infidelity than gay men on three of the six infidelity dilemmas, and it was the gay male participants' significant levels of distress felt towards emotional infidelity that created this difference. This suggests that gay men tend to parallel heterosexual women by responding with significant amounts of distress to emotional infidelity, whereas lesbian women respond similarly to heterosexual men.

Other studies also indicate that heterosexual men are more upset by sexual infidelity than heterosexual women, lesbian women, and gay men, even though within-sex analyses show they rate emotional infidelity either equally or more distressing than sexual infidelity (Harris, 2002; Sheets \& Wolfe, 2001). Therefore, it seems this sexual orientation difference has emerged as a function of the incredibly high levels of distress to emotional infidelity reported by heterosexual women, lesbian women, and gay men (Harris, 2002; Sheets \& Wolfe, 2001). Heterosexual men have also been found to be significantly more distressed by sexual infidelity than lesbian women 
(Harris, 2002), which contradicts other findings that show heterosexual men and lesbians respond similarly to the infidelity dilemmas (deSouza et al., 2006; Dijkstra et al., 2001).

The latest study to examine potential sexual orientation differences in responses to the infidelity scenarios was based on a Brazilian community sample (deSouza et al., 2006). Using forced-choice measures, they found that heterosexual men were significantly more upset by sexual infidelity than heterosexual women. Lesbian women and gay men showed similar levels of distress towards emotional infidelity, with these responses falling in between those of heterosexual participants. Responses from continuous measures revealed that lesbians responded similarly to heterosexual men, while responses of gay men resembled those of heterosexual women.

As a whole, heterosexual men seem to be more distressed by sexual infidelity when compared to heterosexual women, lesbian women, and gay men (Bailey et al., 1994; Harris, 2002; Sheets \& Wolfe, 2001). However, within-sex analyses reveal that heterosexual men tend to rate emotional infidelity as more distressing than sexual infidelity (Harris, 2002; Sheets \& Wolfe, 2001). Another emergent pattern is that lesbians, gay men, and heterosexual women tend to report similar levels of distress to emotional infidelity (Bailey et al., 1994; Harris, 2002; Sheets \& Wolfe, 2001). Lesbian women have also been found to be more upset by sexual than emotional infidelity when compared to gay men (Dijkstra et al., 2001), but in most cases, no differences were found between these two groups (Bailey et al., 1994; deSouza et al., 2006; Dijkstra et al., 2001; Sheets \& Wolfe, 2001). It is possible that lesbians hold similar views as heterosexual men (sexual infidelity as more upsetting) relative to gay men, whereas gay men hold similar views as heterosexual women (emotional infidelity as more upsetting) relative to lesbian women. However, this statement too must be interpreted with caution, as heterosexual men have also been found to be significantly more distressed by sexual infidelity than lesbian women (Harris, 2002).

Distress associated with sexual and emotional infidelity has also been explored in relation to individuals' expectations about the likelihood of their partners committing each type of 
infidelity (Cramer et al., 2008). The violation of infidelity expectations hypothesis states that an individual finds an unfaithful partner's infidelity more upsetting when it does not meet the individual's expectations. As proposed by the authors, women find emotional infidelity more upsetting than men because women expect that men will be sexually unfaithful, but not emotionally unfaithful. Men, on the other hand, are more upset by women's sexual infidelity because emotional infidelity is expected whereas sexual infidelity is not expected. Among a sample of undergraduate students, women were statistically significantly more likely to expect men to be sexually unfaithful, whereas men were statistically significantly more likely to expect women to be emotionally unfaithful. Results from the Relationship Dilemmas Questionnaire (RDQ) revealed that women were statistically significantly more upset by emotional infidelity than sexual infidelity when compared to men. Merging these results, the authors found support for their proposed violation of infidelity expectations hypothesis. However, when logistic regression analyses were conducted, participant sex was the only statistically significant predictor of which infidelity type was more distressing. These results fail to lend support to the violation of infidelity expectations hypothesis and provide additional support for the evolutionary hypothesis.

Level of love within one's relationship was also assessed for its possible impact on distress related to sexual and emotional infidelity among a group of undergraduate students in the United States (Russell \& Harton, 2005). Using Rubin's Love Scale (Rubin, 1970), an instrument comprised of 13 items and measured on a 9-point Likert-scale, the researchers found that participants who scored higher on amount of love felt toward their partners were more upset by imagined sexual infidelity, whereas emotional infidelity was more distressing for those who were less in love with their current partners.

Sternberg's Triangular Love Scale, although it has not been studied in regard to which infidelity type is more upsetting or distressing, has been shown to correlate highly with Rubin's Love Scale and be a better predictor of relationship satisfaction than Rubin's Love Scale (Sternberg, 1987). This 45-item scale was developed by Sternberg to test his triangular theory of 
love, and it consists of three subscales (intimacy, passion, and decision/commitment) with 15 items in each subscale. According to Sternberg, intimacy, passion, and decision/commitment are the three main components that interact to comprise the construct of love. The importance that is given to each of these components seems to differ depending on whether a relationship is considered short-term or long-term, with passion being more important in short-term relationships and intimacy and commitment being of greater importance in long-term relationships. Finally, the shape of the triangle changes as the amount of each one of these three components increases or decreases. Greater satisfaction in love between two people is most likely when the shapes of their ideal triangles are similar and significantly overlap. Given the extensive amount of attention Sternberg's triangular theory of love has received, the greater number of items included in Sternberg's measure, and presence of theoretical framework as compared to Rubin's Love Scale (Rubin, 1970), it seems possible that the use of Sternberg's Triangular Love Scale may produce more valid results than Rubin's Love Scale regarding how levels of love experienced in one's relationship influence which infidelity type is viewed as more upsetting or distressing.

\section{Statement of the Problem}

A clear sex difference seems to exist in relation to which infidelity type is viewed as more upsetting, especially when forced-choice infidelity dilemmas are used. However, this sex difference has been less pronounced when using continuous measures of emotions associated with each infidelity type. Sexual orientation has also been explored in relation to which infidelity type is found to be more upsetting or distressing, but a number of inconsistencies are present when comparing these findings. Furthermore, the effects of infidelity expectations on distress related to emotional and sexual infidelity have only been explored in one study, and the same is true regarding the influence of love on distress associated with emotional and sexual infidelity. In addition, neither infidelity expectations nor love has been investigated among a sample of both heterosexual and lesbian and gay individuals. Taken together, this set of independent variables as 
possible predictors of emotional responses to sexual and emotional infidelity has yet to be investigated.

\section{Research Questions}

The questions addressed in this study were as follows:

1) To what extent do the independent variables [sex, sexual orientation, infidelity expectations, love (intimacy, passion, and commitment)] predict distress related to sexual infidelity (as measured by the total composite distress score for the emotion ratings across the three sexual scenarios)?

2) To what extent do the independent variables [sex, sexual orientation, infidelity expectations, love (intimacy, passion, and commitment)] predict anger, anxiety, jealousy, and humiliation related to sexual infidelity (as measured by the sum score for each of the four emotions across the three sexual scenarios)?

3) To what extent do the independent variables [sex, sexual orientation, infidelity expectations, love (intimacy, passion, and commitment)] predict distress related to emotional infidelity (as measured by the total composite distress score for the emotion ratings across the three emotional scenarios)?

4) To what extent do the independent variables [sex, sexual orientation, infidelity expectations, love (intimacy, passion, and commitment)] predict anger, anxiety, jealousy, and humiliation related to emotional infidelity (as measured by the sum score for each of the four emotions across the three emotional scenarios)?

5) Do participant sex and sexual orientation significantly interact to influence levels of anger, anxiety, jealousy, and humiliation felt in response to emotional and sexual infidelity?

6) Do sexual and emotional infidelity elicit significantly different levels of distress, anger, anxiety, jealousy, and humiliation? 


\section{Significance of the Study}

The occurrence of infidelity within romantic relationships undoubtedly generates many negative emotions, especially feelings of jealousy. Jealousy is a common problem in romantic relationships, with one-third of couples reporting jealousy as a problem in therapy (White \& Devine, 1991; in Pines, 1998) and approximately two-thirds of individuals reporting the strongest feelings of jealousy when a partner shows interest for an outsider (Mullen \& Martin, 1994). When asked about behavioral responses to jealousy-provoking situations, those who experienced significantly higher reported feelings of jealousy while in romantic relationships were significantly more likely to question their partners, call their partners to see where they were, show up randomly without warning, look through their possessions, follow them, and dig through clothing for evidence of sexual contact (Mullen \& Martin, 1994).

Individuals who have experienced infidelity are more prone to jealous feelings and show increased hypervigilance to even small indicators of infidelity, regardless of whether they were witnesses, victims, or perpetrators of infidelity (Buss, 2000; Pines, 1998). Jealous feelings are felt more intensely by individuals with lower levels of implicit self-esteem (DeSteno, Valdesolo, \& Bartlett, 2006), and insecure individuals are more likely to act on these jealous feelings in explosive and uncontrollable ways (Person, 2007).

Intense feelings of jealousy amplify aggressive feelings (DeSeno et al., 2006) and are a strong predictor of partner aggression for both men and women (O'Leary, Smith Slep, \& O’Leary, 2007). Although acts of aggression are not necessarily synonymous with violent behaviors, jealous feelings can trigger individuals to act in violent ways. Jealousy is the primary cause of partner violence, with anywhere from 10 to 60 percent of men and women having engaged in some form of violence against his or her partner (Buss, 2000). This was demonstrated in a community sample of men, in which self-reported levels of jealousy were a significant predictor of intimate partner violence (Foran \& O'Leary, 2008). When compared to women, men have been found to respond to imagined acts of sexual infidelity with significantly greater 
feelings of anger and increased likelihood of violent behavior (Miller \& Maner, 2008). On the contrary, Buss (2000) summarized a number of studies that examined sex differences in perpetration of physical violence, stating that women were just as likely as men to act-out against their partners in physically aggressive ways. However, women tend to act out in self-defense, do not typically initiative the violence, and do not cause as much physical damage to their partners as men (Buss, 2000). Support for this can be found by looking at prisoner demographics, where the majority of individuals serving time for violent acts of jealousy are young men of low socioeconomic statuses (Pines, 1998). Worst of all, jealousy sparked from infidelity is a leading cause of homicide in the United States, where suspicion of or confirmed acts of infidelity account for approximately one-third of murders (Barash \& Lipton, 2001; Pines, 1998). These murderous acts are most often committed by men: in one study, men were the offenders in two-thirds of investigated martial killings, whereas women were the murderers in the remaining one-third of these cases (Daly \& Wilson, 1988; in Buss, 2000). As frightening as it may be, spousal violence seems to serve the adaptive purposes of preventing the victim from engaging in future acts of infidelity and subsequently increases the control that the violent perpetrator has on the victim (Buss, 2000).

Considering the negative views that our society holds about infidelity and the devastating consequences that often accompany the disclosure of infidelity, acts of infidelity are often kept hidden from the betrayed partner. Nevertheless, infidelity is one of the three main presenting problems in couples' therapy (Lerner, 1989). The discovery of unfaithfulness can be even more devastating if the betrayed partner did not expect his or her cheating partner to commit the type of infidelity that occurred. Additionally, the effects of betrayal can be even more tragic when high levels of love are felt between romantic partners. Lastly, it is important to remember that samesex couples do not always have the same rules regarding monogamy in comparison to oppositesex couples, thus possibly leading to differential reactions to infidelity when compared to heterosexuals. 
The results of the current study may be useful in distinguishing any sex and sexual orientation differences that exist when exploring emotional reactions to hypothetical acts of sexual and emotional infidelity. Identifying possible sex differences contributes to the vast amount of research already available regarding the apparent sex difference by exploring various emotional reactions to infidelity, above and beyond which infidelity type causes more distress. This research will also help clarify the previously noted discrepancies regarding the effects of sexual orientation on distress related to emotional and sexual infidelity. In addition, this is the first study known to examine sexual orientation or love as possible predictors of emotional reactions to sexual and emotional infidelity. Although the influence of infidelity expectations and love on distress to emotional and sexual infidelity has been tested among heterosexual individuals, this is the first known study to examine this hypothesis among lesbian and gay individuals. Lastly, no other study has examined this set of independent variables (i.e. sex, sexual orientation, infidelity expectations, and love) as likely predictors of emotional reactions to sexual and emotional infidelity. The results of this study will add to the literature on sexual orientation which is extremely important in today's society, when LGB individuals continue to struggle daily to receive similar amounts of respect and dignity as given to heterosexual individuals. Finally, as counselors who often work with romantic couples, we need to understand how individuals respond to incidents of infidelity in their relationships and how this varies when working with opposite versus same-sex couples. In doing so, we will increase our effectiveness in helping dyads cope with the devastating effects of infidelity on romantic partnerships.

\section{Hypotheses}

The following null hypotheses were examined:

1. Sex, sexual orientation, infidelity expectations, and love (defined as intimacy, passion, and decision/commitment) are not significant predictors of distress related to sexual infidelity. 
2. Sex, sexual orientation, infidelity expectations, and love (defined as intimacy, passion, and decision/commitment) are not significant predictors of distress related to emotional infidelity.

3. Sex, sexual orientation, infidelity expectations, and love (defined as intimacy, passion, and decision/commitment) are not significant predictors of anger, anxiety, jealousy, or humiliation related to sexual infidelity.

4. Sex, sexual orientation, infidelity expectations, and love (defined as intimacy, passion, and decision/commitment) are not significant predictors of anger, anxiety, jealousy, or humiliation related to emotional infidelity.

5. Sex and sexual orientation do not significantly interact to influence levels of anger, anxiety, jealousy, and humiliation felt in response to emotional and sexual infidelity.

6. Sexual and emotional infidelity do not elicit significantly different levels of distress, anger, anxiety, jealousy, or humiliation. 


\section{CHAPTER II}

\section{METHODOLOGY}

\section{$\underline{\text { Participants }}$}

A total of 321 individuals of varying sexual orientations participated in the current study. In order to meet participant criteria, individuals had to be 18 years of age or older at the time of study participation and consider themselves to be currently involved in a committed romantic relationship. This latter variable was essential as past studies have failed to find sex differences in distress related to infidelity among people not currently involved in committed romantic relationships (Dijkstra et al., 2001; Ward \& Voracek, 2004). Of these 321 participants, 25 were excluded from data analyses for various reasons: seven failed to respond to ten percent or more of survey questions, fifteen self-reported bisexual identities, two participants did not report their sex, and one individual reported being under 18 years of age. The final sample consisted of 296 participants: 72 lesbian women, 114 heterosexual women, 53 gay men, and 57 heterosexual men. See Table 1 for demographics of the sample.

Among the final sample, seven individuals who self-identified as lesbian or gay on a forced-choice question of sexual orientation endorsed a Kinsey scale score (Kinsey, Pomeroy, \& Martin, 1948) that was incongruent with this self-reported identify (i.e. their Kinsey scale scores fell on the heterosexual end of the continuum). It was assumed that these individuals misread the response choices on the Kinsey scale, and their self-reported lesbian and gay identities were 
accepted as accurate. Therefore, their Kinsey scores were corrected by replacing them with the equivalent score on the other end of the continuum. For example, a Kinsey score of 1 (opposite sex interests only) was changed to 7 (same sex interests only), and a score of 2 (mostly opposite sex, rare same sex interests) was changed to 6 (mostly same sex, rare opposite sex interests).

Once these corrections were made, average Kinsey scores were as follows: lesbian women $=(M$ $=6.39, S D=0.64)$, heterosexual women $=(M=1.05, S D=0.22)$, gay men $=(M=6.81, S D=$ $0.40)$, and heterosexual men $=(M=1.04, S D=0.19)$.

The mean age for the total sample was 26.1 years $(S D=10.2$, range $=18-73)$, with four participants not answering this question. The majority of participants identified as Caucasian $(n=$ 224; 75.7\%), 12 identified as African American (4.1\%), 9 identified as Asian American (3.0\%), 5 identified as Native American (1.7\%), 9 identified as Hispanic/Latina(o) (3.0\%), and 35 identified as biracial, multiracial, or other (11.8\%), with two participants not reporting racial identity. In terms of marital status, 163 participants were single (55.1\%), 102 were partnered or common law (34.5\%), 24 were married (8.1\%), two were divorced $(0.7 \%)$, one participant was widowed $(0.3 \%)$, and four did not respond. The average length of the current relationship was 37.38 months $(\mathrm{SD}=51.85$ months), or approximately three years and one month, with responses ranging from one month to 368 months (i.e. 30 years and 8 months).

\section{$\underline{\text { Measures }}$}

The following instruments were used in the study.

1) A demographic sheet was used to collect information from participants including age, sex, sexual orientation, Kinsey scale scores of sexual orientation (Kinsey et al., 1948), racial identity, marital status, duration of current romantic relationship, and history of infidelity experiences.

2) The Infidelity Expectations Questionnaire (IEQ; Cramer et al., 2008), one of the predictor variables, measured individuals' beliefs regarding the likelihood of their hypothetically unfaithful partners engaging in ten emotion-intimacy behaviors and ten 
sexual behaviors. Established Cronbach's alphas were .92 for the emotion-intimacy items and .94 for the sexual items (Cramer et al., 2008). Participants were asked to rate the likelihood of the occurrence of each item on a seven-point Likert scale. The ratings were summed across each subscale which resulted in two scores, one for the emotionintimacy items (possible range of 10 to 70 ) and one for the sexual items (possible range of 10 to 70$)$.

3) Sternberg's Triangular Love Scale (Sternberg, 1987), another predictor variable in the current study, measures self-perceived amount of love within participants' current romantic relationships and consists of three components: intimacy, passion, and decision/commitment. Each of these three subscales is comprised of fifteen items that were rated by participants on a nine-point Likert scale in regard to how much they agree with each statement when thinking about their current romantic partners. Ratings for each subscale were then summed, resulting in three subscales scores (intimacy, passion, decision/commitment,) that could range from 15 to 135 . According to Chojnacki \& Walsh (1990), the measure is highly reliable, with Cronbach's alphas for each subscale and for the total score of no less than .90 . Test-retest reliability was also reported for the overall scale and each subscale, with correlations ranging from .75 to .81. Evidence for concurrent validity has also been reported, with subscales significantly correlating with predicted variables. However, discriminative validity was not established which seems to be related to the high degree of interrelatedness between the subscales, with reported correlations between .79 and .90 .

4) Continuous emotion ratings (Penke \& Asendorpf, 2008) served as the dependent variable and were used to assess how angry, anxious, jealous, and humiliated each participant felt in response to Buss et al.'s (1999) six infidelity dilemmas using a fivepoint Likert scale. This measure was adapted from Buss et al.'s (1999) Relationship Dilemmas Questionnaire and allows participants to state which and to what degree 
specific emotions are experienced when imagining instances of both emotional and sexual infidelity. Suggested by Penke \& Asendorpf (2008) as a way of preventing boredom and fatigue, the six sexual infidelity hypothetical scenarios were merged so that the end result was only three questions regarding sexual infidelity. The same was completed for the responses regarding emotional infidelity so that the original six scenarios were condensed down to three questions. This resulted in a total of six questions, three for each infidelity type. Although continuous measures have been criticized for having ceiling effects, Penke \& Asendorpf (2008) prevented against this by adjusting their measure. An average internal consistency reliability of .77 was reported by Penke \& Asendorpf (2008) for all eight scales of the measure (four scales for the sexual infidelity situations: anger, anxiety, jealousy, and humiliation, and four scales for the emotional infidelity situations: anger, anxiety, jealousy, and humiliation). For the purposes of the current study, five scores were computed for each participant across the three sexual situations: 1) an anger sum score, 2) an anxiety sum score, 3) a jealousy sum score, 4) a humiliation sum score, 5) and a total composite distress score which was calculated by adding together the sum scores for all four emotions. These five sum scores were also computed for each participant across the three emotional situations, resulting in a total of ten sum scores for each participant. Emotion sum scores (i.e. anger, anxiety, jealousy, humiliation) for each infidelity type had a possible range from 3 to 15 , and the total composite distress scores for each infidelity type could range from 12 to 60 . As these total composite distress scores are a sum of continuous emotional reactions to sexual and emotional infidelity, they were used instead of having participants respond to Buss et al.'s (1992) forced-choice questions. 


\section{Procedure}

A non-random snowball sampling technique was used to recruit individuals of varying sexual orientations through a number of methods. IRB-approved recruitment scripts were sent to potential participants via email and social networking Internet websites (i.e. Facebook).

Furthermore, undergraduate students enrolled in psychology courses at a large midwestern university in Oklahoma were invited to participate through an on-line research participant pool. University students were also invited to participate through email and in-person communication with their professors. Moreover, lesbian and gay individuals were recruited through a variety of LGBT-friendly organizations.

IRB-approved recruitment scripts were used to briefly introduce the researcher, specify participant criteria, and provide an overview of the research project including the purposes of the study and instructions for participation. Individuals interested in participating were instructed to click on a website link that would connect them directly to the 30 to 45 -minute online survey website.

Once directed to the website, an informed consent page appeared where the general purposes of the study were described, along with benefits and risks of participation. Although it was clearly stated that there were no foreseeable risks associated with the study, participants were encouraged to end their participation at any time or skip any of the questions if they began to experience discomfort or stress. Participants were also informed that their participation would be anonymous and confidential. Upon clicking the "Agree to Participate" box, they were randomly directed to one of three separate survey websites. These three survey websites were identical except that each website presented the three measures (IEQ, Triangular Love Scale, continuous emotion ratings) in a different order. In other words, the measures were counterbalanced. After submitting their responses, they were thanked for their participation. Since numerous participants were recruited through a large university, organizations, or social connections in Oklahoma, a list of Oklahoma counseling agencies was provided upon study completion for participants to contact 
if needed. Psychology student participants recruited through the on-line research participant pool were given one-half research credit for their participation. In addition, all participants had the option of connecting to yet another separate website (so that names could not be connected to survey responses) where they could enter into a drawing to win one of two $\$ 25.00$ gift cards to Walmart by providing the following information: name, email address, and telephone number. In total, $45.9 \%$ of study participants $(n=136)$ decided to enter into the optional drawing. Two randomly chosen participants were notified of their winnings, and gift cards were mailed to their preferred addresses.

Predictive Analytics SoftWare (PASW) Statistics 18.0 version for Windows and OSUpak (Miller, 1990) were used to complete all statistical analyses. Internal consistency reliabilities for the measures ranged from .92 to .96: IEQ emotion-intimacy subscale $(\alpha=.92)$, IEQ sexual subscale $(\alpha=.94)$, Triangular Love Scale intimacy subscale $(\alpha=.94)$, Triangular Love Scale passion subscale $(\alpha=.95)$, Triangular Love Scale decision/commitment subscale $(\alpha=.96)$, total composite distress score for sexual infidelity from continuous emotion ratings $(\alpha=.94)$, and total composite distress score for emotional infidelity from continuous emotion ratings $(\alpha=.93)$. 


\title{
CHAPTER III
}

\author{
RESULTS
}

\section{$\underline{\text { Preliminary Analyses }}$}

Preliminary analyses were conducted to explore possible sex and sexual orientation group differences in demographic variables of age, length of current relationship, and infidelity history. A two-way factorial ANOVA was conducted to explore possible age differences, an additional two-way factorial ANOVA was conducted to examine possible group differences in length of current relationship, and chi-squares analyses were performed to investigate possible differences in infidelity history.

Results from the first two-way factorial ANOVA revealed a significant main effect for sexual orientation $[F(1,288)=152.03, p<.001]$, where lesbian and gay participants $(M=33.1)$ were significantly older than heterosexual participants $(M=20.6)$. The interaction effect of sex and sexual orientation and main effect of sex did not reach statistical significance.

Exploring group differences in length of current relationship with a second two-way factorial ANOVA, a significant interaction effect was found $[F(1,281)=4.765, p=.030]$ along with a significant main effect for sexual orientation $[F(1,281)=32.193, p<.000]$. Although lesbian and gay individuals $(M=56.6)$ were involved in their current relationships significantly longer than heterosexual women and men $(M=21.8)$, this difference was significantly more profound among males, with gay men $(M=63.9)$ involved with their current romantic partners 
for a significantly longer duration than heterosexual men $(M=15.6)$. It should be noted that the main effect for sex did not reach statistical significance.

Exploring participants' experiences with infidelity in both current and past relationships, seventy-seven participants reported cheating on their current partner $(26.0 \%)$ and a similar number $(n=76 ; 25.7 \%)$ endorsed being cheated on by their current partner. A larger number of participants reported cheating in the past $(n=140 ; 47.3 \%)$ or being cheated on by a past partner ( $n=167 ; 56.4 \%)$. Across all four questions regarding actual experiences with infidelity, it was most common for participants and/or their partners to mutually engage in emotional and sexual infidelity as opposed to emotional or sexual infidelity alone.

Chi-square analyses for sex and history of infidelity experiences in current and past romantic partnerships showed that sex was not significantly related to history of cheating on one's current partner, history of cheating on a past partner, or history of being cheated on by a past partner. However, there was a significant difference between women and men related to history of being cheated on in their current relationships $\left(\chi^{2}=3.918, d f=1, p=0.048\right)$, with a small effect size of .116. Whereas only $22.2 \%$ of women endorsed being cheated on by their current partner, $32.7 \%$ of men reported a history of being cheated on in their current relationship.

Follow-up chi-square analyses were then conducted to examine if women and men differed regarding which type(s) of infidelity they had experienced in their current and past relationships: emotional infidelity, sexual infidelity, or both types (co-occurrence of emotional and sexual infidelity). Results indicated sex was not significantly related to which type of infidelity participants' current partners had committed, but women and men did significantly differ in which type of infidelity they had committed in their current $\left(\chi^{2}=6.899, d f=1, p=\right.$ 0.032 ) and past relationships $\left(\chi^{2}=17.203, d f=1, p<0.001\right)$. In both current and past relationships, men were significantly more likely to commit sexual infidelity than emotional or both types of infidelity, and women were more likely to commit emotional or both types of infidelity than sexual infidelity. There was also a significant relationship between sex and type of 
infidelity committed by participants' past unfaithful partners $\left(\chi^{2}=6.143, d f=1, p=0.046\right)$, with men's past unfaithful partners more likely to be sexually unfaithful than commit both types of infidelity. Women's past partners, on the other hand, were more likely to commit both types of infidelity than sexual infidelity alone.

In regard to sexual orientation, a significant relationship was not found between sexual orientation and history of cheating on one's current partner, history of being cheated on by one's current partner, or history of being cheated on by a past partner. However, sexual orientation was significantly related to history of being unfaithful in a past relationship, with $40.7 \%$ of heterosexual participants reporting a history of cheating on a past partner as compared to $58.1 \%$ of lesbian and gay participants $\left(\chi^{2}=8.577, d f=1, p=0.003\right)$. This had a small effect size of .172 .

Follow-up chi-square analyses were then conducted to examine if lesbian and gay participants differed from heterosexuals regarding which type(s) of infidelity they had experienced in their current and past relationships: emotional infidelity, sexual infidelity, or both types (co-occurrence of emotional and sexual infidelity). Sexual orientation was not significantly related to which type of infidelity participants' current or past partners had committed. On the other hand, sexual orientation was significantly related to which type of infidelity participants had committed in their current $\left(\chi^{2}=7.487, d f=1, p=0.024\right)$ and past relationships $\left(\chi^{2}=7.272, d f=\right.$ $1, p=0.026)$. In both current and past relationships, heterosexual participants were significantly more likely to commit emotional infidelity than sexual or both types of infidelity, whereas lesbian and gay participants were significantly more likely to commit sexual or both types of infidelity than emotional infidelity.

\section{$\underline{\text { Main Analyses }}$}

\section{Predictors of Emotional Reactions to Sexual and Emotional Infidelity}

Multiple regression analyses with predictors entered simultaneously were conducted to assess the extent to which sex, sexual orientation, infidelity expectations, and love were predictive of emotional reactions to hypothetical acts of sexual and emotional infidelity. One 
multiple regression was conducted for each criterion variable, for a total of ten analyses. The five continuous variables were the three subscales from the Triangular Love Scale (intimacy, passion, decision/commitment) and the two subscales from the IEQ (likelihood of partner committing emotional infidelity, likelihood of partner committing sexual infidelity). The two categorical variables were sex (female, male) and sexual orientation (lesbian/gay, heterosexual). Dummy coding was used to code categorical variables. Sum scores from the continuous emotion ratings (anger, anxiety, jealousy, humiliation, and total composite distress), with five sum scores for each infidelity type (emotional, sexual), served as the criterion variables. All multiple regression equations were analyzed for statistical significance using an F-test. If significant, b-weights and ttests were examined to assess the significance of each predictor. Because ten univariate regression analyses were conducted, t-tests were analyzed at a more stringent alpha level of .001 in order to control for Type I error. Descriptive information and intercorrelations among the predictor variables are presented in Table 2. Means and standard deviations for the criterion variables and bivariate correlations among the criterion and predictor variables are provided in Table 3.

1) To what extent do the independent variables (sex, sexual orientation, infidelity expectations, intimacy, passion, and commitment) predict distress related to sexual infidelity (as measured by the total composite distress score for the emotion ratings across the three sexual scenarios)? Multiple regression analysis determined that distress related to sexual infidelity did vary as a function of sex, sexual orientation, infidelity expectations, and love (intimacy, passion, commitment). Overall, this set of predictors accounted for $29.6 \%$ of the variability in distress related to sexual infidelity, $F(7,288)=17.34, p<.001$. Sex $[t(288)=4.61, p<.001]$, sexual orientation $[t(288)=-7.01, p<.001]$, and intimacy $[t(288)=-3.67, p<.001]$ contributed significantly to the prediction of distress from sexual infidelity, whereas infidelity expectations, passion, and commitment were not significant predictors (see Table 4). Females and 
heterosexuals reported more distress to sexual infidelity, than males and lesbian/gay individuals respectively. Less intimacy was also predictive of greater distress by sexual infidelity.

2) To what extent do the independent variables (sex, sexual orientation, infidelity expectations, intimacy, passion, and commitment) predict anger, anxiety, jealousy, and humiliation related to sexual infidelity (as measured by the sum score for each of the four emotions across the three sexual scenarios)?

a) $\mathrm{DV}=$ anger

Sex, sexual orientation, infidelity expectations, and love (intimacy, passion, commitment) accounted for a significant proportion of variance in anger related to sexual infidelity, $R^{2}=.26$, $F(7,288)=14.38, p<.001 . \operatorname{Sex}[t(288)=3.55, p<.001]$ and sexual orientation $[t(288)=-6.32, p$ $<.001]$ contributed significantly to the prediction of anger from sexual infidelity, whereas infidelity expectations, intimacy, passion, and commitment were not significant predictors (see Table 4). Again, females and heterosexuals were more angered by sexual infidelity than males and lesbian/gay individuals, respectively.

b) $\mathrm{DV}=$ anxiety

Anxiety related to sexual infidelity also varied as a function of sex, sexual orientation, infidelity expectations, and love (intimacy, passion, commitment). Overall, this set of predictors significantly accounted for $21.8 \%$ of the variability in anxiety related to sexual infidelity, $F(7$, $288)=11.50, p<.001 . \operatorname{Sex}[t(288)=3.92, p<.001]$, sexual orientation $[t(288)=-5.11, p<.001]$, and intimacy $[t(288)=-3.51, p=.001]$ contributed significantly to the prediction of anxiety from sexual infidelity, whereas infidelity expectations, passion, and commitment were not significant predictors (see Table 4). Greater levels of anxiety in response to sexual infidelity were reported by females and heterosexuals. Lower levels of intimacy were also predictive of higher levels of anxiety.

c) $\mathrm{DV}=$ jealousy 
Sex, sexual orientation, infidelity expectations, and love (intimacy, passion, commitment) also accounted for a significant proportion of jealousy from sexual infidelity, $R^{2}=.19, F(7,288)$ $=9.86, p<.001$. Sexual orientation $[t(288)=-5.11, p<.001]$ was the only significant predictor of jealousy from sexual infidelity, whereas sex, infidelity expectations, intimacy, passion, and commitment were not significant predictors (see Table 4). A heterosexual orientation was associated with more jealousy in response to sexual infidelity.

d) DV = humiliation

Humiliation related to sexual infidelity varied significantly as a function of sex, sexual orientation, infidelity expectations, and love (intimacy, passion, commitment), with this set of predictors accounting for $24.8 \%$ of the variability $F(7,288)=13.56, p<.001$. Sex $[t(288)=4.60$, $p<.001]$ and sexual orientation $[t(288)=-6.70, p<.001]$ contributed significantly to the prediction of humiliation from sexual infidelity, whereas infidelity expectations, intimacy, passion, and commitment were not significant predictors (see Table 4). Once again, females and heterosexuals were more humiliated by sexual infidelity than males and lesbian/gay individuals, respectively.

3) To what extent do the independent variables (sex, sexual orientation, infidelity expectations, intimacy, passion, and commitment) predict distress related to emotional infidelity (as measured by the total composite distress score for the emotion ratings across the three emotional scenarios)?

Distress related to emotional infidelity also varied as a function of sex, sexual orientation, infidelity expectations, and love (intimacy, passion, commitment). Overall, this set of predictors significantly accounted for $25.5 \%$ of the variability in distress related to emotional infidelity, $F(7$, $288)=14.07, p<.001 . \operatorname{Sex}[t(288)=4.26, p<.001]$, sexual orientation $[t(288)=-6.29, p<.001]$, and commitment $[t(288)=3.39, p=.001]$ contributed significantly to the prediction of distress from emotional infidelity, whereas infidelity expectations, intimacy, and passion were not significant predictors (see Table 5). Greater levels of distress in response to emotional infidelity 
were reported by females and heterosexuals than males and lesbian/gay individuals, respectively. Higher levels of commitment also predicted greater distress by emotional infidelity.

4) To what extent do the independent variables (sex, sexual orientation, infidelity expectations, intimacy, passion, and commitment) predict anger, anxiety, jealousy, and humiliation related to emotional infidelity (as measured by the sum score for each of the four emotions across the three emotional scenarios)?

a) $\mathrm{DV}=$ anger

Sex, sexual orientation, infidelity expectations, and love (intimacy, passion, commitment) accounted for a significant proportion of variance in anger related to emotional infidelity, $R^{2}=$ $.22, F(7,288)=11.54, p<.001 . \operatorname{Sex}[t(288)=3.65, p<.001]$, sexual orientation $[t(288)=-6.00$ and commitment $[t(288)=3.36, p=.001]$ contributed significantly to the prediction of anger from emotional infidelity, whereas infidelity expectations, intimacy, and passion were not significant predictors (see Table 5). Females and heterosexuals were more angered by emotional infidelity than males and lesbian/gay individuals, respectively. More commitment was also predictive of greater levels of anger in response to emotional infidelity.

b) $\mathrm{DV}=$ anxiety

Anxiety related to emotional infidelity also varied as a function of sex, sexual orientation, infidelity expectations, and love (intimacy, passion, commitment). Overall, this set of predictors significantly accounted for $18.7 \%$ of the variability in anxiety related to emotional infidelity, $F(7$, $288)=9.45, p<.001 . \operatorname{Sex}[t(288)=3.88, p<.001]$ and sexual orientation $[t(288)=-3.96, p<$ .001] contributed significantly to the prediction of anxiety from emotional infidelity, whereas infidelity expectations, intimacy, passion, and commitment were not significant predictors (see Table 5). Greater levels of anxiety in response to emotional infidelity were reported by females and heterosexuals than males and lesbian/gay individuals, respectively.

c) $\mathrm{DV}=$ jealousy 
Sex, sexual orientation, infidelity expectations, and love (intimacy, passion, commitment) also accounted for a significant proportion of jealousy from emotional infidelity, $R^{2}=.20, F$ (7, $288)=10.32, p<.001 . \operatorname{Sex}[t(288)=3.69, p<.001]$ and sexual orientation $[t(288)=-4.98, p<$ .001] contributed significantly to the prediction of jealousy from emotional infidelity, whereas infidelity expectations, intimacy, passion, and commitment were not significant predictors (see Table 5). Females and heterosexuals were also more jealous in response to emotional infidelity than males and lesbian/gay individuals, respectively.

d) DV = humiliation

Humiliation related to emotional infidelity varied significantly as a function of sex, sexual orientation, infidelity expectations, and love (intimacy, passion, commitment), with this set of predictors accounting for $21.4 \%$ of the variability $F(7,288)=11.20, p<.001$. Sex $[t(288)=$ $3.44, p=.001]$ and sexual orientation $[t(288)=-6.41, p<.001]$ contributed significantly to the prediction of humiliation from emotional infidelity, whereas infidelity expectations, intimacy, passion, and commitment were not significant predictors (see Table 5). Once again, females and heterosexuals were more humiliated by emotional infidelity than males and lesbian/gay individuals, respectively.

Effects of Sex and Sexual Orientation on Emotional Reactions to Sexual and Emotional Infidelity

5) Do participant sex and sexual orientation significantly interact to influence levels of anger, anxiety, jealousy, and humiliation felt in response to emotional and sexual infidelity?

A mixed ANOVA was conducted with sex and sexual orientation as between factors and infidelity type (2 levels: emotional and sexual) and emotions (4 levels: anger, anxiety, jealousy, humiliation) as within factors. The homogeneity of variances assumption was not met, as indicated by Levene's Test of Equality of Error Variances. As a result, the $F$ ratios for the between-subjects effects were analyzed at a more stringent alpha level of .01, as suggested by Stevens (1999). Mauchley's Test of Sphericity indicated that the heterogeneity of covariances 
assumption was not met. Therefore, Greenhouse-Geisser corrections for degrees of freedom were used to evaluate the $F$ ratios for the within-subjects effects when appropriate. ANOVA summary tables for the between and within-subjects effects are presented in Tables 6 and 7, respectively.

The higher-order interaction between sex and sexual orientation with emotions across infidelity type did not reach statistical significance. Thus, the lower-order interactions were examined. Although the interaction between sexual orientation and infidelity type on emotions was not statistically significant, a significant interaction was found between sex and infidelity type on emotions $[F(2.567,749.632)=3.027, p=.036]$. This interaction had a small effect size $\left(\eta_{\mathrm{p}}{ }^{2}=.01\right)$. Interaction comparison post-hoc analyses revealed that males and females had a different pattern of emotional responses to sexual infidelity $[F(3,876)=5.668, p=.001]$. However, males and females did not show pattern differences across the emotions in response to emotional infidelity $[F(3,876)<1, \mathrm{NS}]$. As shown in Figure 1, males and females agreed that a partner's emotional infidelity would elicit greatest amounts of jealousy, followed by anxiety, anger, and humiliation. In response to sexual infidelity, women and men gave highest ratings for anger, followed by anxiety and jealousy. However, they differed in their responses to humiliation. Males were much less concerned by humiliation $(M=11.2)$ in comparison to the other emotions, whereas females were almost as humiliated $(M=13.1)$ as they were anxious and jealous. The means for this significant interaction are presented in Table 8 .

The lower-order interaction between infidelity type and emotions also reached statistical significance $[F(3,876)=28.034, p<.001]$ with a medium effect size $\left(\eta_{\mathrm{p}}{ }^{2}=.09\right)$. Post-hoc results for this interaction are presented in the following section, as these results directly answer the sixth research question.

The lower-order interaction between sexual orientation and emotions also reached statistical significance $[F(2.629,767.543)=8.207, p<.001]$, with sexual orientation accounting for a small amount of the variance in emotions $\left(\eta_{\mathrm{p}}{ }^{2}=.03\right)$. Simple main effect post-hoc analyses revealed that across both types of infidelity, there were significant differences between 
heterosexual and lesbian/gay individuals for anger $[F(1,876)=53.179, p<.001]$, anxiety $[F(1$, $876)=29.584, p<.001]$, jealousy $[F(1,876)=36.686, p<.001]$, and humiliation $[F(1,876)=$ 97.304, $p<.001]$. As noted in Figure 2, the greatest difference appeared in humiliation, with lesbian and gay participants reporting significantly less humiliation $(M=10.5)$ than heterosexual participants $(M=13.1)$. See Table 9 for the means for this significant interaction. All other lowerorder interactions did not reach statistical significance.

Tests for between-subjects effects revealed that there was not a statistically significant interaction between sex and sexual orientation. However, both main effects for sex $[F(1,292)=$ $25.344, p<.001]$ and sexual orientation $[F(1,292)=47.452, p<.001]$ were statistically

significant. Sex had a medium effect on emotion ratings $\left(\eta_{\mathrm{p}}{ }^{2}=.08\right)$, whereas sexual orientation had a large effect on emotion ratings $\left(\eta_{\mathrm{p}}{ }^{2}=.14\right)$. Across all emotions and both infidelity types, women's scores were significantly higher than males, and heterosexuals' scores were significantly higher than lesbian and gay participants' scores.

\section{Effect of Infidelity Type on Emotional Reactions}

6) Do sexual and emotional infidelity elicit significantly different levels of distress, anger, anxiety, jealousy, and humiliation?

As previously mentioned, a mixed ANOVA was conducted with sex and sexual orientation as between factors and infidelity type ( 2 levels: emotional and sexual) and emotions (4 levels: anger, anxiety, jealousy, humiliation) as within factors. As stated above, the lower-order interaction between the within factors, infidelity type and emotions, reached statistically significance $[F(3,876)=28.034, p<.001]$. Follow-up post-hoc results for this significant interaction are presented here as they directly answer this sixth research question. It should be noted that the main effect for infidelity type also reached statistical significance, indicating that participants were significantly more distressed by sexual than emotional infidelity $[F(1,292)=$ 24.527, $p<.001]$. 
Since the sphericity assumption was not met, the Bonferroni approach for post-hoc pairwise comparisons was utilized as suggested by Stevens (1999). A total of sixteen dependent ttests were conducted to locate the significant differences among the emotions both within and between infidelity types. Results were analyzed with a Bonferroni adjusted alpha level of .003 [.05/16 (number of comparisons)].

Examining the significant interaction effect, participants were significantly more angered $[t(295)=8.14, p<.001]$ and humiliated $[t(295)=5.55, p<.001]$ by sexual infidelity than emotional infidelity (see Figure 3). Anxiety and jealousy ratings for sexual and emotional infidelity did not significantly differ.

In response to sexual infidelity, participants stated they would feel more angered than anxious $[t(295)=4.09, p<.001]$, jealous $[t(295)=4.23, p<.001]$, or humiliated $[t(295)=5.74, p$ $<.001$; see Figure 3]. On the other hand, their reported ratings for anxiety, jealousy, and humiliation did not significantly differ.

Participants were most overcome by anxiety and jealousy in response to emotional infidelity, and these ratings did not differ significantly from one another (see Figure 3). They were significantly more anxious than angered $[t(295)=-3.78, p<.001]$ or humiliated $[t(295)=$ $7.33, p<.001]$, and they were significantly more jealous than angered $[t(295)=-4.36, p<.001]$ or humiliated $[t(295)=7.71, p<.001]$. Finally, they were significantly more angered than humiliated $[t(295)=4.32, p<.001]$ when thinking about a current partner's emotional infidelity. The means for this significant interaction are displayed in Table 10. 


\section{CHAPTER IV}

\section{DISCUSSION}

\section{Predictors of Emotional Reactions to Infidelity}

The first four research questions addressed whether sex, sexual orientation, expectations about a partner's potential for infidelity, and love were predictive of emotional reactions to hypothetical scenarios of sexual and emotional infidelity. Summarizing these findings, participant sex and sexual orientation were significant predictors of almost all five emotions (i.e. general distress, anger, anxiety, jealousy, humiliation) in response to both emotional and sexual infidelity. In fact, the only scenario for which sex was not a significant predictor was in a jealous response to sexual infidelity. Reviewing the influence of love on emotional responses, commitment (one component of love) was predictive of distress and anger in response to emotional infidelity, whereas intimacy (a second component of love) was predictive of distress and anxiety in response to sexual infidelity. Interestingly, neither passion (the third component of love) nor expectations about the likelihood of a partner committing sexual or emotional infidelity were significant predictors of emotional responses to either emotional or sexual infidelity. As a whole, these findings indicate that females and heterosexuals were more prone to feeling significantly distressed by a current partner's sexual or emotional infidelity, in comparison to their male and lesbian and gay counterparts. Moreover, those who are more committed to their partners are more likely to be distressed and angered by a partner's emotional infidelity, while individuals who feel 
their relationships are less intimate will be more distressed and anxious by a partner's sexual infidelity. Lastly, no matter how passionate your relationship is, or whether or not you expect your partner to be unfaithful, simply imagining one's partner committing infidelity evokes strong, negative emotions.

Sex as a significant predictor of emotional responses to sexual and emotional infidelity lends support to some previous studies (Cramer et al., 2008; Green \& Sabini, 2006) yet contradicts others (DeSteno \& Salovey, 1996; Dijkstra et al., 2001). While continuous emotion ratings were used to measure emotional reactions to sexual and emotional infidelity in the current study, all of these previous studies used forced-choice questions. Interestingly, the two studies in which sex was found not to be a significant predictor (DeSteno \& Salovey, 1996; Dijkstra et al., 2001) actually showed that sex was no longer a significant predictor once participants' beliefs about the co-occurrence of emotional and sexual infidelity (aka. "double-shot hypothesis") were put into the equation. Therefore, it seems participants' beliefs tend to mediate the relationship between sex and distress by emotional and sexual infidelity. Another interesting finding of the current study was that sex was not predictive of jealousy in response to sexual infidelity. This supports the idea that neither sex is more jealous than the other (Buss, 2000; Fisher, 1992).

Upon review, this seems to be the first study that has investigated sexual orientation as a possible predictor of emotional reactions to sexual and emotional infidelity. However, researchers have found sexual orientation differences in response to sexual and emotional infidelity (Bailey et al, 1994; deSouza et al., 2006; Harris, 2002; Sheets \& Wolfe, 2001). Specifically, heterosexual men often report more distress in response to sexual infidelity than heterosexual women, lesbian women, and gay men, whereas these latter three groups tend to report similarly high levels of distress to emotional infidelity (Bailey et al., 1994; Harris, 2002; Sheets \& Wolfe, 2001).Considering sexual orientation was found to be a significant predictor of emotional reactions to emotional and sexual infidelity in the current study, it seems important to question the impact of this variable on reactions to infidelity in future research and clinical endeavors. 
Exploring characteristics of love as predictors of emotional reactions to infidelity, more commitment to the relationship was predictive of distress and anger in response to emotional infidelity, but not sexual infidelity. On the other hand, less intimacy was predictive of distress and anxiety in response to sexual infidelity, but not emotional infidelity. These findings are not only interesting but puzzling. Perhaps greater levels of commitment, or a decision to maintain the relationship and belief that the relationship is stable and permanent (Sternberg, 1987), leads to heightened feelings of distress and anger in response to emotional infidelity, as this indicates the unfaithful partner breached trust and was not as equally committed to the relationship as the betrayed partner. Regarding intimacy, or emotional support and connectedness among partners (Sternberg, 1987), it is possible that having less of an emotional bond decreases the betrayed partner's sense of safety and security when faced with a partner's sexual infidelity, thereby leading to significant distress and anxiety. For example, with less emotional connectedness between partners, it is possible the betrayed individual may question whether his or her partner cares enough to honestly self-disclose information about the affair. This includes aspects of the infidelity that could jeopardize the betrayed partner's well-being, such as whether or not safe-sex was practiced, whether or not the infidelity is still occurring, and whether the unfaithful partner wants to stay in the current relationship or abandon it. Notably, it is more difficult to speculate on why these emotions were felt in response to one infidelity type and not the other. The current findings also revealed that passion, or strong physiological and psychological needs and desires for one's partner, was not a significant predictor in any regard. According to Sternberg (1987), passion is more important during short-term relationships and tends to fade over time, whereas intimacy and commitment are more important in long-term relationships. Considering average length of one's current relationship was around three years for participants in this study, it seems probable that passion was less important for these couples and therefore had less of an impact on their emotional reactions to infidelity scenarios. 
Neither subscale from the IEQ was predictive of emotional responses to emotional or sexual infidelity. In a nutshell, people's expectations about the likelihood of their partners being unfaithful have little, if any, influence on their emotional reactions to their partners' hypothetical infidelity. This does not lend support to Cramer et al.'s (2008) violation of infidelity expectations hypothesis. On the other hand, it supports their finding that sex was a significant predictor of distress in response to infidelity, whereas infidelity expectations were not significant predictors. Effects of Sex and Sexual Orientation on Emotional Reactions to Infidelity

Sex and sexual orientation did not significantly interact to effect emotional responses to emotional and sexual infidelity. Across all emotions and both types of infidelity, women's emotion ratings were significantly higher than men's scores. Regardless of sexual orientation, women and men agreed that emotional infidelity evoked more jealousy and anxiety than all other emotions, sexual infidelity evoked more anger, and both types of infidelity caused the least amounts of humiliation. Women's reactions to emotional infidelity paralleled men's reactions across all emotions. In response to sexual infidelity, however, women were almost as humiliated as they were anxious and jealous, whereas men were much less concerned with humiliation.

Although a sex difference did emerge, with women reporting significantly higher emotion ratings than men, this was the case for both emotional and sexual infidelity. Comparing means within each sex, both women and men were more distressed by sexual infidelity than emotional infidelity. This is congruent with DeSteno et al.'s findings (2002), but it is inconsistent with multiple previous findings that highlight women's tendencies to respond with incredibly higher levels of distress to emotional than sexual infidelity. Aside from women reacting stronger than men, it seems women and men were more alike than different.

These results marginally support the well-documented sex difference, where women are said to be significantly more distressed by emotional infidelity than men, and men are said to be significantly more distressed by sexual infidelity than women (Buss et el., 1992; Buss et al., 1999; Buunk et al., 1996; Cramer et al., 2001; Cramer et al., 2008; DeSteno \& Salovey, 1996; 
DeSteno et al., 2002; Edlund et al., 2006; Fernandez et al., 2007; Green \& Sabini, 2004; Harris, 2003; Harris \& Christenfeld, 1996; Penke \& Asendorpf, 2008; Sabini \& Green, 2004; Sagarin et al., 2003; Schützwohl, 2008; Ward \& Voracek, 2004). According to Penke \& Asendorpf (2008), the evolutionary hypothesis can only be confirmed when all four differences (two between-sex and two within-sex) are found in the predicted directions. The current findings fail to confirm the evolutionary hypothesis, as only one between-sex difference (i.e. women react with stronger emotions than men in response to emotional infidelity) and one within-sex difference (i.e. men react with stronger emotions to sexual than emotional infidelity) were found. Nonetheless, these ordinal effects lend marginal support to the evolutionary hypothesis. Bearing in mind that continuous measures were used in this study, these findings support the idea that the sex difference disappears or diminishes in significance when continuous measures are employed instead of forced-choice questions (DeSteno et al., 2002; Green \& Sabini, 2006; Harris, 2003). The inclusion of lesbian and gay individuals may have also contributed to a lack of sex differences between sexual and emotional infidelity, which has also been found in past research (Harris, 2003).

The pattern of women responding with stronger feelings than men to both infidelity types has also been demonstrated in the past (Edlund et al., 2006; Penke \& Asendorpf, 2008). It is possible that this sex difference is reflective of popular gender stereotypes that most women are overly emotional and dramatic and that "real" men can control their emotions. Remembering that participants were asked to self-report their emotional reactions, it is possible that women and men responded in these socially acceptable ways. Women and men also differed in their emotional reactions to sexual infidelity, whereas their responses to emotional infidelity were similar. This contradicts previous findings (Penke \& Asendorpf, 2008) in which the opposite was true: women and men had different emotional reactions to emotional infidelity, but not sexual infidelity. In the current study, women and men agreed that sexual infidelity most elicited anger, followed by anxiety, and jealousy. Although they agreed that humiliation would be the least felt emotion, 
women's ratings for humiliation were notably higher than men's humiliation ratings. Women's greater tendency to feel humiliated by a partner's sexual infidelity may reflect the current views of Western societies, which expect women to be able to sexually please their partners and often hold women responsible when their partners commit infidelity. Therefore, it seems logical that women might have been taught by society that they are at least partially to blame when a partner is unfaithful, which can easily lead to feelings of humiliation.

Heterosexuals' scores were also significantly higher than lesbian and gay individuals' scores, but no significant sexual orientation differences were found between emotional and sexual infidelity. This finding supports the evolutionary idea that lesbian and gay individuals should not be as affected by infidelity as compared to heterosexuals, as unfaithful acts by same-sex partners do not pose the same evolutionary threats of raising another man's child or losing a male partner's resources to another woman. Heterosexuals may also be more distressed by infidelity because Western societal norms tell them they should feel this way, whereas lesbian and gay individuals do not have overarching societal rules to follow regarding infidelity. These results support those of previous researchers who failed to find differences in emotional responses between lesbian women and gay men (Bailey et al., 1994; de Souza et al., 2006; Dijkstra et al., 2001; Sheets \& Wolfe, 2001). Nevertheless, the current findings failed to confirm the majority of previous findings. For example, although past research indicates heterosexual men are more distressed by sexual infidelity when compared to heterosexual women, lesbian women, and gay men (Bailey et al., 1994; Harris, 2002; Sheets \& Wolfe, 2001), the current findings indicate heterosexual women were actually more distressed by sexual infidelity than heterosexual men. Moreover, heterosexuals were more distressed by both types of infidelity when compared to lesbian and gay individuals. Previous researchers have also found heterosexual women to report similar levels of distress to emotional infidelity as lesbian and gay individuals (Bailey et al., 1994; Harris, 2002; Sheets \& Wolfe, 2001), whereas current findings reveal that heterosexual women were significantly more distressed by both types of infidelity when compared to lesbian 
and gay individuals. Finally, lesbian and gay individuals responded with similar emotion ratings in response to both infidelity types in the current study, whereas past research indicates that lesbians are more distressed by sexual infidelity than gay men, and gay men are more distressed by emotional infidelity than lesbians (Dijkstra et al., 2001).

Heterosexual and lesbian/gay individuals agreed that both infidelity types created similar amounts of anger, anxiety, and jealousy. They also agreed that humiliation would be the least experienced emotion; however, heterosexuals were almost as humiliated as they were angry, anxious, or jealous, while lesbian and gay individuals were considerably less humiliated than they were angry, anxious, or jealous. Speculating on the reasons for this difference, it is plausible that heterosexuals' increased concern with humiliation may be a derivative of Western societal rules which praise monogamy among heterosexual couples. Therefore, when monogamy is violated by infidelity, it is possible that the betrayed partner feels an increased amount of responsibility for not being able to keep their partner from breaking that monogamous bond. Heterosexuals may also feel more humiliated because their relationships are much more socially accepted and consequently publicized more freely to family, friends, co-workers, etc. Among same-sex couples, it is possible that a partner's infidelity is less internalized due to a lack of societal rules about how each partner should behave when confronted by infidelity. Moreover, same-sex couples who keep private the details of their relationships in order to refrain from hearing negative societal messages will be more able to keep any infidelities hidden as well, resulting in less humiliation for the betrayed partner.

\section{Effects of Infidelity Type on Emotional Reactions}

Among all participants, sexual infidelity elicited significantly higher emotion ratings than emotional infidelity for all emotions, with differences in distress, anger, and humiliation reaching statistical significance. Sexual infidelity elicited significantly more anger than the other emotions, whereas the other emotions were reported at similar levels. Emotional infidelity elicited 
significantly more anxiety and jealousy than anger and humiliation, and significantly more anger than humiliation.

That sexual infidelity caused significantly more anger than all other emotions may reflect the common viewpoint that sexual infidelity is preventable and intolerable whereas emotional infidelity is often seen as less controllable or intentionally harmful. This finding parallels those found in previous studies (Green \& Sabini, 2006; Sabini \& Green (2004), where feelings of anger and blaming the unfaithful partner were more consistent responses to sexual infidelity than emotional infidelity. Also of interest is that participants in the current study responded least of all with humiliation to sexual and emotional infidelity. This may be a positive indicator that people try to limit the extent to which they internalize and find themselves at fault for a partner's infidelity. $\underline{\text { Implications for Practice }}$

Considering infidelity is one the top three reasons couples present for counseling (Lerner, 1989) and is often addressed as an issue during individual therapy, it is crucial that therapists are able to thoroughly conceptualize the impact that infidelity can have on clients and understand how to best help clients process and cope with infidelity. The results of the current study can help mental health professionals understand the complexities in their clients' emotional reactions to infidelity, and thereby render them better able to help their clients.

One of the unique challenges counselors face is formulating hypotheses about clients prior to the initial session based on a limited amount of information. Fortunately, the results of this study indicate that by paying attention to basic demographic information, counselors may be able to better understand clients' emotional well-being when infidelity is reported as the presenting problem. For example, females in the current study reported experiencing significantly greater negative emotions than males in response to a partner's sexual or emotional infidelity, and the same was true of heterosexuals when compared to lesbian and gay individuals. Therefore, counselors may consider that females and heterosexuals will react to infidelity with greater 
emotional intensity in comparison to males and lesbian/gay individuals. Counselors can also query their clients either formally or informally about how much intimacy and commitment they believe is present in their relationships, as higher levels of commitment and lower levels of intimacy were predictive of various emotional responses to emotional and sexual infidelity.

The current findings indicate that a whole range of emotions are typically experienced by persons when betrayed by an unfaithful partner, including anger, anxiety, jealousy, and humiliation. This information can be presented to clients educationally to help normalize for them the intense emotions they may be experiencing. By normalizing their emotions, clients will likely feel comfortable and safe enough to disclose and process their feelings in-session. When an individual's sex, sexual orientation, and/or perceived amount of love in their relationship seems to fit with the intensity of their emotions as predicted, therapists can reassure them that others with similar characteristics responded in similar ways. Counselors can also help clients understand that a partner's infidelity leads to painful emotions, no matter whether or not the infidelity was expected. It is also possible that when working with heterosexual couples, we can use the current findings to help the unfaithful partner empathize with the feelings of the betrayed partner, since women and men responded similarly regarding which emotions were triggered more by sexual versus emotional infidelity. Similarly, therapists can use this information to increase empathy among same-sex couples, as the current findings indicate lesbian and gay couples will likely report similar emotions of equal intensities. By increasing empathy, couples can hopefully reconnect with one another and begin to heal from the challenges that infidelity poses for individuals in romantic partnerships.

The results of this study may be used to anticipate emotional reactions that heterosexual, lesbian, and gay individuals might have to sexual and emotional infidelity. For example, sexual infidelity was found to elicit more anger than all other assessed emotions. Knowing this, we can ask our clients about any feelings of anger they might be experiencing in response to sexual infidelity. Given that intense anger can lead to self-destructive behavior or harm to others, 
therapists can ask clients who have been cheated on about possible thoughts, plans, or intent to harm themselves, their partners, or the other person. Jealousy and anxiety were also frequently endorsed across all participants in response to sexual and emotional infidelity. By asking about feelings of jealousy, therapists can help prevent clients from engaging in illegal behaviors such as invading their partner's private records or stalking. Therapists can also screen for high levels of anxiety amongst betrayed clients, as these emotions can lead to excessive worry, restlessness, and sleep difficulties. Lastly, it seems particularly important for therapists to be alert to individuals who endorse greater feelings of humiliation than other emotions, as humiliation was reported less than all other emotions by participants in the current study. When this occurs, clinicians can assess why the individual is internalizing his or her partner's actions. By intervening early, therapists may be able to prevent these clients from isolating from others or ruminating on negative thoughts, which can quickly exacerbate other negative feelings like shame and embarrassment or possibly lead to severe symptoms of depression.

$\underline{\text { Limitations }}$

Given the sensitive nature of many of the survey questions (e.g. personal history of infidelity experiences, perceived amount of love in one's current relationship, infidelity expectations of one's partner, emotional reactions to infidelity scenarios), it is quite possible participants gave socially acceptable as opposed to candid responses. Participants were also asked to indicate their emotional reactions to hypothetical infidelity scenarios, instead of discussing how they had reacted in the past to actual experiences with infidelity. According to Harris (2002), no sex difference emerges regarding which type of infidelity is more upsetting when participants who have been cheated on in the past are asked to reflect on those memories. In the current study, females and males significantly differed regarding specific emotions they felt in response to these hypothetical infidelity scenarios. Therefore, it is possible this sex difference would have disappeared if participants were asked to recall actual experiences with infidelity. 
Participants' racial identities and marital statuses may have also influenced the findings, as these percentages were disproportionate to those found in the general population. In addition, convenience sampling was used instead of one of the preferred random sampling techniques.

Finally, there is a lack of randomization, manipulation, and control as a result of have pre-existing groups instead of random assignment to groups.

Results of preliminary analyses show lesbian and gay individuals were significantly older and involved in their current romantic relationships for a significantly longer duration than heterosexual participants. This is not surprising, seeing how the majority of heterosexual participants were college students who were recruited from a university setting whereas many of the lesbian and gay participants were gathered through social connections and gay-friendly organizations throughout the United States. Nevertheless, there is a strong possibility these age and length of relationship differences may have contributed to the sex and sexual orientation differences that emerged in response to the infidelity scenarios.

With a mean age of approximately 26 years, the majority of the current sample fell into a younger generation of individuals. Recalling that the sex difference in lifetime rates of committing infidelity has disappeared when studying individuals under 40 years of age (Wiederman, 1997), with women committing infidelity at similar or higher rates than men, it is possible that the age of this younger cohort of participants had an influence on their emotional responses to sexual and emotional infidelity.

Findings from preliminary chi-square analyses on history of infidelity experiences indicate that sex and sexual orientation often did not significantly relate to infidelity histories. In fact, the only differences found were that more men than women reported being cheated on by their current partners, and more lesbian and gay individuals reported cheating on a past partner than heterosexuals. Moreover, men were more likely to be sexually unfaithful, and women were more likely to engage in emotional infidelity or both infidelity types. And whereas heterosexual participants were more likely to be emotionally unfaithful, lesbian and gay individuals were more 
likely to engage in sexual infidelity or both infidelity types. Although most of these associations did not reach statistical significance, past research (Edlund et al., 2006; Sagarin et al., 2003) suggests history of infidelity experiences may have influenced participants' emotional responses to infidelity scenarios.

\section{$\underline{\text { Recommendations for Future Research }}$}

When conducting research on this topic in the future, multiple improvements can be made to the research design to increase external validity. First, random sampling should be utilized to gather a sample of adults who vary in sexual orientation and whose demographic variables such as age, length of relationship, racial identity, and marital status accurately represent that of the general population. These individuals could then be grouped by age to see if any generational differences emerge regarding emotional responses to sexual and emotional infidelity.

Other independent variables could be tested to see if they account for any of the variance in emotional responses to infidelity. For example, researchers have shown that sex is no longer a reliable predictor of emotional responses to infidelity once participants' beliefs about the cooccurrence of emotional and sexual infidelity are examined (DeSteno \& Salovey, 1996; Dijkstra et al., 2001). Although this research was first executed with a heterosexual sample and then investigated with a lesbian and gay sample, participants' beliefs have not been examined among a mixed sample of heterosexual, lesbian, and gay individuals.

Current findings reveal women's and heterosexuals' scores were significantly higher than men's and lesbian/gay individuals' scores, respectively. These interesting findings could be examined further to see how societal norms may be influencing participants' emotional responses. For example, the widely-accepted notions that women are "overly" emotional and that "real" men do not show emotion might help to explain this significant sex difference. Moreover, the relevant absence of social norms for lesbian and gay individuals regarding how they should feel in response to infidelity may explain why they were less distressed by a partner's infidelity 
than heterosexual participants. On the other hand, this sexual orientation difference might reflect possible norms within the LGBT subculture that view infidelity as something to be expected and tolerated more so than it is among monogamous-practicing heterosexuals.

Finally, future researchers could use these emotional responses to infidelity to predict betrayed individuals' actions and coping strategies. For example, it is possible that high levels of anger and jealousy could lead to increased risk for physical aggression, stalking, or homicidal ideation, whereas high levels of anxiety and humiliation could lead to the development or exacerbation of mental health problems such as clinically-significant symptoms of anxiety or depression. Further research could also attempt to identify which individuals are at an increased risk for engagement in poor coping mechanisms upon discovering a partner's infidelity, such as substance abuse, self-harm, and suicidal ideation.

\section{$\underline{\text { Summary }}$}

The results of this study suggest that sex and sexual orientation are significant predictors of emotional responses to sexual and emotional infidelity. While more commitment within relationships predicted distress and anger towards emotional infidelity, less intimacy predicted distress and anxiety in response to sexual infidelity. Interestingly, passion in relationships and expectations about a partner's likelihood of committing infidelity were not significant predictors of emotional reactions to emotional or sexual infidelity.

Across all participants, sexual infidelity elicited more negative feelings than emotional infidelity. Moreover, women's emotion ratings were significantly higher than men's ratings in response to both emotional and sexual infidelity. Although women were significantly more distressed by emotional infidelity than men, men were not found to be significantly more distressed by sexual infidelity than women, as indicated multiple times in past literature. Therefore, only marginal support was found for this well-documented sex difference, which may have diminished because of the inclusion of lesbian and gay individuals and/or with use of continuous instead of forced-choice questions. Heterosexuals' emotion ratings were also 
significantly higher than lesbian and gay individuals' ratings, across all emotions and both types of infidelity. This contradicts previous findings which indicate heterosexual women respond similarly to lesbian and gay individuals, and that heterosexual men respond with higher ratings than heterosexual women, lesbians, and gay men in response to sexual but not emotional infidelity. This tendency for heterosexuals to respond with significantly higher ratings than lesbian and gay individuals may be explained by the evolutionary idea that lesbian and gay individuals may not be as concerned about infidelity as are heterosexuals, since same-sex couples do not face the same reproductive threats. This sexual orientation difference could also be the result of lesbian and gay individuals not having societal rules to follow that dictate how they should feel in response to infidelity.

Looking at specific emotional responses to infidelity, women and men agreed that emotional infidelity caused more jealousy and anxiety than anger and humiliation, sexual infidelity elicited more anger than all other emotions, and humiliation was the least experienced emotion across both infidelity types. In response to sexual infidelity, however, men were much less humiliated than they were angry, anxious, and jealous, whereas women were almost as humiliated as they were angry, anxious, and jealous. Sex orientation differences in humiliation were also observed, with heterosexuals reporting significantly more humiliation in response to both types of infidelity than their lesbian and gay counterparts. Taken together, these findings can be used by mental health professionals to assess clients' emotional responses to infidelity, normalize for clients' their emotional reactions to infidelity, and build empathy between partners. These results may also be helpful in preventing negative consequences that can ensue as a result of experiencing these intense, negative emotions in response to what many romantic partners fear the most, namely, infidelity in their relationships. 


\section{REFERENCES}

Bailey, J. M., Gaulin, S., Agyei, Y., \& Gladue, B. A. (1994). Effects of gender and sexual orientation on evolutionary relevant aspects of human mating psychology. Journal of Personality and Social Psychology, 66(6), 1081-1093. doi:10.1037/0022-3514.66.6.1081

Barash, D. P., \& Lipton, J. E. (2001). The myth of monogamy: Fidelity and infidelity in animals and people. New York: W. H. Freeman \& Company.

Blow, A. J., \& Hartnett, K. (2005). Infidelity in committed relationships II: A substantive review. Journal of Marital and Family Therapy, 31(2), 217-233. Retrieved from http://www.jmft.net/

Brand, R. J., Markey, C. M., Mills, A., \& Hodges, S. D. (2007). Sex differences in self-reported Infidelity and its correlates. Sex Roles, 57, 101-109. doi:10.1007/s11199-007-9221-5

Brotherton, P. N. M., \& Komers, P. E. (2003). In U. H. Reichard \& C. Boesch (Eds.), Monogamy: Mating strategies and partnerships in birds, humans and other mammals (pp. 42-58). United Kingdom: Cambridge.

Buunk, B. P., Angleitner, A., Oubaid, V., \& Buss, D. M. (1996). Sex differences in jealousy in evolutionary and cultural perspective: Tests from the Netherlands, Germany, and the United States. Psychological Science, 7(6), 359-363. doi: 10.1111/j.14679280.1996.tb00389.x

Buss, D. M. (2000). The dangerous passion: Why jealousy is as necessary as love and sex. New York: The Free Press. 
Buss, D. M., Larsen, R. J., Westen, D., \& Semmelroth, J. (1992). Sex differences in jealousy: Evolution, physiology, and psychology. Psychological Science, 3(4), 251-255. doi:10.1111/j.1467-9280.1992.tb00038.x

Buss, D. M., Shackelford, T. K., Kirkpatrick, L. A., Choe, J. C., Kim, H. L., Hasegawa, M., Hasegawa, T., \& Bennett, K. (1999). Jealousy and the nature of beliefs about infidelity: Tests of competing hypotheses about sex differences in the United States, Korea, and Japan. Personal Relationships, 6(1), 125-150. doi:10.1111/j.1475-6811.1999.tb00215.x

Chojnacki, J. T., \& Walsh, W. B. (1990). Reliability and concurrent validity of the Sternberg Triangular Love Scale. Psychological Reports, 67, 219-224. Retrieved from http://www.amsciepub.com/

Coombs, R. H. (1991). Marital status and personal well-being: A literature review. Family Relations, 40(1), 97-102. Retrieved from http://www.blackwellpublishing.com/journal.asp?ref=0197-6664

Cott, N. F. (2000). Public vows: A history of marriage and the nation. Cambridge: Harvard University Press.

Cramer, R. E., Abraham, W. T., Johnson, L. M., \& Manning-Ryan, B. (2001). Gender differences In subjective distress to emotional and sexual infidelity: Evolutionary or logical inference explanation? Current Psychology, 20 (4), 327-336. doi:10.1007/s12144-001-1015-2

Cramer, R. E., Lipinski, R. E., Meteer, J. D., \& Houska, J. A. (2008). Sex differences in subjective distress to unfaithfulness: Testing competing evolutionary and violation of infidelity expectations hypotheses. Journal of Social Psychology, 148(4), 389-405. Retrieved from http://www.tandf.co.uk/journals/titles/00224545.asp

Daly, M., Wilson, M., \& Weghorst, S. J. (1982). Male sexual jealousy. Ethology \& Sociobiology, 3(1), 11-27. doi:10.1016/0162-3095(82)90027-9

de Souza, A. A. L., Verderane, M. P., Taira, J. T., \& Otta, E. (2006). Emotional and sexual jealousy as a function of sex and sexual orientation in a Brazilian sample. Psychological 
Reports, 98(2), 529-535. doi: 10.2466/PR0.98.2.529-535

DeSteno, D., Bartlett, M. Y., Braverman, J., \& Salovey, P. (2002). Sex differences in jealousy: Evolutionary mechanism or artifact of measurement? Journal of Personality and Social Psychology, 83(5), 1103-1116. doi:10.1037/0022-3514.83.5.1103

DeSteno, D. A., \& Salovey, P. (1996) Evolutionary origins of sex differences in jealousy? Questioning the 'fitness' of the model. Psychological Science, 7(6), 367-372. doi:10.1111/j.1467-9280.1996.tb00391.x

DeSteno, D., Valdesolo, P., \& Bartlett, M. Y. (2006). Jealousy and the threatened self: Getting to The heart of the green-eyed monster. Journal of Personality and Social Psychology, 91(4), 626-641. doi:10.1037/0022-3514.91.4.626

Dijkstra, P., Groothof, H. A. K., Poel, G. A., Laverman, T. T. G., Schrier, M., \& Buunk, B. P. (2001). Sex differences in the events that elicit jealousy among homosexuals. Personal Relationships, 8(1), 41-54. doi:10.1111/j.1475-6811.2001.tb00027.x

Druckerman, P. (2007). Lust in translation: The rules of infidelity from Tokyo to Tennessee. New York: Penguin Press.

Edlund, J. E., Heider, J. D., Scherer, C. R., Farc, M.-M., \& Sagarin, B. J. (2006). Sex differences in jealousy in response to actual infidelity. Evolutionary Psychology, 4, 462-470. Retrieved from http://www.epjournal.net/

Feeney, J. A. (2004). Hurt feelings in couple relationships: Towards integrative models of the negative effects of hurtful events. Journal of Social and Personal Relationships, 21, 487508. doi:10.1177/0265407504044844

Fernandez, A. M., Vera-Villarroel, P., Sierra, J. C., \& Zubeidat, I. (2007). Distress in response to emotional and sexual infidelity: Evidence of evolved gender differences in Spanish students. Journal of Psychology, 141(1), 17-24. doi: 10.1177/0022022106288474

Fisher, H. E. (1992). Anatomy of love: The natural history of monogamy, adultery, and divorce. New York: W. W. Norton and Company. 
Foran, H. M., \& O’Leary, K. D. (2008). Problem drinking, jealousy, and anger control: Variables predicting physical aggression against a partner. Journal of Family Violence, 23, 141148. doi:10.1007/s10896-007-9136-5

Godoy, M. (2009, December 15). State by state: The legal battle over gay marriage. Retrieved From National Public Radio website: http://www.npr.org/templates/story/story.php?storyId=112448663

Green, M. C., \& Sabini, J. (2006). Gender, socioeconomic status, age, and jealousy: Emotional responses to infidelity in a national sample. Emotion, 6(2), 330-334. doi:10.1037/15283542.6.2.330

Harris, C. R. (2002). Sexual and romantic jealousy in heterosexual and homosexual adults. Psychological Science, 13(1), 7-12. doi:10.1111/1467-9280.00402

Harris, C. R. (2003). A review of sex differences in sexual jealousy, including self-report data, Psychophysiological responses, interpersonal violence, and morbid jealousy. Personality \& Social Psychology Review, 7(2), 102-128. doi:10.1207/S15327957PSPR0702_102-128

Harris, C. R., \& Christenfeld, N. (1996). Gender, jealousy, and reason. Psychological Science, 7 (6), 364-366. doi:10.1111/j.1467-9280.1996.tb00390.x

Heaphy, B., Donovan, C., \& Weeks, J. (2004). A different affair? Openness and nonmonogamy in same sex relationships. In J. Duncombe, K. Harrison, G. Allan, \& D. Marsden (Eds.), The state of affairs: Explorations in infidelity and commitment (pp. 167-186). Mahwah, NJ: Lawrence Erlbaum Associates.

Kamp Dash, C. M., \& Amato, P. R. (2005). Consequences of relationship status and quality for subjective well-being. Journal of Social and Personal Relationships, 22, 607-627. doi:10.1177/0265407505056438

Kanazawa, S., \& Still, M. C. (2001). The emergence of marriage norms: An evolutionary psychological perspective. In M. Hechter, \& K.-D. Opp (Eds.), Social norms (pp. 274304). New York: Russell Sage Foundation. 
Kinsey, A. C., Pomeroy, W. B., \& Martin, C. E. (1948). Sexual behavior in the human male. Philadelphia: W. B. Saunders.

Lerner, H. G. (1989). The dance of intimacy: A woman's guide to courageous acts of change in key relationships. New York: Harper \& Row.

Low, B. S. (2003). In U. H. Reichard \& C. Boesch (Eds.), Monogamy: Mating strategies and partnerships in birds, humans and other mammals (pp. 161-176). United Kingdom: Cambridge.

Lusterman, D. (2005). Infidelity: Theory and Treatment. In M. Harway (Ed.), Handbook of Couples Therapy (pp. 337-351). Hoboken, NJ: John Wiley \& Sons.

Marchand-Reilly, J. F. (2009). Depressive symptoms in young adults: The role of attachment orientations and romantic relationship conflict. Journal of Adult Development, 16, 31-38. doi:10.1007/s10804-009-9049-z

Martell, C. R., \& Prince, S. E. (2005). Treating infidelity in same-sex couples. Journal of Clinical Psychology, 61(11), 1429-1438. doi:10.1002/jclp.20192

Mathes, E. W. (2005). Men's desire for children carrying their genes and sexual jealousy: A test of paternity uncertainty as an explanation of male sexual jealousy. Psychological Reports, 96(3), 791-798. doi:10.2466/pr0.96.3.791-798

Miller, J.W. (1990). OSU-pak [Computer Software]. Oklahoma State University, Stillwater, OK: Author.

Miller, S. L., \& Maner, J. K. (2008). Coping with romantic betrayal: Sex differences in responses to partner infidelity. Evolutionary Psychology, 6(3), 413-426. Retrieved from http://www.epjournal.net

Mullen, P. E., \& Martin, J. (1994). Jealousy: A community study. British Journal of Psychiatry, 164, 35-43. Retrieved from http://bjp.rcpsych.org/

O’Leary, K. D., Smith-Slep, A. M., \& O’Leary, S. G. (2007). Multivariate models of men's and women's partner aggression. Journal of Consulting and Clinical Psychology, 75(5), $752-$ 
764. doi:10.1037/0022-006X.75.5.752

Penke, L., \& Asendorpf, J. B. (2008). Evidence for conditional sex differences in emotional but not in sexual jealousy at the automatic level of cognitive processing. European Journal of Personality, 22, 3-30. doi:10.1002/per.654

Person, E. S. (2007). Dreams of love and fateful encounters: The power of romantic passion. Washington, DC: American Psychiatric Publishing.

Pines, A. M. (1998). Romantic jealousy: Causes, symptoms, and cures. New York: Routledge.

Reese-Weber, M., \& Marchand, J. F. (2002). Family and individual predictors of late adolescents' romantic relationships. Journal of Youth and Adolescence, 31(3), 197-206. doi:10.1023/A:1015033219027

Reichard, U. H. (2003). In U. H. Reichard \& C. Boesch (Eds.), Monogamy: Mating strategies and partnerships in birds, humans and other mammals (pp. 3-25). United Kingdom: Cambridge.

Rubin, Z. (1970). Measurement of romantic love. Journal of Personality and Social Psychology, 16(2), 265-273. doi:10.1037/h0029841

Russell, E. B., \& Harton, H. C. (2005). The "other factors": Using individual and relationship characteristics to predict sexual and emotional infidelity. Current Psychology, 24(4), 242257. doi:10.1007/s12144-005-1026-5

Sabini, J., \& Green, M. C. (2004). Emotional responses to sexual and emotional infidelity: Constants and differences across genders, samples, and methods. Personality \& Social Psychology Bulletin, 30, 1375-1388. doi:10.1177/0146167204264012

Sagarin, B. J., Vaughn Becker, D., Guadagno, R. E., Nicastle, L. D., \& Millevoi, A. (2003). Sex differences (and similarities) in jealousy: The moderating influence of infidelity experience and sexual orientation of the infidelity. Evolution \& Human Behavior, 24(1), 17-23. doi:10.1016/S1090-5138(02)00106-X

Schützwohl, A. (2008). Relief over the disconfirmation of the prospect of sexual and emotional 
infidelity. Personality and Individual Differences, 44, 668-678.

doi:10.1016/j.paid.2007.09.026

Sheets, V. L., \& Wolfe, M. D. (2001). Sexual jealousy in heterosexuals, lesbians, and gays. Sex Roles, 44(5), 255-276. doi:10.1023/A:1010996631863

Smith, T. (2006). American sexual behavior: Trends, socio-demographic differences, and risk Behavior (GSS Topical Report No. 25). Chicago: National Opinion Research Center.

Soons, J. P. M., \& Liefbroer, A. C. (2008). Together is better? Effects of relationship status and resources on young adults' well-being. Journal of Social and Personal Relationships, 25, 603-624. doi: 10.1177/0265407508093789

Sternberg, R. J. (1987). The triangle of love: Intimacy, passion, commitment. New York: Basic Books.

Stevens, J. (1999). Intermediate statistics: A modern approach $\left(2^{\text {nd }}\right.$ ed $)$. New Jersey: Lawrence Erlbaum Associates.

Sun, L. (2003). In U. H. Reichard \& C. Boesch (Eds.), Monogamy: Mating strategies and partnerships in birds, humans and other mammals (pp. 138-146). United Kingdom: Cambridge.

Ward, J., \& Voracek, M. (2004). Evolutionary and social cognitive explanations of sex differences in romantic jealousy. Australian Journal of Psychology, 56(3), 165- 171. doi:10.1080/00049530412331283381

Wiederman, M. W. (1997). Extramarital sex: Prevalence and correlates in a national survey. The Journal of Sex Research, 34(2), 167-174. doi:10.1080/00224499709551881

Wiederman, M. W., \& Hurd, C. (1999). Extradyadic involvement during dating. Journal of Social and Personal Relationships, 16(2), 265-274. doi:10.1177/0265407599162008

Yeniçeri, Z., \& Kökdemir, D. (2006). University students' perceptions of, and explanations for, infidelity: The development of the infidelity questionnaire (INFQ). Social Behavior and Personality, 34(6), 639-650. Retrieved from http://www.sbp-journal.com/ 


\section{APPPENDICES}

\section{APPENDIX A:}

\section{REVIEW OF THE LITERATURE}

\section{$\underline{\text { Positive and Negative Effects of Romantic Relationship Involvement }}$}

Looking at the impact of relationship involvement on personal well-being, Coombs (1991) reviewed over 130 studies. Summarizing findings from studies that addressed relationship status in relation to rates of alcoholism, suicide, mortality, serious mental illnesses, and happiness, he concluded that married persons, especially men, experience less emotional distress and greater levels of happiness than unmarried individuals.

The effects of relationship status and happiness on well-being were further explored in another study (Kamp Dash \& Amato, 2005). First, a sample of 691 young adults with a mean age of 23 were asked about their current relationship status and placed into groups based on their responses: married, cohabitating, exclusively dating one person, dating multiple people, and not dating. Findings of well-being as a function of current relationship status were hierarchical in nature, with higher levels of commitment signifying greater levels of subjective well-being. In other words, married individuals reported the greatest levels of well-being, followed by cohabitating couples, persons dating exclusively, individuals dating nonexclusively, and then, single participants. In addition, a positive relationship was found between levels of happiness and well-being. Even after controlling for happiness, those with greater levels of commitment were still found to experience greater well-being. Therefore, it seems individuals believe that being in an unhappy relationship is still better for well-being than no relationship at all. 
Findings from a large Dutch young adult sample (2,818 responses) add support to the previously-mentioned articles (Soons \& Liefbroer (2008). With four levels of relationship status (married, cohabitating, dating, and single) and three types of resources (material, personal, and social), they found that levels of well-being were highest among married participants, followed by cohabiting individuals, dating adults, and then singles. Close to one-third of the variance in well-being was due to the influence of resources, which suggests that some of the positive effects of relationship involvement on well-being may be related to the potential increases in resources that ensue as a result of forming a romantic partnership with another individual.

Although romantic relationships seem to heighten well-being and happiness, conflict in relationships is inevitable. Actions taken to resolve conflict in romantic relationships were examined with a sample of college students $(n=256)$ between the ages of 18 and 21 who were currently involved in romantic relationships (Reese-Weber \& Marchand, 2002). They found that males who exhibited more negative and less positive conflict resolution tactics were more likely to report the presence of depressive symptoms. Females, on the other hand, were more likely to use more negative and less positive ways to handle conflict if they had more anxious attachments characterized by fear of abandonment and rejection by their partners.

When a relationship is formed, each individual enters into the partnership with learned patterns for resolving conflict along with personal characteristics. In one study, 110 undergraduate students' attachment orientations (comfort with closeness, comfort depending on others, and anxiety over experiencing abandonment and rejection) and conflict behaviors were investigated regarding the potential impact on symptoms of depression (Marchand-Reilly, 2009). Both attachment orientation and conflict behaviors were found to be significant predictors of depression. Findings suggest increased use of attacking behaviors during periods of conflict along with discomfort with closeness, discomfort with depending on others, and fear of abandonment and rejection were experienced more by individuals who reported more depressive symptoms. 
The positive and negative feelings that accompany romance are highlighted in a recent book about romantic passion (Person, 2007). The author explains that new lovers move from living in an illusionary state where they feel their partners are immaculate to facing the reality that their partners are imperfect. As situations change, new roles emerge, and the passion that characterizes the beginning stage of a new relationship dwindles, people are more vulnerable to falling out of love. Adultery is also addressed, with an emphasis on a variety of reasons for why this is viewed with such disapproval and disgust. Stated reasons are that adultery shatters an important dyad which is unconsciously linked with the disruption of the first significant dyad between mother and child (i.e. Oedipal or Electra complex); violates rules of possession; threatens one's sense of security; triggers fears of abandonment, loneliness, and rejection; elicits feelings of insecurity and jealousy; and destroys the family unit, especially when children are involved.

\section{$\underline{\text { The History and Development of Monogamy and Marriage as Social Norms }}$}

Several works referenced for this project cover a broad range of topics and therefore do not fit neatly into any one specific category. One of these works contains a multitude of subjects including the development of infidelity as sinful and condemned by God, a historical account of varying statistics on infidelity, and cross-cultural and historical sex differences as related to infidelity, power, and status (Fisher, 1992). The origins of monogamy are traced as far back as our humanoid ancestors, who found monogamy was their best option for successfully raising offspring and passing on their genes. Although our male humanoid ancestors preferred to live amongst groups of women or harems, their nomadic approach to living made it nearly impossible to find and protect enough food and resources to support multiple women. For females, monogamy became most beneficial as they advanced from a mammalian species that walked on all fours to one that was bipedal. With this change, females were forced to carry offspring in their arms instead of on their backs, which made it more difficult to care for offspring by oneself. As a result, it became advantageous for them to pair with males who would help them care for 
offspring and remain with them over time. Regarding the influence of religion on monogamy, the evolutionary and sociological benefits of practicing monogamy were reinforced by written law as early as 1800 B.C. in ancient Mesopotamia, which punished adulterous women by execution but allowed men to practice adultery as long as they chose unmarried female partners. Then, with the creation of the Ten Commandments around 1440 B. C., adultery became a sin that was condemned by God among the Ancient Hebrews following the Babylonian exile. Fisher (1992) also theorizes that monogamy became the social norm in Westernized societies with the growth of agriculture, which increased levels of power for men and stripped women of the incredible amounts of power they supposedly held in early human civilizations. As men started to gain ownership of farmlands, they were able to conquer the previously established matriarchies. Moreover, the women eventually had to rely on the men's physical strength to use the big farming tools (e.g. plow) that were needed to grow crops and herd animals. Support for this theory can be directly observed in today's world, where women and men in hunter-gatherer, foraging, and gardening societies exhibit more egalitarian behaviors and share equal levels of power. Overall, the dialogue provided by Fisher (1992) is essential to the understanding of how monogamy, from an evolutionary perspective, has become the conventional practice among romantic couples.

The history of marriage, monogamy, and fidelity in the United States from the preRevolutionary era to the present day was portrayed in another book (Cott, 2000). The Puritans, the founders of America, believed that if the people upheld good morals, then they would choose honorable leaders. They also believed that inherent in monogamous marriage was voluntary consent and liberty, which is what they wanted from the British but did not receive. Laws were subsequently enforced that banned sexual relations outside of marriage, and violators were often punished with public beatings and sometimes death. As America grew, states were given the power to create and enforce their own laws on marriage and divorce, and by the mid $19^{\text {th }}$ century, most states would only permit divorce for the following reasons: adultery, sexual incapacity, 
long-term abandonment from one of the spouses, extreme cruelty, neglect of familial responsibilities, or chronic drunkenness. By 1900, panic ensued as Americans realized that the divorce rate in the United States, which was four divorces for every one thousand marriages, was drastically higher than the divorce rate in Europe. Unbelievably, it was 1967 before the Supreme Court rejected bans on interracial marriage, and it was 1985 before all 50 states legalized "no fault" divorce or incompatibility between spouses. In 2000, Vermont made history by becoming the first state to legalize same-sex civil unions. In sum, Cott (2000) thoroughly describes the role of Christianity in shaping beliefs about marriage and adultery, how politics were used to reinforce the necessity of fidelity, the development of state and federal mandates on marriage and fidelity, the legalization of divorce and interracial marriage, the women's movement, and the legalization of civil unions for same-sex couples.

Other ideas about the origins of monogamy were presented, with an emphasis on the development of social and marriage norms (Kanazawa \& Still, 2001). From a sociological perspective, an inequality hypothesis for the existence of monogamy was supported by crosscultural data from 127 countries. According to proponents of this inequality hypothesis, females control the mating process and have the power of choosing whether to engage in a polygamous or monogamous marriage due to the greater costs that females are susceptible to when poor mating choices are made. In the absence of cultural norms, women will choose to be involved in a polygamous relationship when this will bring them more resources, but when less resource inequality exists between men, women will choose monogamy. In other words, as men became more equal to one another in power and had similar amounts of resources, monogamy became more beneficial for women and therefore the most commonly chosen option, causing a tremendous shift in marital norms across Westernized societies.

By now, it should be well understood that for Westerners in particular, monogamy is widely viewed as the supreme model for how to conduct oneself within romantic relationships. This romanticized view of monogamy is dispelled in a book that highlights its accompanying 
myths (Barash \& Lipton, 2001). The authors emphasize that although monogamy is praised within many cultures, especially Western societies, and reinforced by religious groups as the best approach to romantic pairing, it is unnatural and difficult to maintain across the lifetime. In fact, human beings' closest relatives, the pygmy chimps, engage in constant sexual encounters with one another. They also use findings from animal research to support their view by stating that no more than a mere one percent of mammals (less than 40 out of 4,000 species) practice sexual monogamy. Reasons for engaging in sex outside of one's romantic partnership are also presented, with a specific focus on how females and males differ in this regard. The authors then discuss the evolutionary and sociological benefits and reasons for remaining monogamous. Specifically, monogamy allows women to capitalize on resources, leads to shared parental investment, prevents ostracism from community and church and possible abandonment, and deflects a partner's rage and potentially violent behavior. In closing, they propose that although monogamy is unnatural, no other method of navigating romantic relationships (e.g. polygamy, open relationships) has been more successful.

Monogamy as an unnatural social standard was subsequently supported by several authors in an edited work by Reichard \& Boesch (2003). Within it, a clear distinction is made between social and sexual monogamy: social monogamy, which is synonymous with monogamous marriage in humans, is a "male and female's social living arrangement without inferring any sexual interactions or reproductive patterns" whereas sexual monogamy refers to "an exclusive sexual relationship between a female and a male based on observations of sexual interactions" (Reichard, 2003, p. 4). The rarity of monogamy among animals and the factors that lead to the practice of social monogamy are discussed. It is estimated that no more than five percent of mammals practice social monogamy in which mating pairs are formed between females and males, with the vast majority practicing polygamy or promiscuity. Moreover, sexual monogamy occurs in even smaller frequencies. In other words, although socially monogamous animals may form pair-bonds and live and raise offspring together, it is foolish to assume that 
they do not engage in outside sexual relations. Findings regarding monogamy among humans are then provided, revealing that only 200 out of 563 human societies around the world (around 35\%) practice some form of monogamy, with the other 65 percent engaging in other practices including polygamy.

\section{$\underline{\text { Infidelity in Romantic Relationships }}$}

Infidelity is a worldwide phenomenon that occurs with alarming frequency and throughout numerous countries around the globe. The prevalence of infidelity, beliefs and expectations about infidelity, and common reactions to discovering a partner's unfaithfulness vary immensely across cultural groups. These cross-cultural differences are uncovered by Druckerman (2007), with a particular emphasis on how other countries' views of infidelity compare and contrast with those of Americans. Believe it or not, individuals from the United States vary tremendously from those in other nations regarding engagement in infidelity. To start, people in the United States report similar rates of infidelity as those in France, Italy, Switzerland, and Australia. However, men from the United States report incredibly less sexual infidelity within a given 12-month period (3.9\%) in comparison to men from other countries, including Togo (37.0\%), Mozambique (28.9\%), Mexico City (15\%), and Great Britain (9.3\%). Moreover, women and men in the United States report similar rates of infidelity, 3.1\% and 3.9\% respectively, whereas there seems to be a pattern in most other countries for men to cheat at drastically higher rates than women. Americans' views of infidelity and reactions to acts of unfaithfulness are also remarkably different than those in other countries. In the United States, infidelity is linked with guilt, disappointment, and relentless punishment. After affairs are discovered, it is not uncommon for American couples to ruminate constantly over the infidelity for months or even years, disclose all the fine details of the unfaithful acts, and attend couples counseling. In contrast, the French view fidelity as a "good idea rather than a God-given necessity" (p. 133), attempt to work through infidelity by themselves instead of with the help of counselors, keep private the details of the affair, and resolve it quickly with little rumination. In urban Russia, more infidelity seems to 
occur than in any other industrialized nation, with men often bragging about their unfaithful acts and women not only expecting the affairs but believing they will bring happiness and passion to their marriages. For many Japanese couples, sex within marriage happens with such infrequency that the couples begin to view sex as embarrassing or dirty over time. Japanese men, in turn, will go to clubs to get their emotional and sexual needs met, stating that this guilt-free behavior does not constitute cheating since they paid for the services. Lastly, a look at South Africa's sexual culture reveals that one-third of men cheat per year with multiple partners. After exploring infidelity cross-culturally, the general conclusion is made that "adultery brings heartache everywhere, but context and expectations determine the strength of the heartache" (p. 276).

To say that acts of unfaithfulness in romantic relationships create conflict between partners is an understatement. When asked to think of a past hurtful event that had occurred in the context of a current or past relationship, more than 20 percent of 224 Australian undergraduate students (mean age $=20.9)$ chose to discuss an instance of infidelity (Feeney, 2004). For these students, infidelity was associated with more feelings of hurt and rejection in conjunction with negative self-perception than all other types of hurtful events mentioned (i.e. active dissociation, passive dissociation, criticism, and deception). Immediate distress produced by infidelity further predicted negative long-term effects on the victim such as declines in self-esteem and selfconfidence. These negative long-term effects were most significant among individuals who reported infidelity when asked to disclose a past hurtful event.

An in-depth literature review was conducted that focused on several aspects of infidelity (Blow \& Hartnett, 2005) including attitudes toward infidelity, prevalence of infidelity, gender differences in infidelity, cultural differences in infidelity, and sexual orientation differences in infidelity. Four directions for future research were presented: more exploration of individual characteristics that make persons vulnerable to committing acts of infidelity, further analysis of what happens that influences well-intentioned people to engage in extradyadic involvement, 
undertaking of more qualitative studies, and deeper investigation of the healing process that couples go through after the discovery of cheating.

Exploring various topics including reasons for cheating and prevalence rates, 561

university students in the United States were asked a number of questions about infidelity (Brand, Markey, Mills, \& Hodges, 2007). When the definition of infidelity included sexual and/or romantic involvement while in a relationship with another person, $31.4 \%$ of women reported being unfaithful at least once in their lifetime as compared to 24 percent of men. Responses from a second sample comprised of both university students and nonstudents in the United States were similar: when cheating was not limited to episodes of sexual intercourse but included other types of romantic interactions, women $(50.6 \%)$ reported more instances of cheating than men $(39.3 \%)$. However, this sex difference disappeared when the definition of cheating was limited only to interactions in which sexual intercourse took place. Both similarities and differences emerged for women and men regarding reasons for cheating. Similarly, 60 percent of women and men agreed that the top reason for cheating was that they found their extra-pair partner attractive. For significantly more women than men, unhappiness in the relationship (54.6\%) and feeling attractive by the extra-pair partner (42.3\%) were the most common reasons for cheating. Men, more so than women, seemed to engage in infidelity out of boredom in the current relationship (42.9\%) and because the opportunity presented itself (32.1\%).

The results found by Brand et al. (2007) were supported in a study that examined extradyadic dating and extradyadic sexual experiences (Wiederman \& Hurd, 1999). Out of 618 college students who had previously been involved in at least one serious dating relationship, a sex difference was found that was not significant, with more females $(44.7 \%)$ reporting a history of extradyadic dating than males (39.5\%). However, men were significantly more likely to have multiple extradyadic dating partners (62.9\%) than women (37.4\%). As seen in previously mentioned studies, this sex difference reversed when extradyadic experiences were limited to only those that were sexual in nature. Aside from romantic kissing which was not statistically 
different between sexes $($ women $=61.0 \%$; men $=68.2 \%)$, men reported more instances than women across all other types of sexual experience. Specifically, men endorsed higher rates of extradyadic sexual involvement in regard to kissing and fondling $($ women $=49.4 \%$; men $=$ $64.8 \%)$, performing oral sex $($ women $=29.3 \%$; men $=47.2 \%)$, receiving oral sex $($ women $=$ $30.6 \%$; men $=53.4 \%)$, and engaging in sexual intercourse $($ women $=30.8 \%$; men $=49.1 \%)$.

After constructing a questionnaire that stated possible reasons for committing infidelity, Yeniçeri \& Kökdemir (2006) surveyed 404 students at a university in Turkey who had a mean age of 21.90. When asked if they had ever been unfaithful to a partner, almost $20 \%$ of participants admitted to cheating at least once. When asked about the definition of infidelity, $14.7 \%$ of individuals thought emotional infidelity was by itself enough to be labeled an act of unfaithfulness. Reasons for committing infidelity fell under six categories: legitimacy, seduction, normalization, sexuality, social background, and sensation seeking. Men felt the seduction component was of great importance whereas women felt the social background component was important. Participants who had experienced infidelity either as the victim or betrayer in the past rated the reasons for infidelity as more important than those who had no prior history with infidelity.

Infidelity prevalence rates have also been examined within a nationwide annual survey that focuses on the general concept of sexual behavior (Smith, 2006). Data collected from over 2,000 participants in 2004 shows that more men (3.9\%) than women (3.1\%) had engaged in sexual relations with a person other than his or her spouse in the past year. Looking across the lifetime, $20.5 \%$ of men acknowledged having sexual relations with a third party as compared to $11.7 \%$ of married women. Furthermore, in an investigation of potential cohort differences in engagement of extramarital sexual relations, $13 \%$ of young married adults between the ages of 18 and 29 reported at least one instance of sexual relations with an outside person. This increased to 20 percent for married adults aged $40-49$ but then dropped to $9.5 \%$ for older adults aged 70 or 
older. Therefore, it seems that younger cohorts are either engaging in extramarital sexual relations more so than older cohorts, or they are more open to reporting acts of unfaithfulness.

Sex and age differences in the prevalence rates of infidelity was explored in another study that had a sample of individuals who were either currently or previously married and were chosen to represent the U. S. population (Wiederman, 1997). Looking at sex differences in the reported acts of infidelity, $22.7 \%$ of men reported having engaged in extramarital sex at least one time. For women, only $11.6 \%$ reported ever having extramarital sex. Age differences were also found in prevalence of infidelity across the lifetime. For men, rates increased steadily from approximately 14 to $34 \%$ for individuals aged 20 to 69 , respectively, but significantly dropped to $13.2 \%$ for men age 70 and older. A similar pattern emerged for women with percentages of incidences of extramarital sex rising with age and peaking for women between the ages of 40-49 (19.3\%). For women at or above age 50, history of engagement in extramarital sex steadily declined, with females above the age of 70 reporting the lowest prevalence rate $(0.5 \%)$. These findings suggest cohort differences regarding involvement in infidelity, with younger generations reporting a history of extramarital sex with greater frequency than older generations.

The influences that sex and age can have on experiences with infidelity have been mentioned already, but the possible impact of one's sexual orientation on infidelity experiences has yet to be discussed. In a book chapter discussing infidelity in relation to same-sex relationships, the authors make a sound argument for how our typical definitions of affairs may have to be modified when considering same-sex couples, who often decide to practice nonmonogamy or partial monogamy in their relationships (Heaphy, Donovan, \& Weeks, 2004). They also discuss how lesbian, gay, and bisexual individuals are forced to be creative and devise their own rules in forming romantic relationships because society does not have established rules for them as they do for heterosexuals. Moreover, stories are told of same-sex couples who have faced hurtful times and dealt with betrayals following instances of infidelity that occurred in exclusive 
same-sex relationships. The book chapter concludes with a section on relational ethics from a same-sex relational perspective.

Another book chapter was reviewed that speaks to effectively dealing with issues of infidelity in couples counseling (Lusterman, 2005). Within the chapter, the author focuses on specific aspects of infidelity such as definitions of infidelity, frequencies of infidelity, differing characteristics of infidelity (i.e. degree of emotional involvement, secretive or not, heterosexual or non-heterosexual), treatment issues such as setting boundaries about confidentiality, and three phases of treatment that can be used with couples dealing with this issue. More specifically, he advocates for using a definition of extramarital involvement that is not limited to sexual infidelities and highlights certain aspects of infidelity to explore in counseling, particularly the violation-of-trust, factors that led up to the act(s) of unfaithfulness, and then decision-making regarding whether or not the couple wants to try to move forward with or abandon the relationship.

Suggestions for treating infidelity in same-sex couples have also been addressed using a specific approach that focuses on building intimacy, acceptance, and tolerance (Martell \& Prince, 2005). Therapists using this approach will see couples even if an affair is occurring at present as long as both partners are aware of the affair. They attempt to use the affair as a means to understand the relational conflicts that run deeper than the affair. According to the authors, a popular assumption is that infidelity does not exist in gay relationships because gay men have sex with multiple others and do not commit themselves to one person monogamously, whereas lesbians are so clingy that unfaithfulness is not an issue for them. Although it is true that gay couples often establish different rules when forming deep romantic relationships, infidelity does occur in same-sex relationships. In order to best treat same-sex couples dealing with issues of infidelity, they suggest that therapists abandon all assumptions and ask about established rules regarding monogamy within the relationship. Moreover, therapists need to be aware of cultural 
differences as compared to heterosexual couples and not blame individuals for engaging in acts of infidelity.

\section{Romantic Jealousy: A Common Reaction to Infidelity}

It is quite ordinary to feel jealous when a romantic relationship seems threatened in some way, for individuals in the United States and cross-culturally. In a book that explores multiple facets of romantic jealousy, this intriguing emotion is defined, and individual factors are offered that seem to increase one's likelihood of feeling jealous (Pines, 1998). Moreover, sex differences are examined in how individuals emotionally and behaviorally deal with jealous feelings. Jealousy as a frequent presenting problem among couples who seek therapeutic help is also discussed. Finally, Pines (1998) writes about both the positive and negative aspects of jealousy and suggests healthy ways for coping with these painful feelings.

According to Buss (2000), jealousy is an evolutionary adaption that serves to protect romantic pairs. He states that jealousy is inevitable with love and even has some positive and beneficial properties. Feelings associated with jealousy, factors that increase one's chances of experiencing jealous feelings, and the link between jealousy and violence are also examined. Personality traits that predispose some people to cheat and others to be cheated on are presented as well. Buss closes the book by listing a host of coping strategies that people utilize to deal with acts of infidelity.

Although all people experience jealousy at times, the intensity of these feelings varies from person to person, and researchers have shown that individuals with lower levels of implicit self-esteem experience more intense feelings of jealousy (DeSteno, Valdesolo, \& Bartlett, 2006). This was accomplished by experimentally inducing jealousy in a laboratory setting with 46 undergraduate females in the United States. Participants were randomly assigned to either a jealousy or control condition. In the jealousy condition, an opposite-sexed confederate acted as the participant's work partner and a same-sexed confederate played the role of rival partner. In the control condition, the work partnership was threatened by chance. In a second study, the 
relationship between jealousy and aggression was assessed among 30 female and 13 male undergraduates. Using the same jealousy-evoking scenario employed in the first study, increased feelings of jealousy were found to be positively correlated with aggressive behavior, with men displaying significantly more aggression than women. Based on these results, the authors were able to form a model of jealousy with implicit self-esteem as a mediating factor of jealousy intensity and aggression as an outcome of jealousy, particularly for men. However, it is crucial to keep in mind that in these studies, jealous was evoked among students who were not romantically involved with one another but who were working together. Therefore, one should be cautious in generalizing these findings to individuals within romantic relationships.

Feelings and behaviors associated with jealousy were examined in a community random sample of 351 New Zealanders (Mullen \& Martin, 1994). All participants acknowledged having experienced feelings of jealousy in the past, and 63 percent said they were most likely to become jealous when a partner displayed interest for someone else. Jealousy was linked with several fears: fear of losing one's partner, fear of less time with and attention from one's partner, fear of less intimacy in the relationship, fear of shame and humiliation, fear of no longer being sexually exclusive, and fear of financial insecurity in the future. Whereas men were much more afraid of losing their partner to a rival, women were more afraid of losing intimacy and closeness within the relationship. Common feelings associated with jealousy included anger, sadness, agitation, and restlessness. For women more so than men, feelings of insecurity were prominent. Common behavioral responses to intense feelings of jealousy included questioning, calling to know the partner's whereabouts, randomly showing up without warning, searching through their possessions, following them, and digging through clothing for evidence of sexual relations. Women were more likely to search through their partner's belongings. A number of sex differences appeared related to coping with jealousy. Women were significantly more likely to use confrontation and demand explanations from their partners, openly display feelings of hurt and anger, and try to look more attractive. Men, on the other hand, were significantly more likely 
to avoid or deny the problem. Individuals who reported the highest levels of jealousy were significantly more likely to threaten acts of violence and engage in physically aggressive behaviors, with no apparent sex differences regarding anger expression. Low self-esteem was clearly linked with higher levels of jealousy for both men and women, but especially for women.

Sex differences in various coping strategies for dealing with jealous feelings after discovering a partner's infidelity were recently studied in a university sample of 35 women and 34 men (Miller \& Maner, 2008). After imagining that his or her partner or a current romantic interest had been unfaithful, each participant was instructed to write down how they would feel and what they would do in response to the infidelity. These responses were then coded and analyzed. They found that men were significantly more likely than women to become violent (approximately 65 percent of men versus 46 percent of women), whereas women were significantly more likely than men to cope with infidelity by seeking out social support from friends or others (roughly 71 percent versus 68 percent, respectively). Moreover, men were significantly more inclined to feel angry whereas women were significantly more apt to feel sad. Although an abundant number of healthy coping strategies are available to deal with overwhelming feelings of jealousy, some people still resort to physical violence as a way to cope with these feelings. This was demonstrated in a random community sample of 453 heterosexual married or cohabitating couples were the focus of the study was on identifying predictors of partner aggression (O’Leary, Smith Slep, \& O'Leary, 2007). For both women and men, one of three predictors found to have a direct influence on partner aggression was a tendency to become jealous and controlling of one's partner. The other two significant predictors for both women and men were marital satisfaction and the degree to which the participant placed responsibility onto his or partner because of the partner's supposed negative or unpleasant behaviors. Another three variables were found to be direct significant predictors for men only: aggression within one's family-of-origin, expression of anger, and perceived level of social support. For women, the only 
other significant predictor that had a direct effect on partner aggression was a personal history of aggression during childhood or adolescence.

The responses of the men in these 453 couples were then analyzed to see how jealousy influences intimate partner violence (Foran \& O'Leary, 2008). Approximately 20 percent of the male participants endorsed feeling jealous of other men on rare occasions, and these percentages declined as the frequency of jealousy increased (i.e. around seven percent on some occasions, two percent frequently, and one percent almost always). In the past year, around 13 percent of men reported one or more acts of severe violence and roughly 35 percent endorsed one or more acts of non-severe physical aggression. Jealousy was negatively correlated with anger control and positively correlated with non-severe and severe forms of physical aggression against one's partner. Jealousy was found to be a significant predictor of non-severe and severe physical aggression, and it served to moderate the relationship between problematic alcohol use and intimate partner violence.

$\underline{\text { Sex Differences in Affective Responses to Emotional and Sexual Infidelity }}$

Not surprisingly, infidelity has been an incredibly popular research topic for many years, and a large number of sub-categories have been extensively studied as well. One of these is potential differences between two types of infidelity, emotional and sexual infidelity, concerning which infidelity type is viewed as more distressing or upsetting. By far, researchers seem to have been most interested in possible sex differences regarding which infidelity type is more upsetting, and a fairly pronounced sex difference has been observed by many investigators.

The exploration of this topic began with Buss, Larsen, Westen, \& Semmelroth in 1992. Proponents of the evolutionary perspective, they hypothesized that men would find sexual infidelity as more distressing because a woman's sexual unfaithfulness increases a man's risk of raising children that are not his and decreases his chances of passing on his own genes. Women, on the other hand, were hypothesized to be more upset by emotional infidelity because this could signal having to share a partner's resources with another woman. When 1,202 university students 
were asked two forced-choice questions related to which infidelity type would be more distressing, significantly more males than females reported that sexual infidelity would be more distressing. Although this sex difference was still present in response to the second question, approximately $53 \%$ of males were more distressed by emotional infidelity than sexual infidelity, suggesting that it was the women's significant distress to emotional infidelity that created the sex difference. When looking at the effect of involvement in a sexually committed relationship on views of which infidelity type is more distressing, men who had been in at least one sexually committed relationship were significantly more distressed by sexual infidelity than women. However, women were distressed by emotional infidelity regardless of having experience with a sexually committed relationship. Once again, men were more distressed by emotional infidelity (51\%) than sexual infidelity (49\%), which supports the idea that the women's responses produced the significant sex difference.

This sex difference in infidelity choice was further examined cross-culturally using three samples, one from the United States (224 undergraduate students), one from the Netherlands (207 undergraduate students), and one from Germany (200 individuals from the community (Buunk et al., 1996). Using the forced-choice questions (Buss et al., 1992), men were found to be significantly more upset by sexual infidelity as compared to women, but this does not imply that men rated sexual infidelity as more upsetting than emotional infidelity. In fact, only on the first forced-choice question did men from the U.S. and Holland rate sexual infidelity as more upsetting. On all other questions, men from all three countries found emotional infidelity to be more upsetting. Whereas the sex difference between men and women from the U.S. yielded large effect sizes, the sex differences between male and female participants from Germany and the Netherlands only yielded small to medium effect sizes. From the authors' perspective, these results support the evolutionary hypothesis since the predicted sex difference was consistently found across all three cultures. Yet, the men's more distressed ratings towards emotional 
infidelity seriously call into question the legitimacy of the proposed sex difference and show the great impact that culture seems to have on infidelity types that elicit the most jealousy.

Challenging the evolutionary hypothesis, DeSteno \& Salovey (1996) proposed a "doubleshot hypothesis" to explain the sex difference in distress attributed to each infidelity type. They stated that women and men do not view emotional and sexual infidelity as occurring independently of one another. Instead, they proposed that women find emotional infidelity as more upsetting for this implies the occurrence of sexual infidelity, whereas the opposite is true of men. In the first of two studies, 114 undergraduate students were given Buss et al.'s (1992) forced-choice measure along with a measure called the differential infidelity implication (DII) that asked about their assumptions regarding the co-occurrence of infidelity types. On the forcedchoice measure, women were more upset by emotional infidelity than men. Using logistic regression analyses, DII scores accounted for a significant amount of variance in infidelity choice, and sex was not a reliable predictor when both variables were added into the regression equation. In the second study, 141 adults of varying ages were asked the same measures to see if the findings from the first study could be replicated. Once again, women were more distressed by emotional infidelity, and DII scores reliably predicted which infidelity choice would be viewed as more upsetting. In the authors' opinions, these findings support the double-shot hypothesis and refute the evolutionary hypothesis.

Additional supporters of the "double-shot hypothesis" conducted a study with 136 undergraduate female and male students in an attempt to confirm their "double-shot" hypotheses (Harris and Christenfeld, 1996). Upon asking one of Buss et al.'s (1992) forced-choice infidelity scenarios along with two questions regarding beliefs about the implication of one type of infidelity given that the other was said to have occurred, they found that males were once again more upset by sexual infidelity than women. However, when looking at the percentages, $53 \%$ of men were more distressed by emotional infidelity than sexuality infidelity, and the sex difference was only significant because of the women's great amounts of distress to emotional infidelity. 
Looking at the beliefs about the co-occurrence of infidelity type, a significant effect was found for the implication of sexual infidelity in the presence of emotional infidelity, with women believing love implied sex significantly more than sex implied love. The authors stated this means the occurrence of emotional infidelity is significantly more distressing for women as this implies the occurrence of sexual infidelity as well, or a double-shot of infidelity.

A few years later, Buss et al. (1999) made another effort to find support for the evolutionary hypothesis and empirically solve the theoretical debate surrounding the apparent sex difference in responses to emotional and sexual infidelity by examining this sex difference in four studies from both the evolutionary and double-shot perspectives. In study one, 1, 374 male and 748 female students from a southeastern United States university rated which infidelity type they found more distressing, sexual or emotional, when the wording was clear that the other type of infidelity had not occurred. The authors stated they found support for the evolutionary perspective because the sex difference still existed: significantly more men than women were distressed by sexual infidelity. However, the majority of men were still more distressed by emotional infidelity than sexual infidelity.

Study 2 asked 234 university students from the Midwest six questions related to emotional and sexual infidelity dilemmas titled the Relationship Dilemmas Questionnaire (RDQ), two of which originated from prior research (Buss et al., 1992) and another four that were created specifically for the study which rendered the items either mutually exclusive (only one of the infidelity types occurred) or combined (both infidelity types occurred). Participants were also asked six questions related to beliefs about the two types of infidelity, including how likely it is for men and women to engage in both emotional and sexuality infidelity over the same time period. When it was clearly stated that only one or both types of infidelity had occurred, males consistently reported more distress by sexual infidelity in comparison to females across all six dilemmas. It should be noted that on the second forced-choice dilemma, men were more distressed by emotional than sexual infidelity. In addition, sex of the participant was shown to be 
a significant predictor of which infidelity type was viewed as more distressing, regardless of whether participant sex was entered by itself, along with beliefs, or after beliefs were entered. Additional results revealed that both women and men agree that men are more likely than women to engage in sexual relations in the absence of an emotional connection, and this sex difference was also present in women and men's self-reports of the relatedness between sexual and emotional involvement. It was concluded that support was found for the evolutionary hypothesis and not for the "double-shot hypothesis".

Cross-cultural samples were gathered in studies three and four to try to lend further support to this sex difference in jealousy patterns as explained by evolutionary hypotheses. Among 100 male and 90 female Korean university students, the evolutionary hypothesis was supported with males reporting significantly more distress to sexual infidelity than females across all six dilemmas. Administering the twelve questions regarding infidelity dilemmas and beliefs about infidelity to 316 Japanese students (213 males and 103 females), support for the evolutionary hypotheses was found for five of the six infidelity dilemmas. On the two forcedchoice questions, men were significantly more distressed by sexual infidelity then women, yet the majority of men found emotional infidelity to be more upsetting when compared to sexual infidelity. Mirroring results from study 2, participant sex was a significant predictor of chosen infidelity type no matter whether it was entered alone, along with beliefs, or following beliefs. Moreover, the Japanese women and men agreed that men are more likely than women to engage in sexual relations in the absence of an emotional connection, paralleling the responses of U.S. participants. However, this sex difference was not found in the participants' self-reported beliefs regarding sexual and emotional involvement, which is one of the few results that did not lend support to the evolutionary hypotheses. Overall, the authors believed that the four studies generated further support for the evolutionary theoretical lens in evaluating the sex difference in jealousy, and in contrast, did not lend support to the "double-shot" hypotheses. 
With the intention of providing support for the evolutionary hypothesis, researchers again studied the sex difference between women and men regarding infidelity type viewed as more upsetting from both the evolutionary and the double-shot hypotheses (Cramer, Abraham, Johnson, \& Manning-Ryan, 2001). A total of 191 female and male undergraduate students were randomly assigned to one of three treatment groups: forced-choice, conditional probability, or combined infidelity. In the forced-choice group, participants had to choose which infidelity type was more distressing. In the conditional probability group, participants' assumptions regarding the co-occurrence of infidelity types were assessed. Participants in the combined infidelity group were asked to choose which type of infidelity was more upsetting when both types were said to have occurred. Results showed support for the evolutionary hypothesis. In particular, men in the forced-choice condition were more upset by sexual infidelity whereas the women were more upset by emotional infidelity. In the conditional probability group that was derived to test the double-shot hypothesis, statistically reliable results were not found and the double-shot hypothesis was not supported. When both infidelity types were said to have occurred (combined infidelity condition), results once again supported the evolutionary hypothesis with men reporting sexual infidelity as more upsetting and women reporting emotional infidelity as more upsetting.

One of the latest attempts to refute the evolutionary hypothesis and find increased support for the "double-shot" hypothesis was conducted by DeSteno, Bartleet, Braverman, \& Salovey (2002). They used multiple measures instead of just the forced-choice questions (Buss et al., 1992), queried specific feelings elicited by infidelity scenarios instead of using the broad terms of "distressed" and "upset", and examined differing levels of cognitive load. In the first of two studies, 111 undergraduate students were asked questions about sexual versus emotional infidelity using both forced-choice and continuous formats. Although the sex difference emerged using the forced-choice format with women significantly more distressed by emotional infidelity, this difference disappeared using the continuous measures as evidenced by both women and men reporting more negative emotional responses to sexual infidelity than emotional infidelity. Across 
emotional and sexual infidelity, women reported significantly higher levels of emotional distress than men. In the second study, 121 undergraduate student participants responded to Buss et al.'s (1992) forced-choice scenario after being randomly assigned to either a cognitive load condition where they had to memorize and retrieve strings of digits or a control condition. Findings revealed that women in the cognitive load condition who were limited in their cognitive resources were more distressed by sexual infidelity. In other words, the sex difference disappeared with both sexes more upset by sexual infidelity. Only under the control condition when women were able to invest more energy into their answers did the sex difference appear with women more often choosing emotional infidelity as more upsetting. The authors stated that these findings fail to support the evolutionary hypothesis: the sex difference only appeared when the forced-choice questions were asked or when participants were not cognitively restricted. But when continuous questions were asked or when individuals were forced to make quick decisions, both women and men were more distressed by sexual infidelity.

The purpose of another study was to contribute further to the literature regarding sex differences in response to emotional and sexual infidelity (Ward \& Voracek, 2004). The investigators wanted to know if sex differences remained after social beliefs of participants were controlled for through wording of the questions and logistic regression equations. A total of 268 heterosexual college students ( $70 \%$ female, $30 \%$ male) with a mean age of 21 completed a questionnaire comprised of four types of infidelity items: Buss et al.'s 1992 forced-choice items, Harris and Christenfeld's 1996 items regarding social beliefs, DeSteno and Salovey's 1996 items concerning implied beliefs, and Buss et al.'s 1999 items. The researchers showed that social cognitive beliefs were not significant predictors of differences between women and men, and most results lent support to the evolutionary perspective. Although men typically reported sexual infidelity as being more distressing, an unexplainable finding showed that men and women were equally more distressed by sexual infidelity when emotional involvement was not present. Interestingly, two of the sex differences in jealousy were only present when individuals were 
involved in committed relationships. The authors suggested that future research should examine individual characteristics of women and men as predictive of sex differences in jealousy. In addition, they stated that the effect of current involvement in a romantic relationship on sex differences in jealousy should be explored.

The "uncertainty of paternity hypothesis" was directly tested in another study with the aim of explaining this sex difference (Mathes, 2005). This hypothesis states that men will be more upset by sexual jealousy because of the fear of raising children that are not genetically theirs. Using the Desire for Children Scale to measure one's conscious desire to raise geneticallyrelated children along with Buss et al.'s (1992) forced-choice infidelity dilemmas to measure feelings elicited by emotional and sexuality infidelity, responses from 104 college students were gathered and analyzed. Men's scores on the Desire for Children Scale were positively correlated with levels of distress reported for sexual infidelity, confirming that as the desire for having genetically-related children increases, distress attributed to thoughts of sexual infidelity increases also. For women, a statistically significant correlation between scores was not found. These results lend support to the uncertainty of paternity hypothesis, yet caution should be exercised when interpreting these findings as correlation only shows degree of relatedness and does not suggest cause and effect relationships.

Using Buss et al.'s (1992) forced-choice methodology, another groups of researchers studied potential sex differences in responses to emotional and sexual infidelity in a sample of Spanish-speaking individuals from Spain (Fernandez, Vera-Villarroel, Sierra, \& Zubeidat, 2007). In an attempt to replicate findings from a Chilean sample, they expected men would be more upset by sexual infidelity whereas women would be more upset by emotional infidelity. Two hundred and sixty-six heterosexual college students from a Spanish university with an average age of 22.61 participated in the study (140 females; 126 males). On the first infidelity dilemma, a higher percentage of men $(42.1 \%)$ than women $(19.3 \%)$ reported being more upset by sexual infidelity. For the second scenario, similar results were found with more men (26.2\%) upset by 
sexual infidelity than women $(10.7 \%)$. Once again, the majority of men found emotional infidelity to be more upsetting than sexual infidelity, implying that it is women's significant levels of distress to emotional infidelity that produced the sex difference. Results from the current study support the results from the Chilean sample and also give support for the evolutionary perspective among Spanish individuals.

A literature review and accompanying meta-analyses were conducted in another study to investigate the frequently found sex difference in distress related to emotional and sexual infidelity (Harris, 2003). Across 32 samples in which forced-choice questions were used, a moderate effect size for this sex difference was found, with men reporting significantly more distress to sexual infidelity than women. Of interest, this effect size increased when samples of lesbian/gay individuals and adults with a mean age of 26 years or more were excluded from the analyses. In addition, Harris (2003) reviewed and discussed results from multiple studies that failed to support an evolutionary-based sex difference related to which infidelity type is more upsetting. First of all, she mentioned that this sex difference is infrequently found when continuous measures are utilized. She also stated that women and men have both been shown to be more distressed by sexual infidelity. Moreover, this sex difference has not been demonstrated cross-culturally among men, with men from countries outside of the U.S. often rating emotional infidelity as more distressing in percentages that resemble those found among American women. Lastly, Harris (2003) referred to multiple studies in which the sex difference was not found when women and men were asked to reflect on actual experiences with emotional and sexual infidelity.

Harris' findings (2003) were supported by Sabini \& Green (2004), who published three studies that examined distress related to emotional and sexual infidelity. In the first study, they explored specific emotions evoked by emotional and sexual infidelity among 99 male and 136 female undergraduate students from the United States with a mean age of approximately 19 years and a nonstudent sample comprised of 66 male and 63 female adults from the United States with a mean age of around 40 years. For women and men in both the university and nonstudent 
samples, hurt was elicited significantly more by emotional than sexual infidelity. For men and most of the women in both samples, anger was associated significantly more with sexual infidelity than emotional infidelity. Lastly, both undergraduate and nonstudent women and men were significantly or marginally more likely to blame their partners for sexual infidelity than emotional infidelity. Among undergraduate students, women were significantly more likely than men to view emotional infidelity as more distressing, whereas men fluctuated in regard to which infidelity type caused them more distress. In the nonstudent sample, no sex difference emerged, with women and men responding with more distress to emotional infidelity than sexual infidelity at similar levels. Overall, the well-documented sex difference in response to emotional and sexual infidelity was demonstrated among undergraduate students but not among nonstudent adults. In Study 2, the authors used narrative scenarios of emotional and sexual infidelity that described how the infidelities transpired instead of the standard forced-choice questions with a U.S. nonstudent adult sample of 88 women and 77 men (mean age of 34 years). There was no sex difference regarding which infidelity narrative was more distressing, with women and men similarly reporting that emotional infidelity was more upsetting than sexual infidelity. Looking at specific emotions, women and men agreed that they were more likely to be hurt by emotional infidelity, more likely to be angered by sexual infidelity and significantly more likely to blame one's partner over sexual infidelity. Another nonstudent sample consisting of 102 females and 80 males with a mean age of around 31 years was recruited for a third study. After presenting participants with the emotional and sexual infidelity narratives from Study 2, the authors asked participants to rate on a 7-point Likert scale the degree to which they would experience specific emotions in regard to both infidelity types. No sex difference was detected regarding which infidelity narrative elicited more distress, with women and men reporting equal amounts of distress to emotional and sexual infidelity. Although there was no difference regarding the amount of hurt felt towards one type of infidelity over the other, both women and men felt more anger and were more likely to blame their partners in response to sexual infidelity than emotional 
infidelity. In addition, women were significantly more likely to blame their partners over sexual than emotional infidelity. Merging the findings from all three studies, the authors conclude that the typically seen sex difference is reproduced more easily in undergraduate samples and when broader terms of distress and upset are used instead of specific emotions. Finally, anger and blame were more consistently provoked by sexual infidelity than emotional infidelity, whereas hurt feelings were more often attributed to emotional versus sexual infidelities.

Believing that the samples gathered in their previous studies were not large enough to capture variances due to age, Green \& Sabini (2006) conducted a follow-up study to investigate potential effects of age and socioeconomic status, along with specific emotions elicited by emotional and sexual infidelity, in a U.S. representative sample of 777 individuals with a mean age of 48 years. On forced-choice questions, women were found to be significantly more upset by emotional infidelity than men, even though a larger percentage of men were upset by emotional than sexual infidelity. Neither age nor socioeconomic status was a significant predictor of which infidelity type was viewed with more distress. Looking at specific emotions, both women and men experienced more hurt in regard to emotional infidelity but were more likely to become angry and blame their partners over sexual infidelity. Moreover, women were statistically significantly more likely to experience anger over sexual infidelity than men. There were no statistically significant sex differences for feelings of hurt or blaming the partner. On continuous measures of distress to emotional and sexual infidelity, no significant sex differences emerged regarding distress related to emotional versus sexual infidelity. As on the forced-choice methods, women and men were more upset and hurt by emotional infidelity and more angry and likely to blame their partners over sexual infidelity. However, blame was the only reaction that was statistically significantly different across the two infidelity types. In the end, the authors highlighted the disappearance of the sex difference for infidelity type when using continuous measures, which has been demonstrated in other studies as well. 
Another group of researchers attempted to test whether the sex difference would appear using both forced-choice and continuous measures (Sagarin et al., 2003). Second, they explored the influence of prior experiences with infidelity on distress related to emotional and sexual infidelity. With a group of 513 psychology undergraduate students in the United States, statistically significant sex differences were found on both forced-choice and continuous measures. Specifically, women were found to be significantly more upset by emotional infidelity than men. Results from within-sex analyses revealed that women were significantly more upset by emotional infidelity than sexual infidelity, whereas men were only marginally more upset by sexual infidelity than emotional infidelity. A second sample of 353 United States undergraduate students was collected in order to examine the effects of past infidelity experiences on distress related to hypothetical scenarios of emotional and sexual infidelity. Once again, the predicted sex difference appeared, with men reporting significantly more distress to sexual infidelity when compared to women. Regarding past histories with infidelity, men who had previously been victims of infidelity were found to be more significantly more upset by sexuality infidelity than men who had not been cheated on in the past. For women, past victim status did not significantly influence responses to the infidelity scenarios. On the other hand, women who had been perpetrators of infidelity in the past were significantly more distressed by sexual infidelity than women who had not cheated on a partner in the past. For men, a history of cheating on one's partner did not significantly influence their scores.

Sex differences related to which infidelity type evokes more jealousy were examined by another group of authors using both forced-choice and continuous measures (Edlund et al., 2006) In addition, they inquired about participants' levels of jealousy in response to both hypothetical scenarios and actual experiences with emotional and sexual infidelity. In a sample of 206 undergraduate students from the United States with a mean age of almost 22 years, a significant interaction effect was found of moderate effect size using continuous measures across hypothetical scenarios, with men feeling more jealous than women in response to sexual infidelity 
and women responding with more jealousy than men in regard to emotional infidelity. This sex difference was also significant using forced-choice measures. In response to actual bouts of infidelity, these significant sex differences were replicated on both continuous and forced-choice measures with a moderate effect size. Moreover, women were found to be significantly more jealous than men on both measures of emotional and sexual infidelity, across hypothetical scenarios and actual past experiences with infidelity. In study 2, a sample of 125 working adults within the United States with a mean age of almost 26 years were asked to recall actual bouts of infidelity if they had been cheated on in the past and hypothetical scenarios if they had not been cheated on in the past. Results from the hypothetical scenarios revealed a marginal sex difference, with men who had never been cheated on responding with more jealousy to sexual infidelity than women, and women with no history of being cheated on responding with greater jealousy to emotional infidelity than men. Although this difference was only marginally significant, it represented a nearly moderate effect size and was statistically significant using forced-choice methodology. Similar results were found regarding actual bouts of infidelity among working adults, with a statistically significant sex difference emerging that was large in effect size. This significant sex difference also appeared using forced-choice measures. Drawing conclusions from these two studies, the authors stated that the predicted sex differences, with men being significantly more jealous than women in response to sexual infidelity and women being significantly more jealous than men in response to emotional infidelity, were found with students and working adults, using both forced-choice and continuous measures, and across hypothetical and actual infidelity scenarios. Examining effect sizes, the sex differences seem to be more pronounced for those who have experienced infidelity in the past. Lastly, the undergraduate females and males differed significantly regarding overall feelings of jealousy, with women reporting greater overall levels of jealousy to both emotional and sexual infidelity. Interestingly, this sex difference did not emerge among the working adult sample. 
Instead of investigating jealous feelings that arise in light of perceived emotional and sexual infidelity, Schützwohl (2008) looked at feelings of relief upon learning that hypothetical bouts of infidelity had not taken place, predicting that women would be more relieved to discover that emotional infidelity had not occurred and men would be more relieved in finding out that sexual infidelity had not occurred. Almost 200 participants completed one forced-choice question and two continuous rating scales, all of which were counterbalanced. Responses from one hundred eighty college students who had experienced at least one committed heterosexual relationship were included in the study. On the forced-choice question, significantly more women (82\%) than men (53\%) were relieved to know that emotional infidelity had not occurred even in the face of sexual infidelity. When examining the emotion ratings from the continuous questions, men were significantly more relieved by sexual infidelity than women. Although women were more relieved by emotional infidelity than men, this sex difference did not reach statistical significance. Within each sex, women were significantly more relieved to learn that emotional infidelity had not taken place. Although men were more relieved upon learning that sexual infidelity had not occurred, this was not statistically significant.

It was not until the publication of an article by Penke \& Asendorpf (2008) that the consistently reported sex difference in sexual and emotional jealousy was conceptualized in a way that painted a clearer picture of what had previously been found. Prior researchers had confirmed the existence of the sex difference as long as women and men differed in the amount of distress associated with only one type of infidelity. For example, if women were found to be significantly more distressed by emotional infidelity as compared to men, then a sex difference was said to be found. This view is problematic, however, because it was often the case that although a difference was found in emotional infidelity, men and women were equally as distressed by sexual infidelity, not to mention that the majority of men in theses studies would be more distressed by emotional infidelity than sexual infidelity. Penke \& Asendorpf (2008) highlighted this tendency to support the evolutionary hypothesis when only ordinal effects were 
found. They argued that two evolutionary hypotheses, with a total of four sub-hypotheses, should have to be supported in order to confirm that there is an evolutionary basis to this welldocumented sex difference. The first hypothesis and its two associated sub-hypotheses focus on between-sex differences, stating that "men react more jealous to sexual infidelity than women" and that "women react more jealous to emotional infidelity than men" (p. 5). The other two hypotheses and accompanying sub-hypotheses, which relate to within-sex differences, state that "men react more jealous to sexual infidelity than emotional infidelity" and that "women react more jealous to emotional jealousy than to sexual infidelity" (p.5). In order for the evolutionary theory to be confirmed, an interaction effect would have to be found with both both hypotheses and all four sub-hypotheses supported. The goals of the study were to test both evolutionary hypotheses, limit cognitive processing in some conditions, and include not only forced-choice but continuous methods that asked about specific emotions evoked by infidelity scenarios. Two hundred eighty-four young adults between 20 and 30 years of age participated in three conditions in a fixed order: forced-choice questions under cognitive constraint where they were to respond spontaneously, continuous ratings of four emotions (anger, anxiety, jealousy, and humiliation) when asked to vividly imagine each scenario, and forced-choice questions where participants were encouraged to take their time in responding and making a choice. Six forced-choice infidelity questions were administered and possible responses were counterbalanced. Participants were also separated into two groups based on attained level of education: lower level consisting of individuals who did not have a high-school diploma and a higher level who did have a highschool diploma. Findings suggested that although the majority of men rated emotional infidelity as more upsetting than sexual infidelity under the forced-choice conditions, women were significantly more likely to choose emotional infidelity as more upsetting than men. This sex difference was even larger when participants were instructed to make a spontaneous decision and not deliberate. In addition, this sex difference was primarily due to differential rates of jealousy for emotional infidelity, not sexual infidelity. Results from the continuous emotion ratings 
revealed that women, overall, responded more negatively than men across all emotions (i.e. anger, anxiety, jealousy, humiliation). In regard to sexual infidelity, no sex differences were found, with women and men feeling similar levels of anger, anxiety, jealousy, and humiliation in response to hypothetical scenarios of sexual infidelity. Significant sex differences were found in response to emotional infidelity scenarios, with women feeling significantly more jealous, anxious, and humiliated than men. As seen in regard to sexual infidelity, women and men did not differ significantly in feelings of anger over emotional infidelity. Lastly, women in the lower education group rated emotional jealousy as more distressing than all other groups across all three conditions. It is possible that less-educated females are most distressed by emotional infidelity because they are more dependent on males to provide them with financial resources and therefore become more upset at the possibility of men leaving them for other women. These results indicate a sex difference in emotional infidelity but not sexual infidelity, thereby providing support for only one of the posed evolutionary hypotheses.

\section{$\underline{\text { Sexual Orientation Differences in Affective Responses to Emotional and Sexual Infidelity }}$}

In the earliest study found that investigated the relationships among six evolutionarydriven aspects of human mating along with potential sex and sexual orientation differences, 277 adults were recruited through urban advertisements (Bailey, Gaulin, Agyei, \& Gladue, 1994). Out of 140 women, 69 were lesbians and 71 were heterosexual, and of the 137 men, 72 were gay and 65 were heterosexual. The following seven measures were administered with the last five created by the authors: Buss et al.'s (1992) forced-choice questions, a scale measuring sociosexuality, the Interest in Uncommitted Sex scale, the Interest in Visual Sexual Stimuli scale, the Concern with Partner's Status scale, the Preferred Partner Age scale, and the Importance of Partner's Physical Attractiveness scale. They found that heterosexual men were significantly more distressed by sexual infidelity when compared to heterosexual women, lesbian women, and gay men. These later three groups experienced similar levels of distress to emotional infidelity over sexual infidelity. The authors suggested that future research should validate the measures used in this 
study and recruit participants through other means since these participants were volunteers and as a result may have held more liberal views in comparison to the general population.

Another group of researchers (Dijkstra, Groothof, Poel, Laverman, Schrier, \& Buunk, 2001) set out to further the research on lesbian and gay individuals' views on types of infidelity that elicit jealousy by modeling the study conducted by Bailey et al. (1994). Following the double-shot hypothesis, the researchers examined beliefs regarding emotional and sexual infidelity. It was expected that gay males would find emotional infidelity to be more upsetting because this implies sexual infidelity and that lesbians would view sexual infidelity as more upsetting as this would imply emotional infidelity. Furthermore, they wanted to explore the degree to which beliefs about the co-occurrence of infidelity influenced the relationship between the sex of the participant and choice of most upsetting infidelity type. A sample of 237 Dutch lesbian women $(n=99)$ and gay men $(n=138)$ with a mean age of 32.5 were recruited either in gay bars or through a local magazine within the gay community. After rating sexual orientation on a seven-point scale, bisexual participants were excluded from the study. The remaining participants completed a questionnaire that included Buss et al.'s six questions $(1992,1999)$ and six more questions measuring the implications of infidelity (Harris \& Christenfeld, 1996) for one's partner, an average gay individual of the same sex (DeSteno \& Salovey, 1996), and oneself. Lesbians were shown to be more distressed by sexual infidelity than gay men, whereas gay men were more distressed by emotional infidelity than were lesbians. Although lesbians reported being more upset by sexual infidelity, these differences were small, and it was the gay male participants' significant distress by emotional infidelity that heightened the sex difference. It is possible that the choice of which type of infidelity is more upsetting is influenced more so by the sex of one's partner than oneself. When the partner is a male, emotional infidelity was more often viewed as more upsetting, whereas with female partners, emotional and sexual infidelity were chosen at equal rates. In addition, beliefs about the co-occurrence of emotional and sexual infidelity influenced the effect of participant sex on which type of infidelity was more upsetting, 
lending support to the "double-shot hypothesis". Moreover, gay men viewed emotional infidelity as more upsetting with age, whereas no age differences were found in lesbians. In addition, gay men who had a larger reported number of sexual partners more often viewed emotional infidelity as most upsetting. Overall, it seems that lesbians have similar views as heterosexual men (sexuality infidelity as more upsetting), whereas gay men have similar views as heterosexual women (emotional infidelity as more upsetting). More importantly, the sex difference in which type of infidelity was more upsetting was only present for participants who were currently involved in a committed relationship. Future research should include heterosexual participants as a control group.

Sexual orientation as well as possible sex differences in sexual and emotional jealousy as proposed by both evolutionary and sociocultural theories have also been examined (Sheets \& Wolfe, 2001). Following the evolutionary hypothesis, it was predicted that both gay and heterosexual men would be more distressed by sexual infidelity than lesbian and heterosexual females. From a sociocultural perspective that considered relationship beliefs from three hypotheses (double-shot, discounting, cognitive adaption) along with examining the possible influence of gender identity and social support, it was expected that a wide range of jealousy patterns could appear. Over 200 individuals were recruited for participation from a lesbian, gay, and bisexual conference and from a Midwestern university (98 males, 56 gay and 42 heterosexual; 104 females, 29 lesbian and 75 heterosexual). Gay individuals had a mean age of 26.26 whereas heterosexual participants were, on average, 19.94 years of age. Participants completed Buss et al.’s (1992) forced-choice infidelity questions, DeSteno and Salovey’s (1996) "double-shot" hypothesis questions, questions related to the discounting and cognitive adaptation hypotheses, the Personal Attributes Questionnaire measuring gender identity, and the Social Supportive Behaviors Questionnaire. Heterosexual male participants reported being more upset by sexual infidelity than all other groups, even though they too rated emotional infidelity as more distressing on one of the forced-choice hypothetical scenarios. The other three groups rated 
emotional infidelity as more upsetting when compared to sexual infidelity, while heterosexual men rated the two types of infidelity as equally distressing. In addition, an interesting finding was identified in heterosexual men; it seems they may be more upset by sexual infidelity because they are more likely to expect their betraying female partners to leave them. Looking at the results in relation to gender-role adherence and social support, these possible explanations were not supported. Furthermore, the authors stated that the evolutionary theory was not supported because study results showed that infidelity views were not sex-specific. Moreover, neither the "doubleshot" nor "cognitive adaptation" hypotheses were supported. On the other hand, the "discounting" hypothesis was supported with sexual infidelity being less of a threat when the unfaithful partner is a heterosexual male because of the belief that this would not cause the termination of a relationship.

Recruiting lesbian, gay, and heterosexual individuals of varying ages, Harris (2002) attempted to examine participant responses to both real instances of infidelity and imagined scenarios. The sample was comprised of 210 adults from communities in southern California, with each group containing an almost equal number of participants (48 lesbian women, 49 heterosexual women, 50 gay men, and 49 heterosexual men) and a mean age of around 37 years for the total sample. Participants responded to Buss et al.'s (1992) forced-choice infidelity scenarios along with questions regarding experiences with real bouts of infidelity. Heterosexual men were found to be more upset by sexual infidelity than the other three groups (heterosexual females, lesbians, and gay men) However, only one of these differences reached statistical significance; heterosexual men rated sexual infidelity as significantly more distressing than lesbian women. This finding contradicts results from other studies that showed that heterosexual men and lesbian women responded similarly to infidelity dilemmas. Lastly, it is important to mention that in this study as well, it was the responses from heterosexual women, lesbian women, and gay men that created the differences in views about infidelity, not heterosexual men's responses. Moreover, it should be noted that heterosexual men were more distressed by emotional 
infidelity than sexual infidelity. When actual instances of infidelity were examined, around 70 percent of all participants had been the victims of infidelity at least once. Lastly, no sex or sexual orientation differences were found in which infidelity type was more upsetting when examining experiences with infidelity, with emotional infidelity more distressing for all four groups.

Most recently, sexual orientation differences in responses to hypothetical emotional and sexual infidelity scenarios were assessed within a Brazilian sample of lesbian $(\mathrm{n}=35)$ and heterosexual women $(n=72)$, and gay $(n=42)$ and heterosexual men $(n=68)$ using continuous measures and Buss et al.’s (1992) forced-choice questions (deSouza, Verderane, Taira, \& Otta, 2006). Results of forced-choice questions showed heterosexual men to be significantly more upset by sexual infidelity than heterosexual women. Responses of lesbian and gay participants fell in between those of heterosexual participants, indicating similar levels of distress for both sexual and emotional infidelity. When continuous measures were used that assessed jealousy related to specific actions such as pleasurable sex, flirting, and attachment, the sex difference between heterosexual women and men disappeared. Moreover, lesbians responded similarly to heterosexual men. These groups rated pleasurable sex to be significantly more distressing than both flirting and attachment, whereas gay men and heterosexual women resembled one another in rating pleasurable sex, flirting, and attachment as distressing on similar levels.

\section{Effects of Infidelity Expectations on Affective Responses to Emotional and Sexual Infidelity}

Only one study is known of that has examined the violation of infidelity expectations hypothesis as compared to the evolutionary hypothesis to explain sex differences in emotional and sexual infidelity (Cramer, Lipinski, Meteer, \& Houska, 2008). This violation of infidelity expectations hypothesis states that an individual finds an unfaithful partner's infidelity more upsetting when it does not meet the individual's expectations. In other words, women will find emotional infidelity as more upsetting then men because women expect that men will be sexually unfaithful, not emotionally unfaithful. Men, on the other hand, will find women's sexual 
infidelity as more upsetting than emotional infidelity because emotional infidelity would be expected whereas sexual infidelity would not be expected.

One hundred eighty-nine undergraduate women and men voluntarily completed the Infidelity Expectations Questionnaire and the Relationship Dilemmas Questionnaire (RDQ; adapted from Buss et al. 1992 and Buss et al. 1999), which is comprised of forced-choice, mutually exclusive, and combined infidelity questions. Results from the IEQ questionnaire suggested that women were more likely to expect men to be sexually unfaithful, whereas men were more likely to expect women to be emotionally unfaithful. Furthermore, responses from the Relationship Dilemmas Questionnaire (RDQ) revealed that women were more upset by emotional infidelity whereas men were more upset by sexual infidelity. According to the authors, this lends support to the violation of infidelity expectations hypothesis because the participants were more upset by the type of infidelity that was expected not to occur. However, when logistic regression analyses were conducted, no support was found for this hypothesis. Instead, greater support was found for the evolutionary hypothesis with sex of the participant being a stronger predictor of which infidelity type is more distressing than infidelity expectations. Effects of Love on Affective Responses to Emotional and Sexual Infidelity

Amount of love felt within one's romantic relationship, along with other factors that might effect which infidelity type is more distressing, was investigated in another study (Russell \& Harton, 2005). The authors had 142 undergraduate students who were currently involved in heterosexual romantic relationships complete demographic questions along with various measures that examined love, jealousy, sociosexual orientation, and egalitarian attitudes. A 13item Love Scale (Rubin, 1970) with internal consistencies of .84 for women and .86 for men was measured on a 9-point Likert scale. The participants then rated their levels of distress and feelings of insecurity and jealousy when reading either a hypothetical emotional or sexual jealousy scenario. No significant sex difference was found regarding levels of distress attributed to emotional versus sexual jealousy, with both men and women reporting more distress to the sexual 
scenario. Furthermore, sociosexual orientation and egalitarian attitudes were not found to be predictors of which infidelity type was more distressing for participants. However, love was significantly related to one's feelings of distress: people who reported not being as in love with their partners were more upset by the emotional scenarios whereas those who experienced more love with their partners were more upset by the sexual scenarios.

Russell \& Harton (2005) demonstrated that love seems to play a role in which infidelity type is viewed as more upsetting or distressing; however, the questionnaire used in this study to measure level of love within one's relationship is methodologically concerning because of its limited number of items and lack of theoretical framework. On the other hand, Robert Sternberg's triangular theory of love has been extensively researched and applied in various ways. According to Sternberg, love is best conceptualized as a set of overlapping feelings, thoughts, and desires that interact with one another to produce experiences of love (1987). Picturing love as a triangle, Sternberg identified three main ingredients that he believes are consistently found cross-culturally and universally across time and setting: intimacy, passion, and decision/commitment. Intimacy is defined as "feelings in a relationship that promote closeness, bondedness, and connectedness" (Sternberg, 1987, p. 38), passion is defined as "the expression of desires and needs" that "manifest themselves through psychological and physiological arousal" (Sternberg, 1987, p. 42), and the decision/commitment component consists of "the decision to love a certain other" and/or "the commitment to maintain that love" (Sternberg, 1987, p. 46). Whereas passionate feelings are hardest to control, one has the greatest amount of control over how much he or she will commit to another person; level of control associated with intimacy falls somewhere in between that of passion and commitment. In short-term relationships, passion is vital whereas intimacy and commitment seem to be less important. However, as relationships grow and become long-term, the importance of passion declines, and intimacy and commitment increase in importance. Finally, the shape of the triangle changes as the amount of each one of these three components increases or decreases. In order for two people to be satisfied with their loving relationship, it is 
best if their triangles representing ideal love are similar in shape and therefore overlap as much as possible.

Researching his triangular theory of love, Sternberg developed a 45-item scale, called the Sternberg Triangular Love Scale (Sternberg, 1987), consisting of three subscales (passion, intimacy, and decision/commitment) with 15 items in each subscale. The measure was administered to 101 heterosexual adults, 51 women and 50 men, who were either married or currently involved in a romantic relationship. Results of factor analysis indicated that all three components were measuring what they were supposed to measure, and internal-consistency reliabilities were reportedly high. Moreover, scores across all three subscales correlated highly with scores on Rubin's Love Scale (1970). In a test of prediction of relationship satisfaction, Sternberg's Triangular Love Scale was a better predictor than Rubin's Love Scale. 


\section{APPENDIX B:}

TABLES

Table 1

Sample Demographics

\begin{tabular}{|c|c|c|c|}
\hline Characteristic & $M$ & $S D$ & Range \\
\hline Age & 26.10 & 10.23 & $18-73$ \\
\hline \multirow[t]{2}{*}{ Length of Current Relationship in Months } & 37.38 & 51.85 & $1-368$ \\
\hline & $\mathrm{N}$ & & Percentage \\
\hline \multicolumn{4}{|l|}{ Sex } \\
\hline Female & 186 & & 62.8 \\
\hline Male & 110 & & 37.2 \\
\hline \multicolumn{4}{|l|}{ Sexual Orientation } \\
\hline Heterosexual & 171 & & 57.8 \\
\hline Lesbian/Gay & 125 & & 42.2 \\
\hline \multicolumn{4}{|l|}{ Race/Ethnicity } \\
\hline Caucasian & 224 & & 75.7 \\
\hline African American & 12 & & 4.1 \\
\hline Asian American & 9 & & 3.0 \\
\hline Native American & 5 & & 1.7 \\
\hline Hispanic/Latina(o) & 9 & & 3.0 \\
\hline Biracial/Multiracial/Other & 35 & & 11.8 \\
\hline \multicolumn{4}{|l|}{ Marital Status } \\
\hline Single & 163 & & 55.1 \\
\hline Partnered/Common Law & 102 & & 34.5 \\
\hline Married & 24 & & 8.1 \\
\hline Divorced & 2 & & 0.7 \\
\hline Widowed & 1 & & 0.3 \\
\hline \multicolumn{4}{|l|}{ History of Infidelity in Current Relationship } \\
\hline Self Unfaithful & 77 & & 26.0 \\
\hline Partner Unfaithful & 76 & & 25.7 \\
\hline \multicolumn{4}{|l|}{ History of Infidelity in Past Relationship(s) } \\
\hline Self Unfaithful & 140 & & 47.3 \\
\hline Partner Unfaithful & 167 & & 56.4 \\
\hline
\end{tabular}


Table 2

Summary of Intercorrelations, Means, and Standard Deviations for Predictor Variables

\begin{tabular}{lllllllll}
\hline Variables & 1 & 2 & 3 & 4 & 5 & 6 & 7 \\
\hline
\end{tabular}

1. Sex

2. SO

$-.09$

35.11

3. IEQ-E

$-.12 * \quad .10 *$

(14.29)

4. IEQ-S

$-.15^{* *} \quad .08 \quad .59 * * *$

25.98

(15.96)

5. Intimacy

$.19 * * *$

$-.00$

$-.24 * * * \quad-.28 * * *$

119.36

(15.96)

6. Passion

$$
.12 *
$$

$-.05$

$-.32 * *$

$-.26 * * *$

$.69 * * *$

108.88

117.17

$\begin{array}{lllllll}\text { 7. Commitment } & .14 * * & .07 & -.26 * * * & -.25 * * * & .74 * * * & .80 * * *\end{array}$

Note: Means (and standard deviations) for continuous variables are presented along the diagonal, with bivariate correlations entered as off-diagonal elements. Sex: $0=$ male, $1=$ female; SO (sexual orientation): 0 = heterosexual, $1=$ lesbian/gay; IEQ = Infidelity Expectations Questionnaire; $\mathrm{S}=$ sexual infidelity; $\mathrm{E}=$ emotional infidelity.

$* p \leq .05, * * p \leq .01, * * * p \leq .001$. 


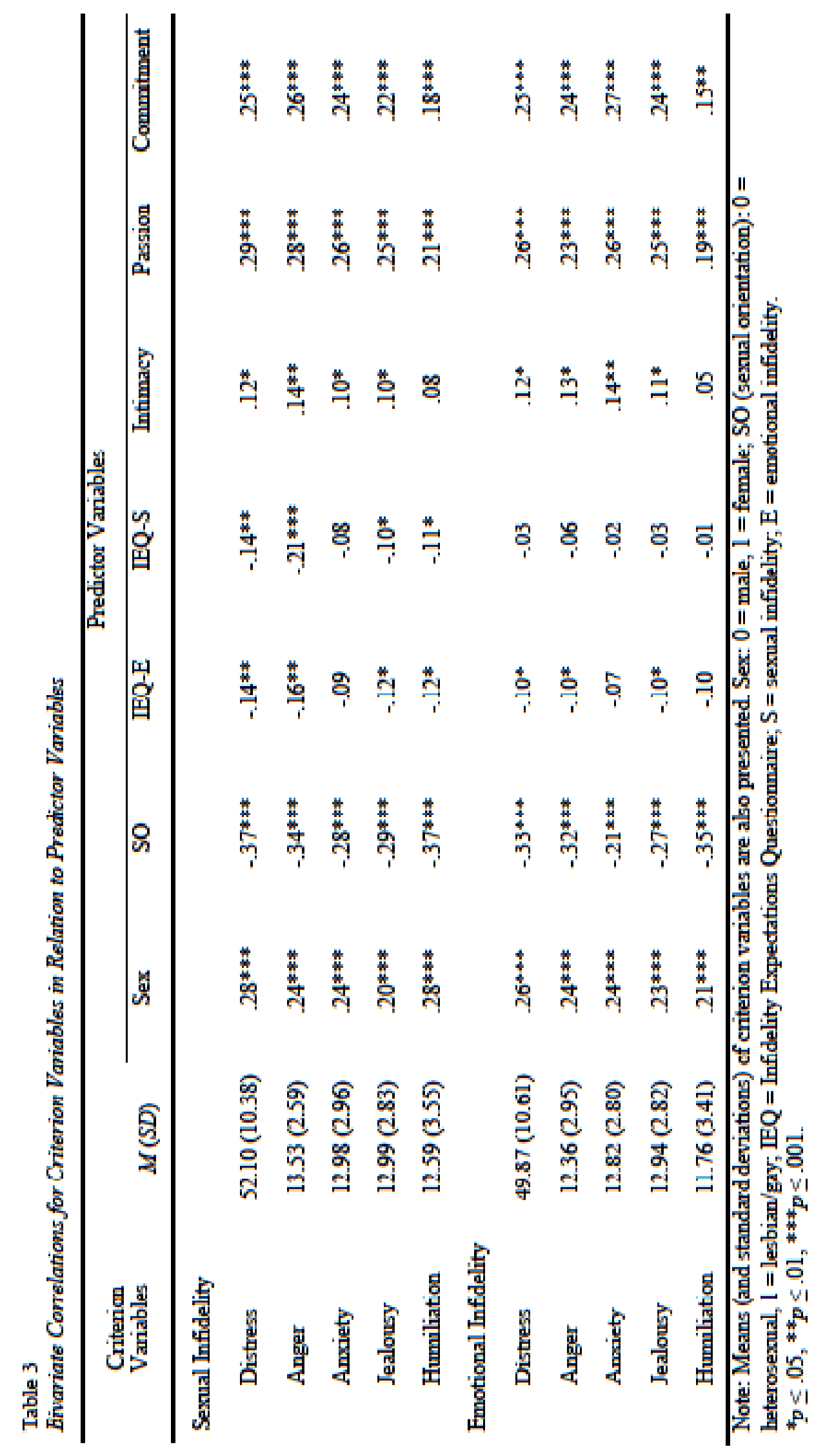




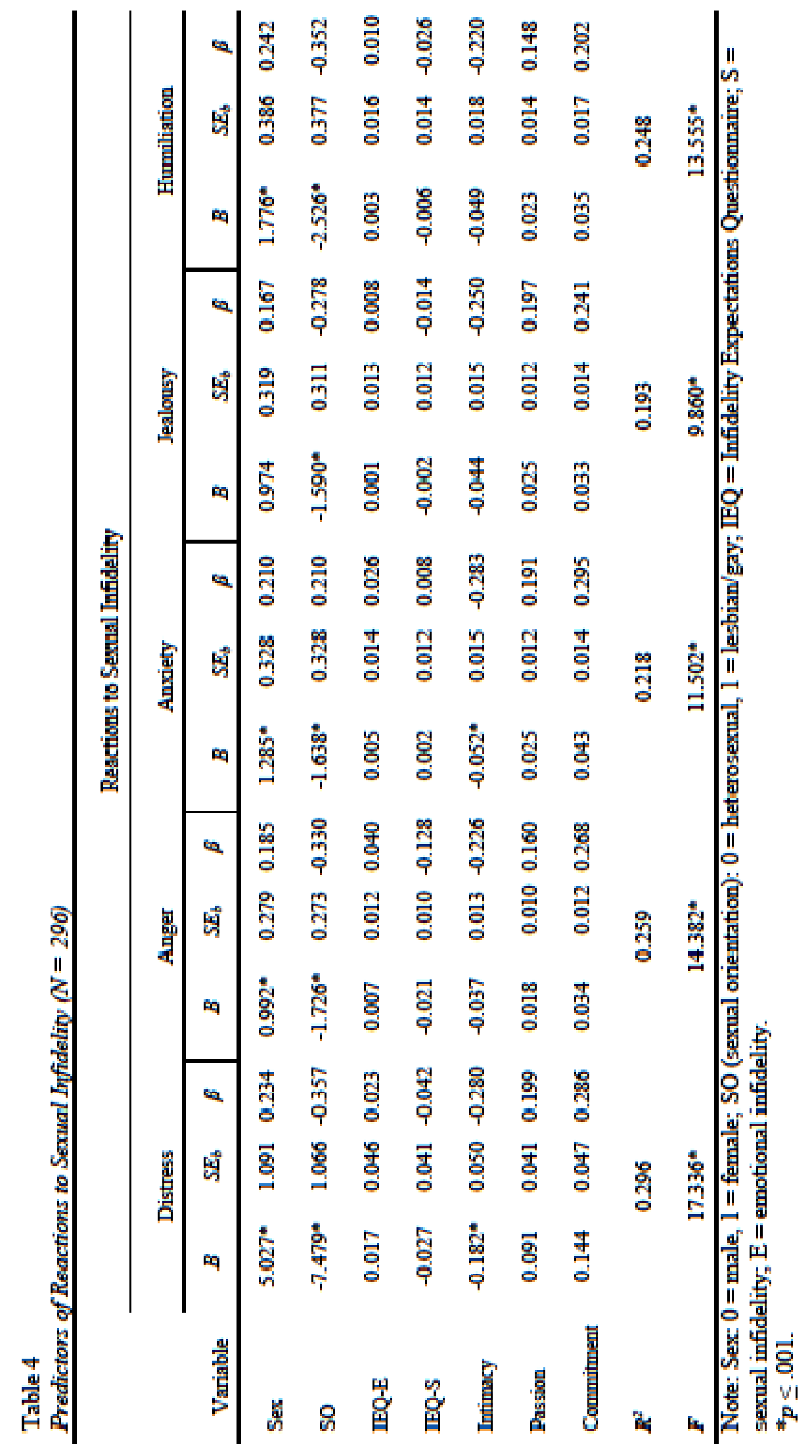




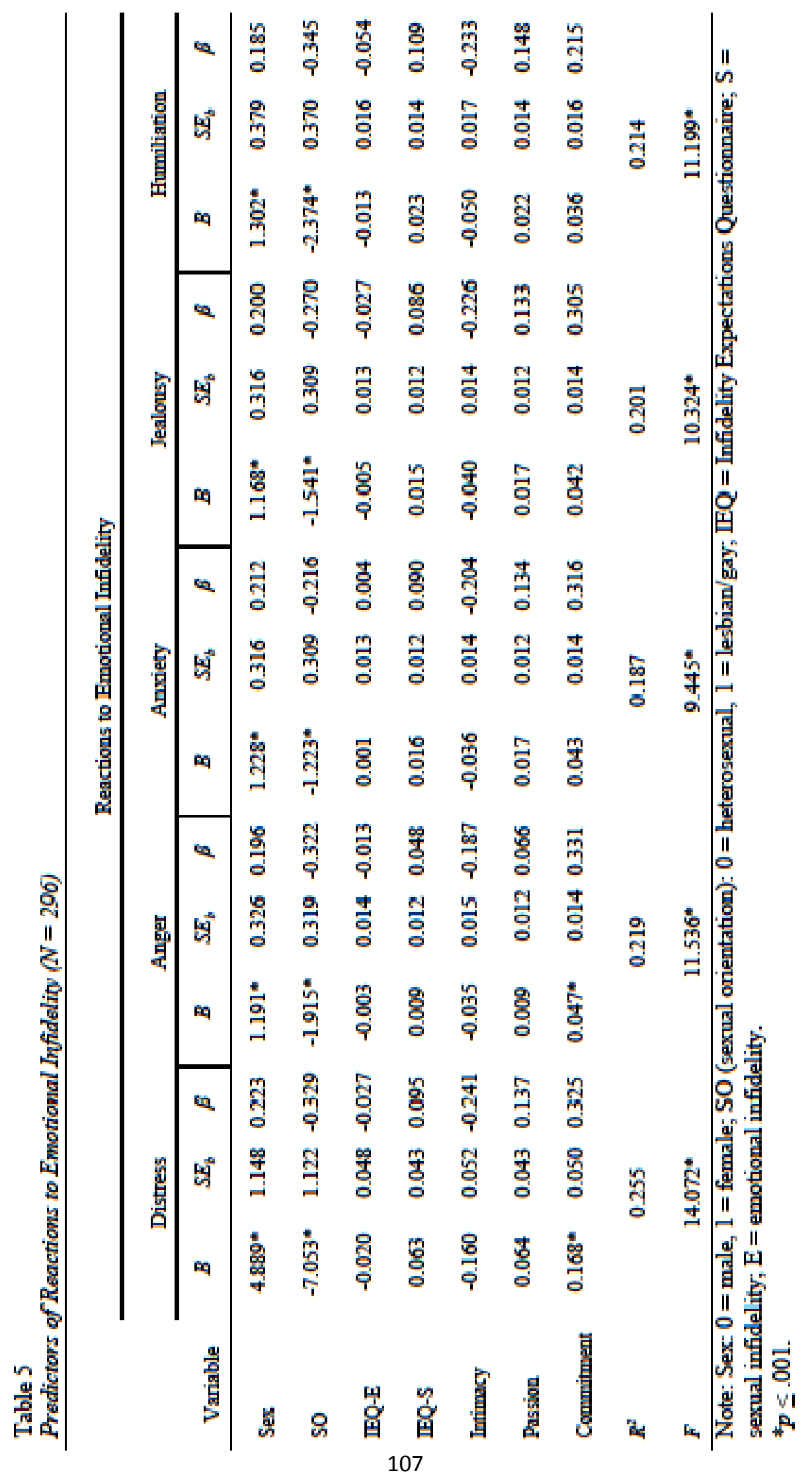


Table 6

ANOVA Summary Table for Between-Subjects Effects

\begin{tabular}{lcc|c|c|c|c}
\hline & Source & $d f$ & $S S$ & MS & $F$ & $p$ \\
\hline Sex & 1 & 983.64 & 983.64 & 25.34 & $<0.001 *$ \\
Orient & 1 & 1841.72 & 1841.72 & 47.45 & $<0.001 *$ \\
Sex * Orient & 1 & 117.05 & 117.05 & 3.02 & 0.08 \\
Error & 292 & 11333.06 & 38.81 & & \\
\hline
\end{tabular}

Note: Orient $=$ Sexual Orientation .

$*$ Significant at the $p \leq .01$ level. 
Table 7

ANOVA Summary Table for Within-Subjects Effects

\begin{tabular}{|c|c|c|c|c|c|c|}
\hline Source & & $D f$ & $S S$ & MS & $F$ & $p$ \\
\hline Inf Type & & 1 & 157.85 & 157.85 & 24.53 & $<0.001 *$ \\
\hline Inf Type * Sex & & 1 & 1.04 & 1.04 & 0.16 & 0.69 \\
\hline Inf Type $*$ Orient & & 1 & 5.60 & 5.60 & 0.87 & 0.35 \\
\hline Inf Type $*$ Sex $*$ Orient & & 1 & 2.93 & 2.93 & 0.46 & 0.50 \\
\hline Error (Inf Type) & & 292 & 1879.21 & 6.44 & & \\
\hline Emotions & $\begin{array}{r}\text { SA } \\
\text { G-G }\end{array}$ & $\begin{array}{c}3 \\
2.63\end{array}$ & $\begin{array}{l}305.13 \\
305.13\end{array}$ & $\begin{array}{l}101.71 \\
116.08\end{array}$ & $\begin{array}{l}24.27 \\
24.27\end{array}$ & $\begin{array}{l}<0.001 * \\
<0.001 *\end{array}$ \\
\hline Emotions * Sex & $\begin{array}{r}\text { SA } \\
\text { G-G }\end{array}$ & $\begin{array}{c}3 \\
2.63\end{array}$ & $\begin{array}{l}14.91 \\
14.91\end{array}$ & $\begin{array}{l}4.97 \\
5.67\end{array}$ & $\begin{array}{l}1.19 \\
1.19\end{array}$ & $\begin{array}{l}0.31 \\
0.31\end{array}$ \\
\hline Emotions * Orient & $\begin{array}{r}\text { SA } \\
\text { G-G }\end{array}$ & $\begin{array}{c}3 \\
2.63\end{array}$ & $\begin{array}{l}103.19 \\
103.19\end{array}$ & $\begin{array}{l}34.40 \\
39.26\end{array}$ & $\begin{array}{l}8.21 \\
8.21\end{array}$ & $\begin{array}{l}<0.001 * \\
<0.001 *\end{array}$ \\
\hline Emotions $*$ Sex $*$ Orient & $\begin{array}{r}\text { SA } \\
\text { G-G }\end{array}$ & $\begin{array}{c}3 \\
2.63\end{array}$ & $\begin{array}{l}12.14 \\
12.14\end{array}$ & $\begin{array}{l}4.05 \\
4.62\end{array}$ & $\begin{array}{l}0.97 \\
0.97\end{array}$ & $\begin{array}{l}0.41 \\
0.40\end{array}$ \\
\hline Error (Emotions) & $\begin{array}{r}\text { SA } \\
\text { G-G }\end{array}$ & $\begin{array}{c}876 \\
767.54\end{array}$ & $\begin{array}{l}3671.59 \\
3671.59\end{array}$ & $\begin{array}{l}4.19 \\
4.78\end{array}$ & & \\
\hline Inf Type * Emotions & $\begin{array}{r}\text { SA } \\
\text { G-G }\end{array}$ & $\begin{array}{c}3 \\
2.57\end{array}$ & $\begin{array}{l}118.09 \\
118.09\end{array}$ & $\begin{array}{l}39.36 \\
45.99\end{array}$ & $\begin{array}{l}28.03 \\
28.03\end{array}$ & $\begin{array}{l}<0.001 * \\
<0.001 *\end{array}$ \\
\hline Inf Type * Emotions $*$ Sex & $\begin{array}{r}\text { SA } \\
\text { G-G }\end{array}$ & $\begin{array}{c}3 \\
2.57\end{array}$ & $\begin{array}{l}12.75 \\
12.75\end{array}$ & $\begin{array}{l}4.25 \\
4.97\end{array}$ & $\begin{array}{l}3.03 \\
3.03\end{array}$ & $\begin{array}{l}0.03 * \\
0.04 *\end{array}$ \\
\hline Inf Type * Emotions * Orient & $\begin{array}{r}\text { SA } \\
\text { G-G }\end{array}$ & $\begin{array}{c}3 \\
2.57\end{array}$ & $\begin{array}{l}5.94 \\
5.94\end{array}$ & $\begin{array}{l}1.98 \\
2.31\end{array}$ & $\begin{array}{l}1.41 \\
1.41\end{array}$ & $\begin{array}{l}0.24 \\
0.24\end{array}$ \\
\hline Inf Type $*$ Emotions $*$ Sex $*$ Orient & $\begin{array}{r}\text { SA } \\
\text { G-G }\end{array}$ & $\begin{array}{c}3 \\
2.57\end{array}$ & $\begin{array}{l}2.79 \\
2.79\end{array}$ & $\begin{array}{l}0.93 \\
1.09\end{array}$ & $\begin{array}{l}0.66 \\
0.66\end{array}$ & $\begin{array}{l}0.58 \\
0.55\end{array}$ \\
\hline Error (Inf Type * Emotions) & $\begin{array}{r}\text { SA } \\
\text { G-G }\end{array}$ & $\begin{array}{c}876 \\
749.63\end{array}$ & $\begin{array}{l}1230.03 \\
1230.03\end{array}$ & $\begin{array}{l}1.40 \\
1.64\end{array}$ & & \\
\hline
\end{tabular}

Note: Inf Type $=$ Infidelity Type, Orient $=$ Sexual Orientation, $S A=$ Sphericity Assumed, G-G = Greenhouse-Geisser $d f$ corrections. Greenhouse-Geisser $d f$ corrections are displayed for withinsubjects effects with more than one degree of freedom.

* Significant at the $p \leq .05$ level. 
Table 8

Means for Sex * Infidelity Type * Emotions Significant Interaction

\begin{tabular}{llcccc} 
& \multicolumn{2}{c}{ Sexual } & \multicolumn{2}{c}{ Emotional } \\
& & & & & \multicolumn{2}{c}{ Males } & Females \\
\multirow{6}{*}{ Emotions } & 12.66 & Females & 13.88 & 11.40 & 12.74 \\
& Anger & 12.03 & 13.40 & 11.92 & 13.23 \\
& Anxiety & 12.21 & 13.28 & 12.06 & 13.31 \\
& Jealousy & 11.24 & 13.15 & 10.77 & 12.09 \\
\hline
\end{tabular}


Table 9

Means for Sexual Orientation * Emotions Significant Interaction

Sexual Orientation

\begin{tabular}{llcc} 
& & Heterosexual & Lesbian/Gay \\
\multirow{3}{*}{ Emotions } & Anger & 13.61 & 11.73 \\
& Anxiety & 13.34 & 11.94 \\
& Jealousy & 13.49 & 11.93 \\
& Humiliation & 13.08 & 10.54 \\
\hline
\end{tabular}


Table 10

Means for Infidelity Type * Emotions Significant Interaction

\begin{tabular}{llcc} 
& & \multicolumn{2}{c}{ Infidelity Type } \\
\multirow{6}{*}{ Emotions } & Sexual & Emotional \\
& Anger & 13.27 & 12.07 \\
& Anxiety & 12.71 & 12.58 \\
& Jealousy & 12.74 & 12.68 \\
& Humiliation & 12.19 & 11.43 \\
\hline
\end{tabular}




\section{APPENDIX C:}

\section{FIGURES}

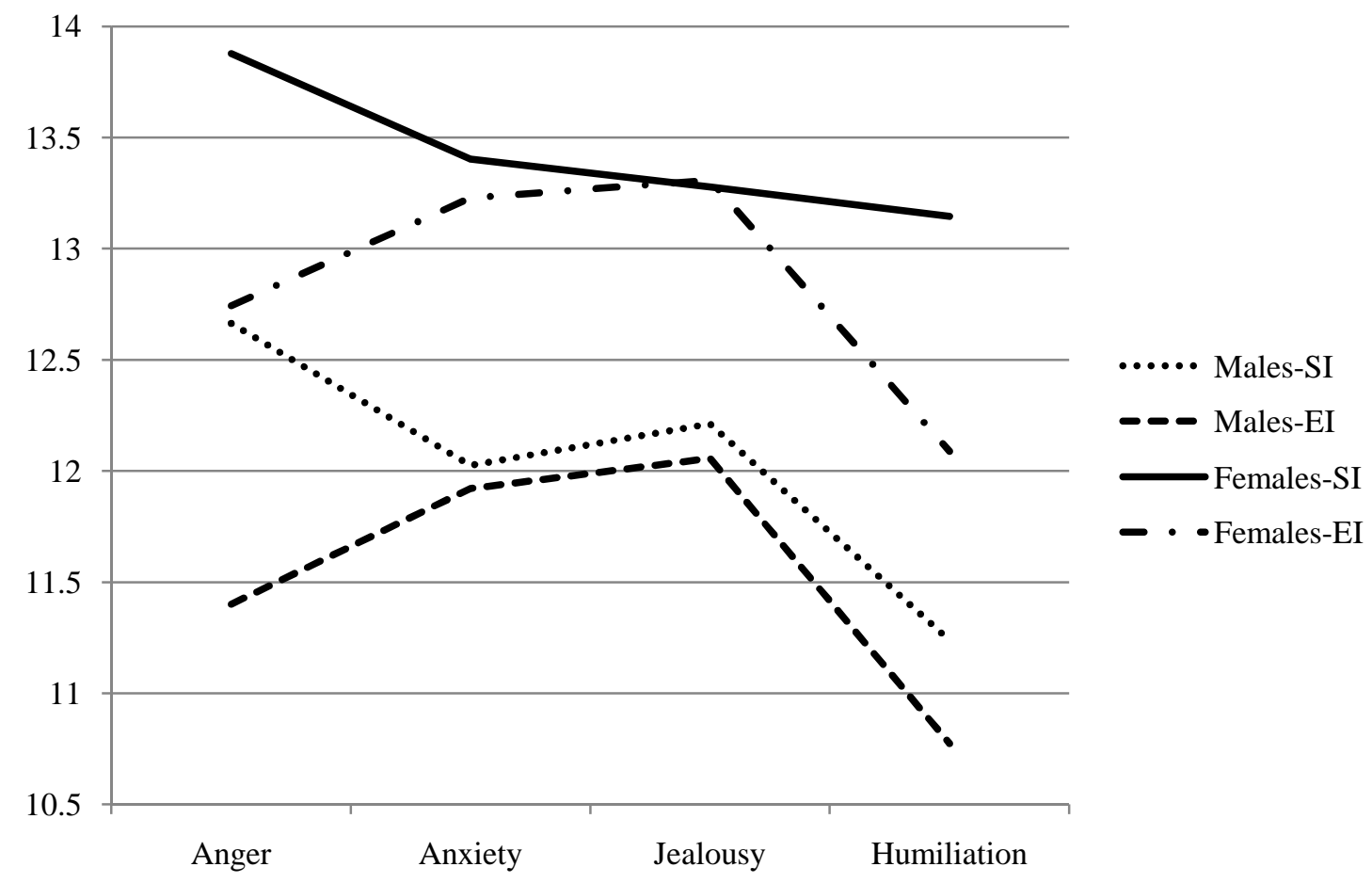

Figure 1: Sex differences in emotional responses to sexual (SI) and emotional (EI) infidelity. 


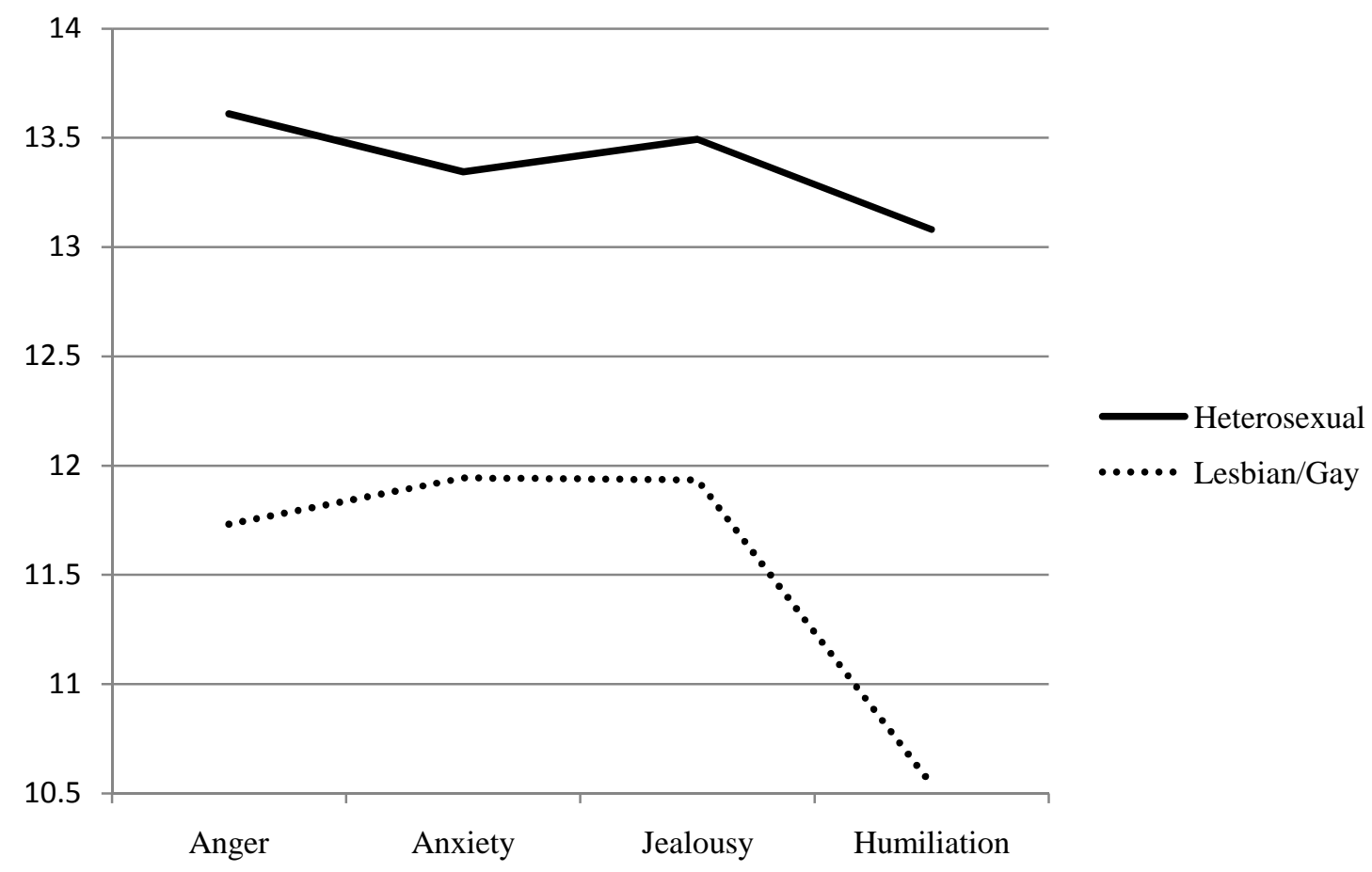

Figure 2: Sexual orientation differences in emotional responses to both infidelity types. 


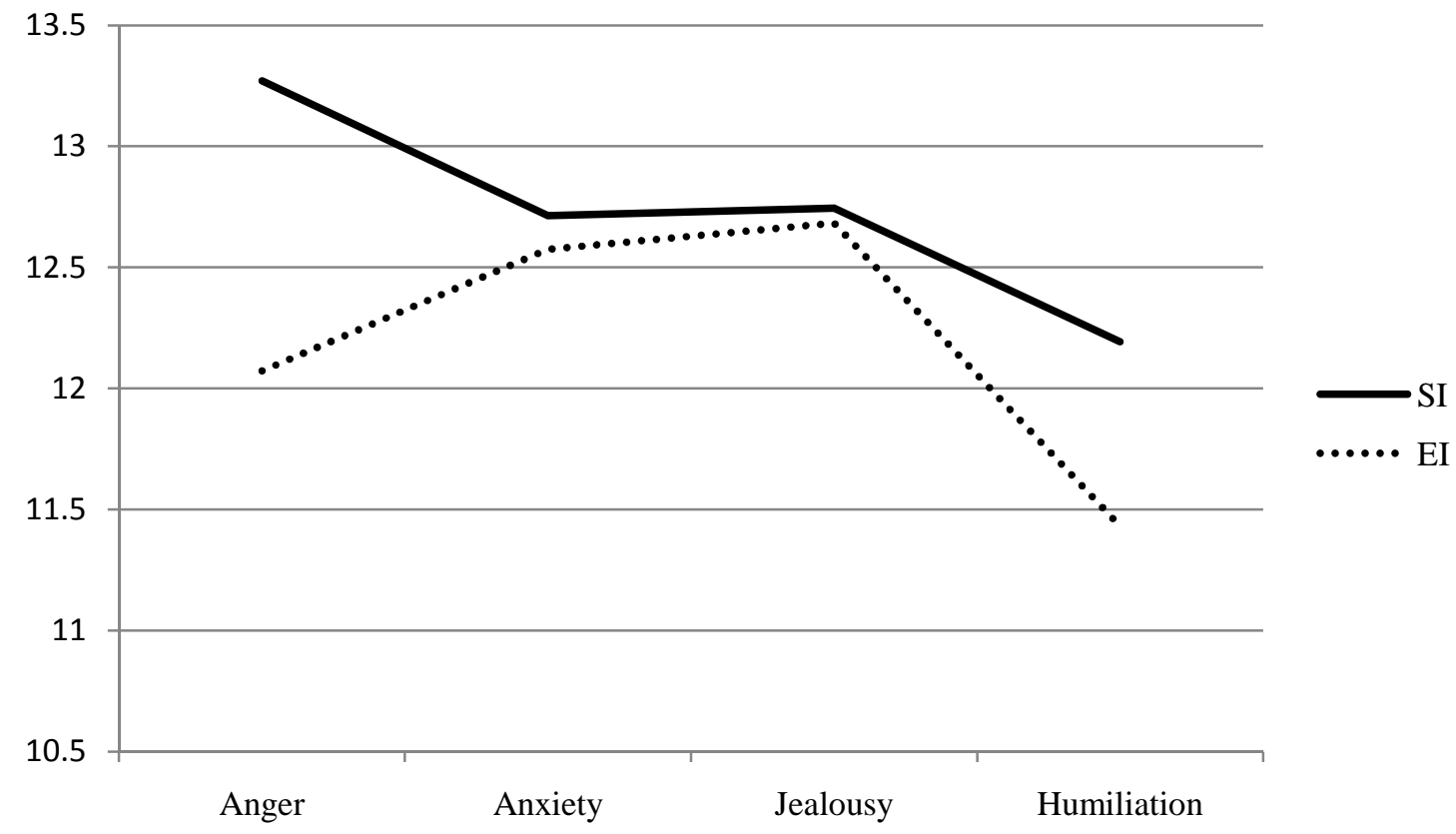

Figure 3: Emotional responses to sexual (SI) and emotional (EI) infidelity. 
APPENDIX D:

RESEARCH STUDY MATERIALS

Informed Consent Page

Olivia Leeker - Research Survey - Invitation to Participate

Page 1 of 2

\begin{tabular}{|c|c|}
\hline & $\begin{array}{c}\text { Oklahoma State University } \\
\text { College of Education }\end{array}$ \\
School of Applied Health \& Educational \\
Psychology
\end{tabular}

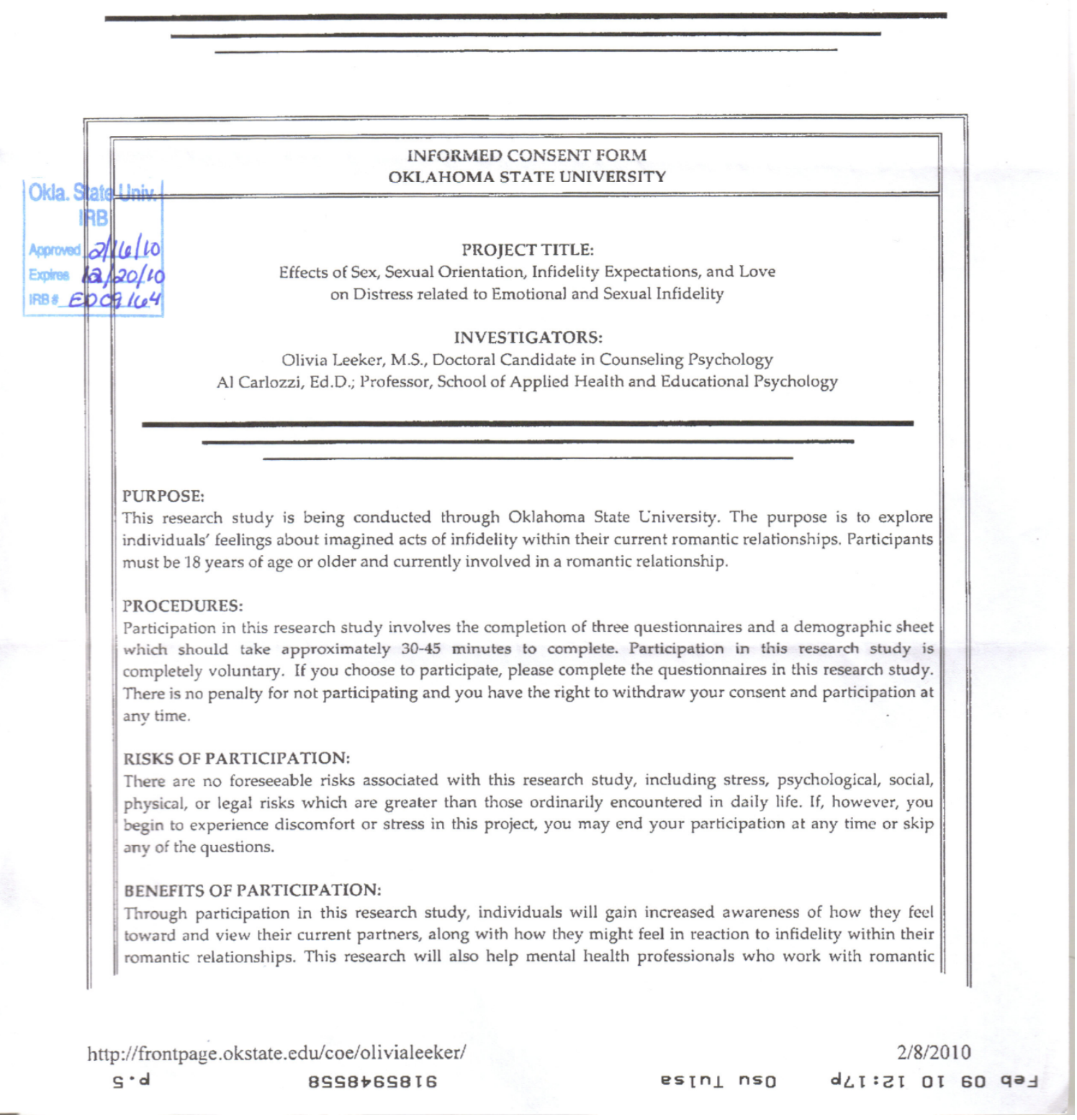


couples to understand how individuals tespond to incidents of infidelity in their relationships and how this varies when working with cypposite and saine-sex couples.

CONFIDENTLALITY:

All infurmation collected in this research study is strictly confictential. There will be no way to connert participants names with responses on the questionnaires. All data will be stored in a Incked file cabinet within the office of one of the principal investigators. Rescarch records will be stored securely for 5 ysors, and only researchers and individuals responsible for reseanch oversight will have access to the records. All rccords will be destroyed at the end of this period of time.

\section{COMPRNSATION:}

Upon completion of the survey, interested participants will be guidud to a sepsrate webpage where they will be asked to prowide their name. email address, and telephone number in order to inter a drawing to win one of two $525: \mathrm{X})$ gift cards from Walmast. Student participarts recruited through the SONA system will alwo be given 6 research credit for their participation in the research study.

\section{CONTACTS:}

If you have any qucstions about the reseanch study, you may contact Olivia Leeker, M.S., at (918) \$94-8568, of Dt. Al Cariorzi at (918) $944-8063$. If you have questions about your fights as a research volunieet, you may cuntact Dr. Shelia Kennison, IRB Chair, 219 Condell North, Stillwabe, OK 74078, 405744337 or irbergknishisdy

\section{PARTICIPANT RIGHTS:}

Your participation in this rescarch is vnluntary. There is no penalry for not participating and you have the right to withdraw your ransent und participation at any time.

\section{CONSENT DOCUMENTATION:}

I have been fully informed about the procedures listed here. I am aware of what I will be asked to do and the benefits of my participation. I affirm that 1 am 18 years of age or older and curtently inwolved in a cummitted rumantic relationship. I have read and fully understand this consent form.
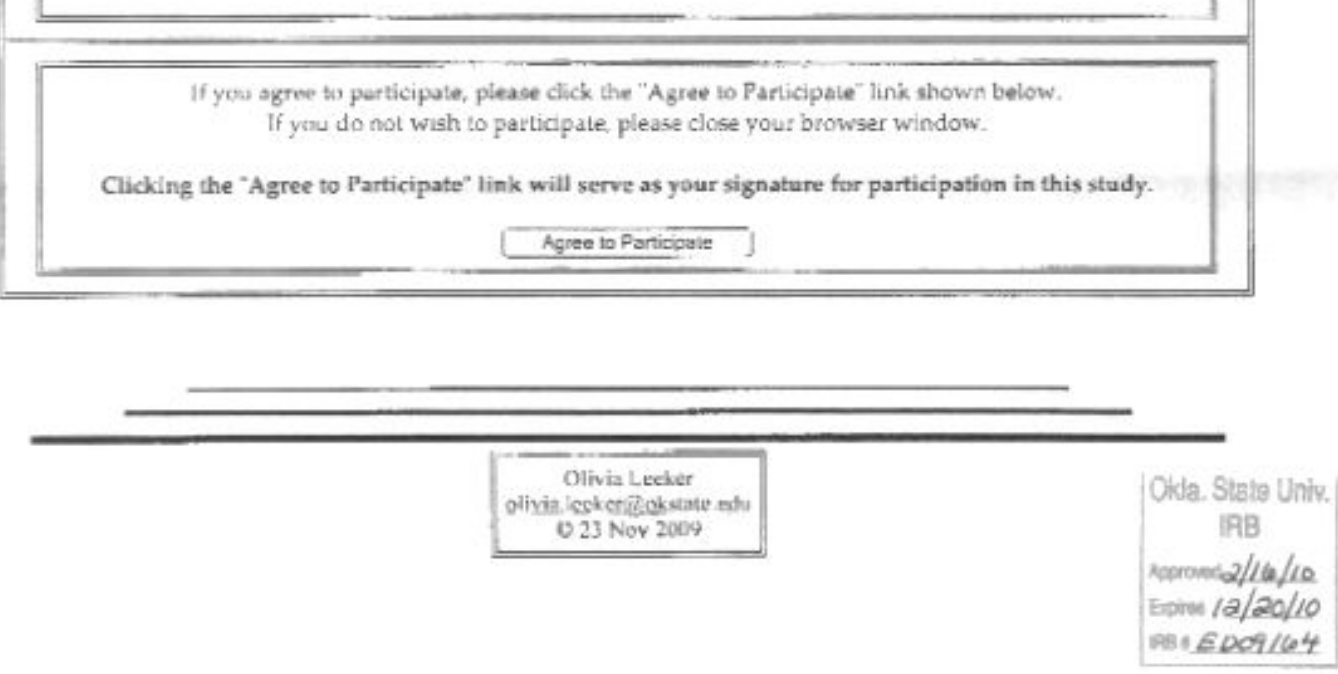

http://frontpage.okstate.edu/coc/olivialceker/ 
Demographic Sheet

Directions: Please answer each question by checking or filling in the blank that best describes you.

1) How old are you? _ _ Years of Age

2) Sex: _ Female _ Male

3) What is your sexual orientation?

_ Heterosexual __ Gay/lesbian __ Bisexual

4) Please check the blank that best describes your sex interests:

__ Opposite sex interests only

__ Mostly opposite sex, rare same sex interests

__ Both opposite sex and same sex interests, with more opposite

Equal same and opposite sex interests

_ Both opposite sex and same sex interests, with more same

___ Mostly same sex, rare opposite sex interests

_ Same sex interests only

5) Race (Check all that apply):

\begin{tabular}{|c|c|}
\hline African American/Black & American Indian/Native American \\
\hline Asian/Asian American & Hispanic/Latino(a) \\
\hline White, non-Hispanic & Other (Describe): \\
\hline
\end{tabular}

6) Are you:

\begin{tabular}{|c|c|c|}
\hline Single & Partnered/Common Law & Married \\
\hline Separated & Divorced & Widowec \\
\hline
\end{tabular}

7) How long have you been involved with your current romantic partner? (Time in years and months, ex. 5 years, 3 months)

8) Have you ever been unfaithful in your current romantic relationship? __ yes __ no

A. If yes, what type(s) of infidelity have you committed? 


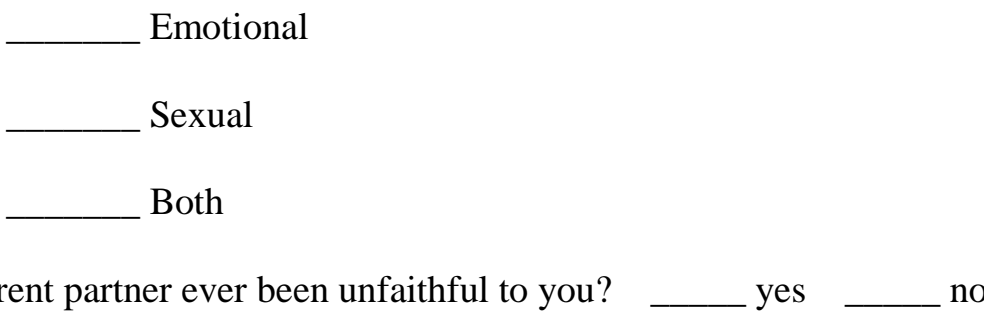

9) Has your current partner ever been unfaithful to you? __ yes __ no

A. If yes, what type(s) of infidelity did she/he commit?

\begin{tabular}{c}
{$\left[\begin{array}{c}\text { Emotional } \\
\text { Sexual } \\
\text { Both }\end{array}\right.$} \\
\hline
\end{tabular}

10) Have you ever been unfaithful in a past romantic relationship? yes no

A. If yes, what type(s) of infidelity did you commit?

\begin{tabular}{c}
{$\left[\begin{array}{c}\text { Emotional } \\
\text { Sexual } \\
\hline\end{array}\right.$} \\
\hline Both
\end{tabular}

11) Has a past partner ever been unfaithful to you? yes no

A. If yes, what type(s) of infidelity did she/he commit? Emotional

$\left[\begin{array}{c}\text { Emotional } \\ \text { Sexual } \\ \text { Both }\end{array}\right.$


Continuous emotion ratings (Penke \& Asendorpf, 2007)

Please now report (without being distracted) what you would feel in the following six situations. Please continue to think about your relationship with your current partner. Please try to imagine the situations vividly and realistically, as well as what you would really feel in the situations.

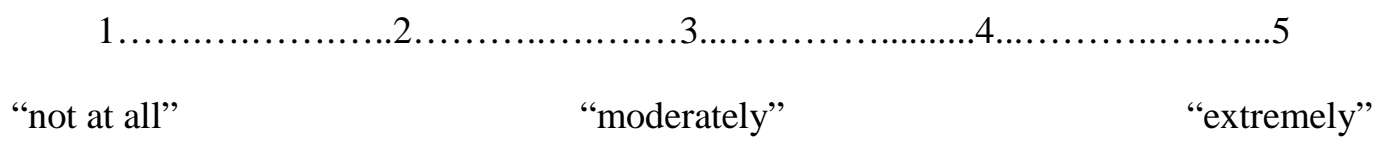

\section{Sexual}

Imagine your partner enjoys passionate sexual intercourse with another person and tries different sexual positions with him/her.

1. ___ How much anger would you feel?

2. How much anxiety would you feel?

3. _ How much jealousy would you feel?

4. __ How much humiliation would you feel?

Imagine that your partner has sexual intercourse with another person, but you are certain that they will not form a deep emotional attachment.

1. __ How much anger would you feel?

2. H__ How much anxiety would you feel?

3. __ How much jealousy would you feel?

4. __ How much humiliation would you feel?

Imagine that your partner has sexual intercourse for just one night with another person and is still sexually interested in the former lover, but is no longer in love with this person.

1. __ How much anger would you feel?

2. How much anxiety would you feel?

3. How much jealousy would you feel?

4. How much humiliation would you feel? 


\section{Emotional}

Imagine your partner forms a deep emotional attachment to that other person and falls in love with that other person.

1. ___ How much anger would you feel?

2. ___ How much anxiety would you feel?

3. ___ How much jealousy would you feel?

4. ___ How much humiliation would you feel?

Imagine that your partner forms a deep emotional attachment to another person, but you are certain that they will not have sexual intercourse.

1. ___ How much anger would you feel?

2. How much anxiety would you feel?

3. ___ How much jealousy would you feel?

4. ___ How much humiliation would you feel?

Imagine that your partner becomes emotionally involved with another person and is still emotionally involved with the former lover, but is no longer sexually interested in this person.

1. ___ How much anger would you feel?

$2 . \quad$ How much anxiety would you feel?

3. ___ How much jealousy would you feel?

4. ___ How much humiliation would you feel? 
Infidelity Expectations Questionnaire (IEQ; Cramer et al., 2008)

Please think of the serious committed romantic relationship that you currently have. Imagine discovering that the person with whom you are seriously involved became interested in someone else.

Rate the likelihood of your partner engaging in the following actions with the other person using the seven-point scale provided below.

\begin{tabular}{|c|c|}
\hline $\begin{array}{l}\text { "partner definitely } \\
\text { will not" }\end{array}$ & $\begin{array}{c}\text { "partner definitely } \\
\text { will"" }\end{array}$ \\
\hline
\end{tabular}

\section{Emotion-intimacy}

1. Trusting another person with his/her deepest thoughts and feelings.

2. Being in situations with another person where they would cry together.

3. Falling in love with another person.

4. Being vulnerable with another person by letting his/her guard down.

5. Becoming extremely happy knowing that he/she is needed by another person.

6. Openly expressing his/her needs to another person.

7. Communicating openly and honestly with another person.

8. Feeling comfortable showing that he/she cares for another person.

9. Being more committed to another person.

10. Spending more money on another person.

Sexual

1. Telling another person that his/her body looks and feels great.

2. Having incredible foreplay with another person using some sexual toys.

3. Trying many different sexual positions with another person.

4. Calling another person at work and talking dirty.

5. Walking into a bedroom wearing nothing but whipped cream for another person. 
6. Putting on a show by undressing slowly for another person.

7. Giving or getting oral sex.

8. Showering and sharing a sensual massage with another person using warm scented oils.

9. Experimenting with rough sex, anal sex, or being tied up.

10. Fulfilling another person's kinkiest sexual fantasies. 
The Sternberg Triangular Love Scale

(Sternberg, 1988)

The blanks represent the person with whom you are in a relationship. Rate each statement on a 1to-9 scale, where 1 = "not at all", $5=$ "moderately", and 9 = "extremely". Use intermediate points on the scale to indicate intermediate levels of feelings.

$1 \ldots \ldots \ldots . .2 \ldots \ldots .3 \ldots \ldots \ldots \ldots \ldots$
"not at all"
Intimacy Component

1. I am actively supportive of 's wellbeing.

2. I have a warm relationship with

3. I am able to count on in times of need.

4. is able to count on me in times of need.

5. I am willing to share myself and my possessions with

6. I receive considerable emotional support from

7. I give considerable emotional support to

8. I communicate well with

9. I value greatly in my life.

10. I feel close to

11. I have a comfortable relationship with

12. I feel that I really understand

13. I feel that really understands me.

14. I feel that I can really trust

15. I share deeply personal information about myself with

Passion Component

16. Just seeing excites me.

17. I find myself thinking about frequently during the day.

18. My relationship with is very romantic.

19. I find to be very personally attractive. 
20. I idealize

21. I cannot imagine another person making me as happy as does.

22. I would rather be with than with anyone else.

23. There is nothing more important to me than my relationship with

24. I especially like physical contact with

25. There is something almost "magical" about my relationship with

26. I adore

27. I cannot imagine life without

28. My relationship with is passionate.

29. When I see romantic movies and read romantic books I think of

30. I fantasize about

\section{Decision/Commitment Component}

31. I know that I care about

32. I am committed to maintaining my relationship with

33. Because of my commitment to , I would not let other people come between us.

34. I have confidence in the stability of my relationship with

35. I could not let anything get in the way of my commitment to

36. I expect my love for to last for the rest of my life.

37. I will always feel a strong responsibility for

38. I view my commitment to as a solid one.

39. I cannot imagine ending my relationship with

40. I am certain of my love for

41. I view my relationship with as permanent.

42. I view my relationship with as a good decision. 
43. I feel a sense of responsibility toward

44. I plan to continue my relationship with

45. Even when is hard to deal with, I remain committed to our relationship. 


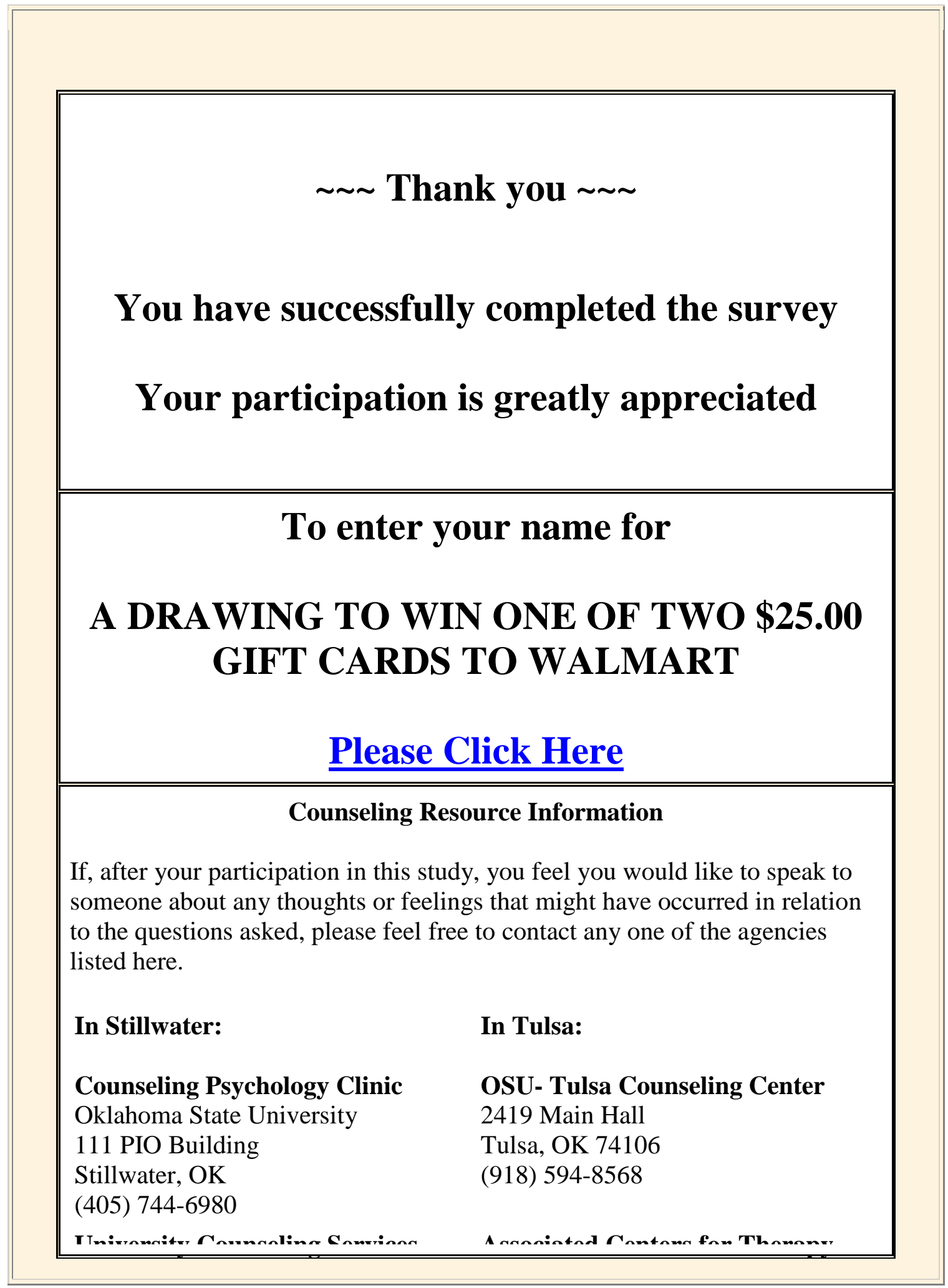


Oklahoma State University

316 Student Union

Stillwater, OK

(405) 744-5472

Psychological Services Center

Oklahoma State University

118 North Murray Hall

Stillwater, OK

(405) 744-5975
7010 S. Yale, Suite 215

Tulsa, OK 74136

(918) 492-2554

Family and Children's Services 650 S. Peoria Ave.

Tulsa, OK 74120

(918) 587-9471

\section{Close your Browser Window to exit this survey}




\section{Drawing Entry Form}

Please provide your information below in order to be entered into a drawing to win one of two $\$ 25.00$ gift cards from Walmart.

(All fields are required)

\begin{tabular}{|l|l|l|}
\hline First Name. & \multicolumn{2}{|l|}{} \\
\hline Last Name. & \multicolumn{2}{|c|}{} \\
\hline E-mail Address. & \multicolumn{1}{|l|}{} \\
\hline Telephone Number & Area Code & Prefix \\
\hline
\end{tabular}




\section{Recruitment Scripts}

\section{$\underline{\text { Recruitment Script for Lesbian/(iay Individuals }}$}

(provided in-person, or via email or Facebook)

Hello, everyone! My name is Olivia Lecker, a $3^{\text {rd }}$ ycar doctoral student in the Counseling Psychology $\mathrm{PhD}$ program at Oklahoma State University. I am currently conducting a research project for my dissertation exploring individuals' feclings about imagined acts of infidelity within their current romantic relationships.

If you are over the age of 18 , self-identity as lesbian or gay, and are involved in a current romantic relationship, we would like to encourage you to participate in this study by completing an online survey at http:/frontnage.okstate.edu/coe/olivialecker// which should take approximately 30 to 45 minutes to complete.

Upon completion of the survey, inlerested participants will be directed to a separate website (so that names will not be connected to survey responses) where they can enter into a drawing to WIN one of two $\$ 25.00$ gift cards to Walmart by providing the following information: name, email address, and telephone number.

Please feel free to ask any questions you may have.

Thank you for your time and heip!

Okla. State Univ.

IRB

Aproied /2/2/102

Exime $12 / 20 / 10$

FR:EDO9164 
Email message to be sent to Oklahoma State University faculty through a list-serve(s) to help in recruitment of university students

\section{Subject: I NEED YOUR HELP IN RICCRUTTING STUDY PARTICIPANTS}

I need your help in inviting undergraduate and graduate students to participate in my dissertation study. My name is Olivia Leeker, a $3^{\text {nf }}$ year doctoral student in the Counscling Psychology PhD program at Oklahoma State University. I am currently conducting a research project for my dissertation exploring individuals' feclings about imagined acts of infidelity within their current romantic relationships.

I am asking that you take a moment to announce this study to your undergraduate and graduate students either during class time or by forwarding this email to them. Anyone over the age of 18 who indicates they are currently involved in a committed romantic relationship is able to participate. Interested students should go to http//frontpage.okstate.edu/coc/olivialecker/ to take this brief $30-45$ minute online survey,

Upun completion of the survey, participants will be directed to a separate website (so that their names will not be connected to their responses) where they can enter into a drawing to WTN one of two $\$ 25.00$ gift cards to Walmart by providing the following information: name, email address, and telephone number.

Please feel free to contact me at olivia,lecker@okstate.edu if you have any questions. Thank you in advance for your time and help! 


\section{Recruitment Script for university students}

(provided in-person, or via email or lacebook)

Ilello, everyone! My name is Olivia Leeker, a $3^{\text {th }}$ year doctoral student in the Counseling Psychology PhD program at Oklahoma State University. I am currently conducting a research project for my dissertation exploring individuals' feelings about imagined acts of infidelity within their current romantic relationships.

If you are over the age of 18 and currently involved in a committed romantic relationship. I would like to cncourage you to participate in this study by completing an online survey at http//frontpage,okstatc,cdu/coc/olivialecker/ which should take approximatcly 30 to 45 minutes to complete.

Upon completion of the survey, interested participants will be directed to a separate website (so that names will not be connected to survey responses) where they can enter into a dnawing to WIN one of two $\$ 25.00$ gift cards to Walmart by providing the following information: name, email address, and telephone number.

Please feel frec to ask any questions you may have.

Thank you for your time and help!

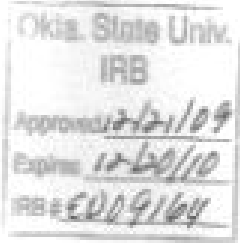




\title{
APPENDIX E:
}

\section{INSTITUTIONAL REVIEW BOARD APPROVAL}

\section{Oklahoma State University Institutional Review Board}

\author{
Date: $\quad$ Monday, December 21, 2009 \\ IRB Application No ED09164 \\ Proposal Title: Effects of Sex, Sexual Orientation, Infidelity Expectations, and Love on \\ Distress Related to Emotional and Sexual Infidelity \\ Reviewed and Exempt \\ Processed as
}

Status Recommended by Reviewer(s): Approved Protocol Expires: 12/20/2010

Principal

Investigator(s):

Olivia Leeker

10950 E. 61st Apt 1317

Tulsa, OK 74133

\author{
A) Cariozi \\ MH 2415. 700 N. Greenwood \\ Tulsa, OK 74106
}

The IRB application referenced above has been approved. It is the judgment of the reviewers that the rights and welfare of individuals who may be asked to participate in this study will be respected, and that the research will be conducted in a manner consistent with the IRB requirements as outlined in section 45 CFR 46 .

X The final veraions of any printed recruitment, consent and assent documents bearing the IRB approval stamp are attached to this letter. These are the versions that must be used during the study.

As Principal Investigator, it is your responsibility to do the following:

1. Conduct this study exactly as it has been approved. Any modifications to the research protocol must be submitted with the appropriate signatures for IRB approval.

2. Submit a request for continuation if the study extends beyond the approval period of one calendar year. This continuation must recelve IRB review and approval before the research can continue.

3. Report any actverse events to the IRB Chair promptly. Adverse events are those which aro unanticipated and impact the subjocts during the course of this researchy and

4. Notify the IRB office in writing when your research project is complete.

Please note that approved protocols are subject to monitoring by the IRB and that the IRB office has the authority to inspect rosearch records associated with this protocol at any time. If you have questions about the IRB procedures or need any assistance from the Board, please contact Beth McTernan in 219 Cordell North (phone: 405-744-5700, beth mcternan (8okstate.edu)

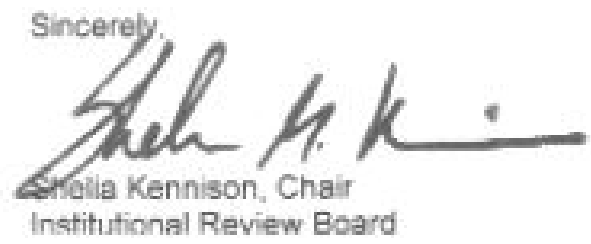


VITA

Olivia Ann Leeker

Candidate for the Degree of

Doctor of Philosophy

Thesis: EFFECTS OF SEX, SEXUAL ORIENTATION, INFIDELITY

EXPECTATIONS, AND LOVE ON DISTESS RELATED TO EMOTIONAL AND SEXUAL INFIDELITY

Major Field: Educational Psychology

Biographical:

Education:

-Completed the requirements for the Doctor of Philosophy in Educational Psychology at Oklahoma State University, Stillwater, Oklahoma in July, 2011.

-Completed the requirements for the Master of Science in Educational Psychology at Oklahoma State University, Stillwater, Oklahoma in July, 2007.

-Completed the requirements for the Bachelor of Arts in Psychology at

University of Missouri-St. Louis, St. Louis, Missouri in December, 2004.

Experience:

-Pre-doctoral Psychology Intern, Colmery-O’Neil VA Medical Center (APA-Accredited Psychology Internship Program), Topeka, Kansas, July 2010 to July 2011.

-Assistant to the Director, Oklahoma State University-Tulsa Counseling Center, August 2009 to June 2010.

-Mobile Assessment Intern/Carl Albert Executive Fellow, State of Oklahoma, Office of Juvenile Affairs, May 2009 to June 2010.

-Practicum student, Central Oklahoma Juvenile Center, September 2008 to April 2009.

-Practicum student, Stillwater Domestic Violence Services, August 2007 to August 2008.

Professional Memberships:

-Divisions 44 and 17: American Psychological Association -American Psychological Association of Graduate Students -Southwestern Psychological Association 

EXPECTATIONS, AND LOVE ON DISTESS RELATED TO EMOTIONAL AND SEXUAL INFIDELITY

Major Field: Educational Psychology

Scope and Method of Study: The purpose of this study was to investigate the influence of participant sex, sexual orientation, infidelity expectations, and love (intimacy, passion, commitment) on emotional responses (distress, anger, anxiety, jealousy, humiliation) to emotional and sexual infidelity. A mixed sample of undergraduate students and community members currently involved in committed romantic relationships (72 lesbian women, 114 heterosexual women, 53 gay men, and 57 heterosexual men) completed a demographic form, continuous emotion ratings in response to hypothetical infidelity scenarios, the Infidelity Expectations Questionnaire (IEQ), and the Triangular Love Scale. Data were analyzed using multiple regression and mixed ANOVA statistical techniques.

Findings and Conclusions: Sex, sexual orientation, commitment, and intimacy among partners were significant predictors of some, if not all, emotional responses to sexual and emotional infidelity. On the other hand, passion and expectations about a partner's likelihood of committing infidelity were not significant predictors of emotional reactions to infidelity. Overall, sexual infidelity elicited more negative feelings than emotional infidelity. Women's and heterosexuals' emotion ratings in response to emotional and sexual infidelity were significantly higher than men's and lesbian and gay individuals' emotion ratings, respectively. These sex differences lend only marginal support to the evolutionary hypothesis and may have diminished due to the inclusion of lesbian and gay individuals and/or the use of continuous instead of forced-choice questions. Sex and sexual orientation differences were also found regarding the degree to which specific emotions were reported in response to sexual and emotional infidelity. For example, females were much more humiliated than men in response to sexual infidelity, and heterosexuals reported significantly more humiliation than lesbian and gay individuals in response to both types of infidelity. Overall, the sex and sexual orientation differences that were found may reflect Westernized views of infidelity along with societal norms that vary based on gender and sexual orientation. Mental health professionals can use these findings to help clients' cope with the negative effects of infidelity on romantic relationships. 